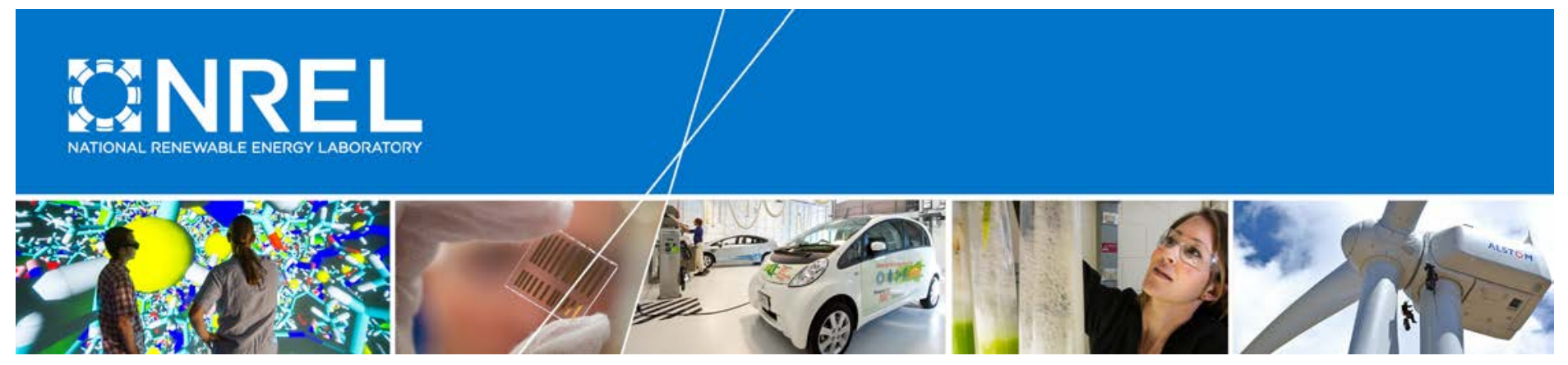

\title{
The Availability of Indium: The Present, Medium Term, and Long Term
}

Martin Lokanc, Roderick Eggert, and Michael Redlinger Colorado School of Mines Golden, Colorado

NREL Technical Monitor: Michael Woodhouse

NREL is a national laboratory of the U.S. Department of Energy Office of Energy Efficiency \& Renewable Energy Operated by the Alliance for Sustainable Energy, LLC

This report is available at no cost from the National Renewable Energy Laboratory (NREL) at www.nrel.gov/publications.

Subcontract Report

NREL/SR-6A20-62409

October 2015 


\title{
The Availability of Indium: The Present, Medium Term, and Long Term
}

\author{
Martin Lokanc, Roderick Eggert, and \\ Michael Redlinger \\ Colorado School of Mines \\ Golden, Colorado
}

NREL Technical Monitor: Michael Woodhouse

Prepared under Subcontract No. UGA-0-41025-20

NREL is a national laboratory of the U.S. Department of Energy Office of Energy Efficiency \& Renewable Energy Operated by the Alliance for Sustainable Energy, LLC

This report is available at no cost from the National Renewable Energy Laboratory (NREL) at www.nrel.gov/publications.

National Renewable Energy Laboratory 15013 Denver West Parkway Golden, CO 80401

303-275-3000 • www.nrel.gov

\section{Subcontract Report}

NREL/SR-6A20-62409

October 2015

Contract No. DE-AC36-08GO28308 


\title{
NOTICE
}

This report was prepared as an account of work sponsored by an agency of the United States government. Neither the United States government nor any agency thereof, nor any of their employees, makes any warranty, express or implied, or assumes any legal liability or responsibility for the accuracy, completeness, or usefulness of any information, apparatus, product, or process disclosed, or represents that its use would not infringe privately owned rights. Reference herein to any specific commercial product, process, or service by trade name, trademark, manufacturer, or otherwise does not necessarily constitute or imply its endorsement, recommendation, or favoring by the United States government or any agency thereof. The views and opinions of authors expressed herein do not necessarily state or reflect those of the United States government or any agency thereof.

This report is available at no cost from the National Renewable Energy Laboratory (NREL) at www.nrel.gov/publications.

Available electronically at SciTech Connect http:/www.osti.gov/scitech

Available for a processing fee to U.S. Department of Energy and its contractors, in paper, from:

\author{
U.S. Department of Energy \\ Office of Scientific and Technical Information \\ P.O. Box 62 \\ Oak Ridge, TN 37831-0062 \\ OSTI http://www.osti.gov \\ Phone: 865.576.8401 \\ Fax: 865.576.5728 \\ Email: reports@osti.gov
}

Available for sale to the public, in paper, from:

\author{
U.S. Department of Commerce \\ National Technical Information Service \\ 5301 Shawnee Road \\ Alexandria, VA 22312 \\ NTIS http://www.ntis.gov \\ Phone: 800.553 .6847 or 703.605 .6000 \\ Fax: 703.605.6900 \\ Email: orders@ntis.gov
}




\section{Acronyms and Abbreviations}

\begin{tabular}{ll}
- & Nil \\
CAGR & Compound annual growth rate \\
CIGS & Copper indium gallium selenide \\
DOE & U.S. Department of Energy \\
e & Estimated \\
EOL & End of life \\
g & gram \\
GW & Gigawatt \\
HHI & Herfindahl-Hirschman Index \\
In & Indium \\
ITO & Indium-tin-oxide \\
JORC & Australasian Joint Ore Reserves Committee \\
kg & kilogram \\
lb & pound \\
LCD & Liquid crystal display \\
LED & Light-emitting diode \\
$\mathrm{m}$ & meter \\
mn & Million \\
MOFCOM & Ministry of Commerce (China) \\
Mohs & A scale of hardness of solids \\
N/A & Not available, not applicable \\
ppb & Parts per billion \\
ppm & Parts per million \\
PV & Photovoltaic \\
SMG & SMG Indium Resources \\
$\mathrm{t}$ & Tonne (metric ton) \\
tpa & Tonnes per annum \\
tpd & Tonnes per day \\
UK & United Kingdom \\
USD & U.S. dollar \\
USGS & U.S. Geological Survey \\
wt\% & Percent of composition by weight \\
wt & weight \\
& \\
\hline &
\end{tabular}




\section{Executive Summary}

\section{The Issue}

The demand for indium could intensify significantly if thin-film materials relying on this element - specifically, copper-indium-gallium-selenide (CIGS) and III-V thin-films-become preferred photovoltaic (PV) materials. Yet the indium supply is potentially fragile for several reasons:

- Markets for metallic forms of indium are small, (about 1000 tonnes per annum [tpa] of world production and use. Any new, widespread use could dramatically alter overall demand, which could grow faster than production capacity for up to about a decade, given the length of time needed to significantly increase production capacity. During this decade, indium prices could be high and volatile enough that thin-film manufacturers find it uncompetitive compared to competing PV materials.

- Indium is currently produced almost solely as a byproduct of zinc smelting and refining. ${ }^{1}$ As a byproduct, indium benefits from sharing some production costs with its associated main product. Thus, costs of producing indium as a byproduct are undoubtedly lower than if it were produced by itself. If future demand for indium exceeds the quantities available as a byproduct, more costly sources of indium will be necessary to satisfy demand from thin-film producers, raising the possibility that indium prices could be much higher than current and recent prices.

- Relevant for the long term, indium is one of the scarcer elements, at least in terms of average abundance in the Earth's crust. Thus, even if indium were available in the short to medium term at prices making CIGS materials competitive with competing photovoltaic materials, such competitiveness could be short lived.

Overall, the concern implied by these three factors is whether the availability or prices of indium constrain the expansion of thin-film materials. Fully answering this question would require detailed evaluation of its demand and supply.

This study focuses only on the supply side of the question and examines the following, narrower question: If the demand for indium grows significantly, what are the likely sources of incremental production, in what quantities, and what might be the expected production costs and prices?

\section{The Approach}

This study examines the availability of indium from three temporal perspectives:

\footnotetext{
${ }^{1}$ A byproduct is produced along with a main product. The main product, more specifically its prices and production costs, largely determine the commercial viability of the mining operation. The associated byproduct, in contrast, has little effect on the overall viability of the mine, although of course the price received for the byproduct must be sufficient to justify the additional costs of separating and recovering the byproduct rather than discarding it. An intermediate situation arises when more than one product importantly influences the viability of an operation; in this case, each product is a coproduct.
} 
1. It describes the present based on estimates of current production capacities and associated production costs.

2. It evaluates the medium term, roughly 5-20 years into the future, based on known developed and undeveloped indium resources.

3. Most speculatively, it examines the long term, beyond 20 years or so into the future, based on (a) the general relationship in the recent past between the concentration of mineral ores for a range of metals; and (b) likely future ore grades for indium.

\section{The Findings}

At present, indium availability has the following characteristics (based on recent data and information):

- Indium reserves are an estimated 15,000 tonnes, more than two thirds of which are in China. A broader estimate, including reserves and resources, from the Indium Corporation of America (Moss et al. 2011) is total reserves and resources of approximately 50,000 tonnes, with some $47 \%$ in China and the Commonwealth of Independent States and 53\% in other countries. ${ }^{2}$

- Indium is produced mainly as a byproduct of zinc, and to a lesser extent as a byproduct of copper, tin, and polymetallic deposits from mineral ores containing less than 100 parts per million (ppm) (or less than $0.01 \%$ ) indium. ${ }^{3}$ We estimate that the indium content of zinc and other ores from which indium was recovered in 2013 was $\sim 700$ tonnes. Zinc ores accounted for $\sim 90 \%$ of production. For reasons discussed later, we believe these estimates are well below the actual levels of mine production. Considering only zinc ores, mine production of indium was geographically concentrated in China, Peru, Canada, Australia, and the United States, which together accounted for more than $75 \%$ of world production in 2013.

- Primary refined production of indium was $\sim 770$ tonnes in 2013 (Tolcin 2014a). ${ }^{4}$ Production over the last few years was $\sim 600$ to $\sim 800$ tpa. About half of global primary refined indium is produced in China. The remaining production is predominantly in Belgium, Canada, Japan, Peru, and South Korea.

- Secondary refined production capacity was $\sim 610$ tonnes in 2013 , almost all of which represents recycling of manufacturing wastes rather than recovery from end-of-life (EOL) products. Of this total tonnage, 510 tonnes $(84 \%)$ occurs in or near manufacturing centers in Japan, South Korea, and China, and is recovered from spent indium-tin oxide sputtering targets used in the production of flat-panel displays.

\footnotetext{
${ }^{2}$ A reserve is the quantity of material that is known with a high degree of certainty to exist in the Earth's crust and can be extracted and recovered at a profit with current technologies and under current legal and regulatory regimes and current prices and production costs. As such, a reserve is only a fraction of the material in the crust. Resources of a particular material are larger than reserves in that resources represent material that is known with some degree of certainty to exist in the crust and might be technically, legally, and commercially viable to produce under some conceivable circumstances.

${ }^{3}$ Ore is rock that contains one or more valuable minerals, from which the desired material is recovered (in this case, indium). Ore is mined and then serves as the input for subsequent processing, upgrading, and recovery of the desired material.

${ }^{4}$ Primary production uses raw minerals as inputs. Secondary production uses manufacturing wastes and materials from EOL products as inputs.
} 
- Combining primary (770 tonnes) and secondary (610 tonnes) supplies, we estimate that total global refined indium supply was 1,380 tonnes in $2013,40 \%$ of which occurred in China.

- As for production costs, this analysis indicates that producers require a minimum indium price of $\$ 100 / \mathrm{kg}$ (in 2011 U.S. dollar terms) to produce indium. Below this price, even the highest grade deposits cannot economically recover indium. At prices of $\sim \$ 150$ $\$ 300 / \mathrm{kg}$ of refined metal, most producers cover their variable costs of production, which are necessary to induce supply in the short run. At prices higher than $\$ 350 / \mathrm{kg}$, indium supply is highly inflexible because of short-run capacity constraints.

For the medium term (5-20 years into the future), incremental or increased indium production conceivably could come from five sources:

1. New byproduct production

2. Increased recovery efficiencies at primary operations

3. Increased secondary production from recycling of manufacturing wastes

4. Increased secondary production from recycling of EOL products

5. New mines that produce indium as a main product or coproduct (i.e., not as a byproduct).

The quantitative analysis in this study is limited to all but the fourth category; that is, it focuses on new and expanded mines (and associated processing facilities) and improved recovery efficiencies in both primary production and the recycling of manufacturing wastes. We do not analyze the potential for production from EOL recycling from PV modules because the medium term covers the next 5-20 years and solar modules have a useful life of 25-30 years. The quantities of indium available are also constrained by known developed and undeveloped resources (in the ground), as well as the stock of material in existing products.

Medium-term availability of indium has the following characteristics:

- Based solely on expanded and new mines that produce indium as a byproduct or coproduct (mainly along with zinc), primary indium production nearly doubles, from 770 tonnes in 2013 to 1,365 tonnes in 2031.

- Recovery of indium from zinc ores is inefficient, and improvements in recovery efficiencies represent the largest medium-term source of new supply. Typically, less than $20 \%$ of the indium in ore is recovered. When including the possibility for greater recovery throughout the supply chain, primary production could increase to 5,560 tonnes by 2031, highlighting the significant impact that advancements in technology could have on supply.

- The relevant production costs to consider in the medium term are variable (or operating) costs and capital costs, because investments are needed to make medium-term supplies available. Therefore, prices need to cover operating and capital costs to justify investment and operations. The analysis here suggests that prices need to be at least $\$ 350-375 / \mathrm{kg}$ to induce significant medium-term supply. At prices of $\$ 400-\$ 450 / \mathrm{kg}$, most of the tonnage noted in the previous bulleted point would come to market. As such, $\sim \$ 400 / \mathrm{kg}$ can be 
thought of as a medium-term price floor for indium; stated slightly differently, prices lower than $\$ 400 / \mathrm{kg}$ could be justified only if there were a near complete substitution away from the material. (At any specific time in the medium term, market conditions could force prices to drop below $\$ 400 / \mathrm{kg}$, but such low levels are likely to be temporary; at these prices, primary and secondary suppliers are unlikely to continue investing to maintain productive capacity.)

- Although not explicitly modeled as part of this exercise, secondary supply from consumer waste (EOL products) could become a source of supply in the medium term. It is difficult to estimate the cost of such supply, but given that current price levels have not justified the recovery of indium from laptops, cellular phones, and other electronic devices (mostly because they are so widely dispersed), prices would likely need to exceed $\$ 700 / \mathrm{kg}$ to make recovery from these sources profitable. Furthermore, although a less dispersed (and possibly more profitable) source of scrap could be found in EOL solar panels, we do not expect this to contribute significantly to supply until the 2030s. Given the average expected life of solar panels of some 20 years and the relatively recent installation of most panels, significant quantities of indium-bearing solar panels would not become sources of secondary supply until the 2030s.

Finally, for the long term (in the 2030s and beyond), indium availability is constrained mostly by our level of knowledge about the Earth's crust and our technological capabilities. We are not in danger of "running out" of indium, considering the scale of its potential demand relative to its estimated amount in the crust. Rather, the critical issues relate to production costs. As a starting point, using a methodology developed by Green (2009), we estimate that the central tendency for long-term prices to be $\sim \$ 600 / \mathrm{kg} ; \$ 100-\$ 3,300 / \mathrm{kg}$ would cover $80 \%$ of possible outcomes (all in 2011 U.S. dollars). 


\section{Table of Contents}

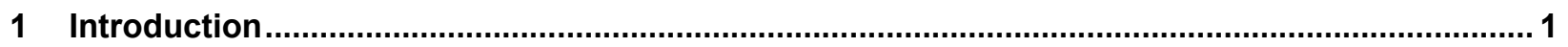

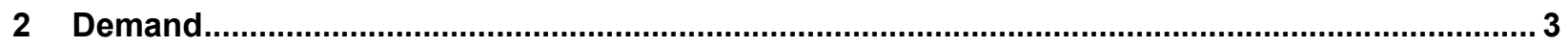

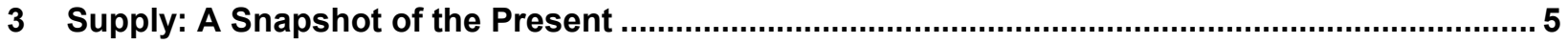

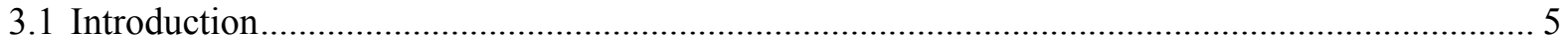

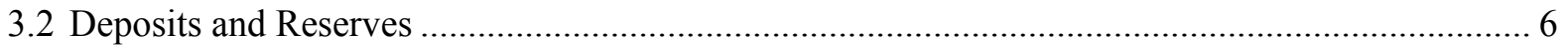

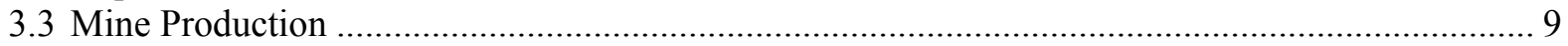

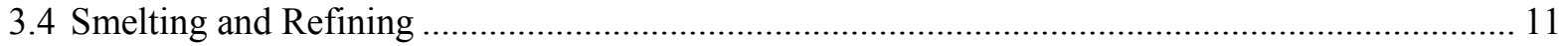

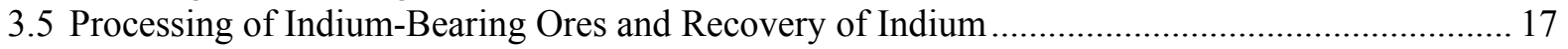

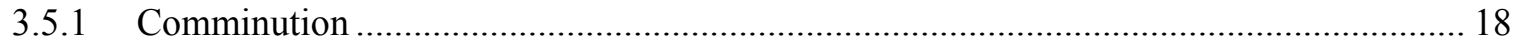

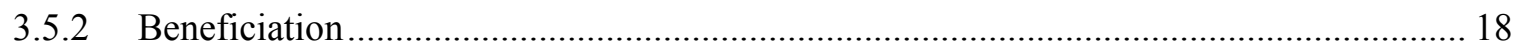

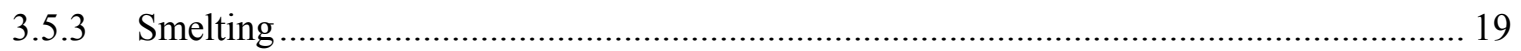

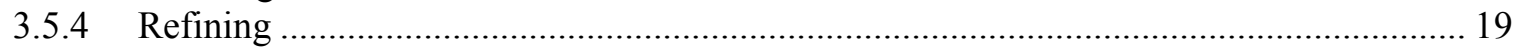

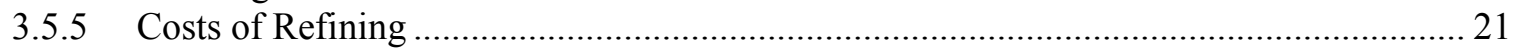

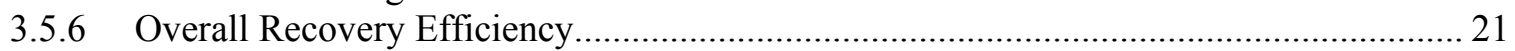

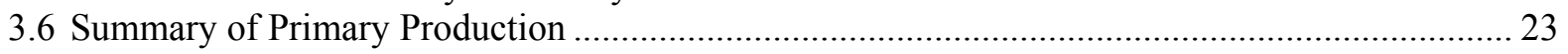

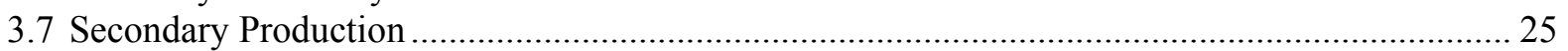

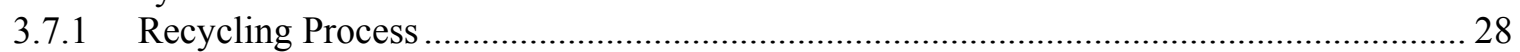

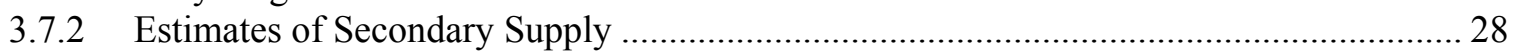

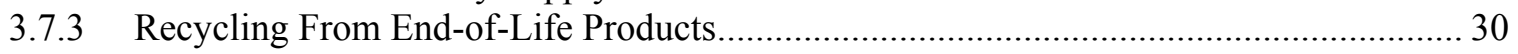

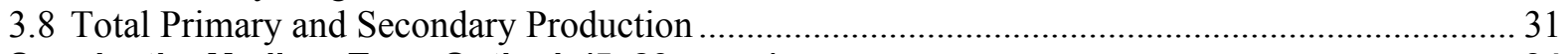

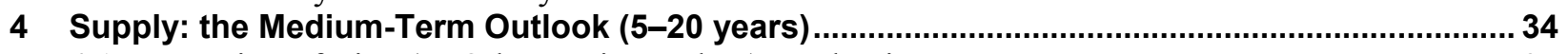

4.1 Expansion of Zinc (or Other Main Product) Production............................................................ 35

4.1.1 Mount Pleasant (North Zone), Canada ................................................................ 37

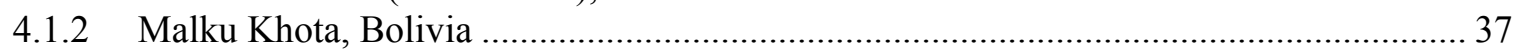

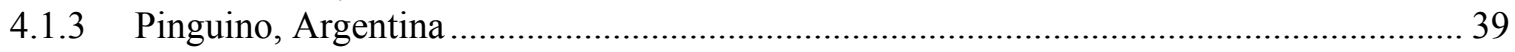

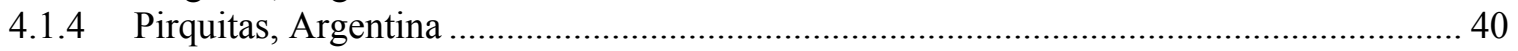

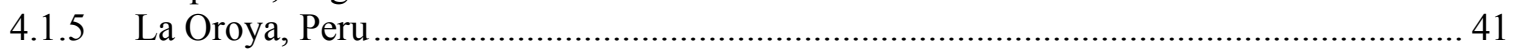

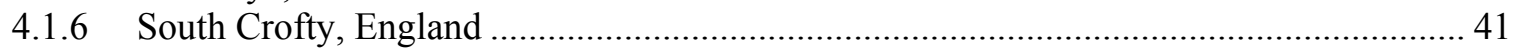

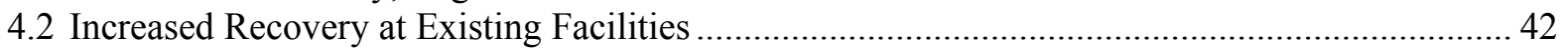

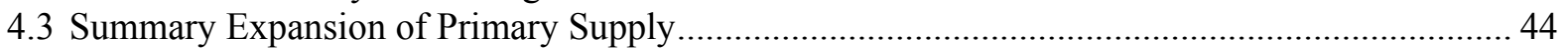

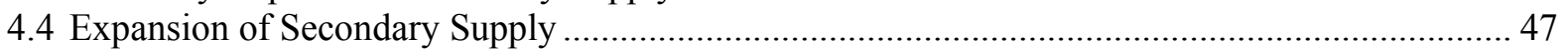

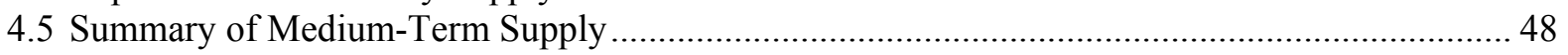

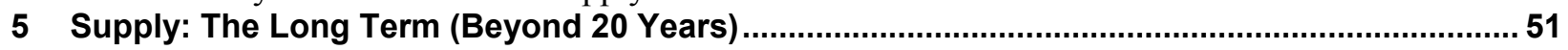

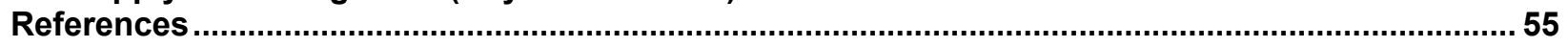

Appendix A: Zinc, Copper, and Tin Reserves and Production Estimates ......................................61

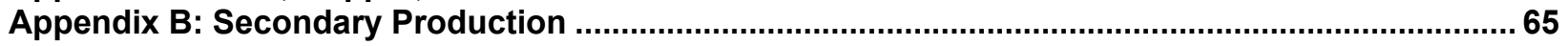

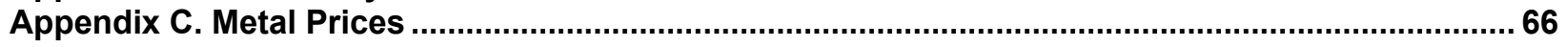

Appendix D: Methodology Used To Derive the Short- and Medium-Term Supply Curves ..............67

Appendix E: Earth Abundance of Various Elements ............................................................... 79 


\section{List of Figures}

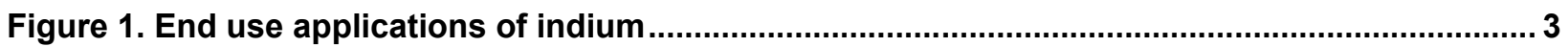

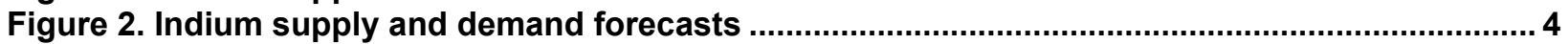

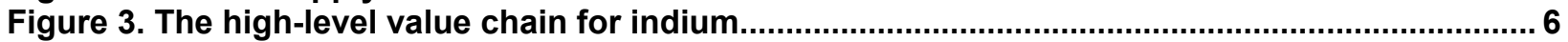

Figure 4. Distribution of world indium, gallium, and tellurium resources and production ................. 8

Figure 5. Share of primary indium refinery production by country (2009 to 2013) ........................ 14

Figure 6. Tonnes of primary indium refinery production by country (2009 to 2013) ........................15

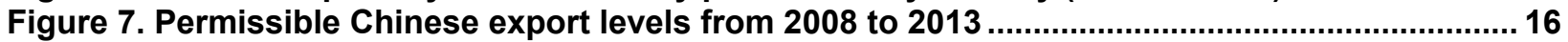

Figure 8. Smelting of zinc ores to yield zinc slabs and indium precipitate ...................................... 19

Figure 9. Advanced refining of indium from the precipitates of zinc smelting ...............................20

Figure 10. Indium value chain and overall recovery efficiency .................................................... 22

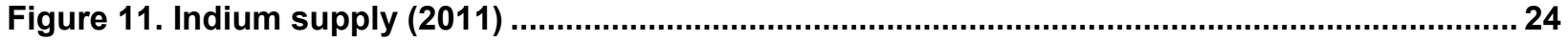

Figure 12. Short-term primary indium supply. including pipeline efficiency improvements............ 25

Figure 13. Geographic distribution of secondary refined indium................................................ 29

Figure 14. An example of recycling LCDs from discarded mobile phones using vaporization ........ 31

Figure 15. Comparison of short-term primary and total indium supply........................................... 33

Figure 16. Comparison of short-term total indium supply under differing assumptions of pipeline efficiency

Figure 17. Illustrative medium-term indium supply curve …......................................................... 35

Figure 18. Indium value chain and overall recovery efficiency.................................................... 43

Figure 19. Medium-term base case primary indium supply projected to 2016 and 2031 (indium production growth in base case is solely due to zinc production growth) ................................45

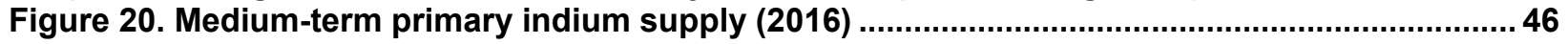

Figure 21. Medium-term primary indium supply (2031) .................................................................... 46

Figure 22. Medium-term primary indium supply (2016), including positioning of known potential

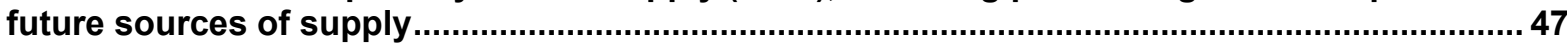

Figure 23. Comparison of medium-term primary and total indium supply in 2016.........................49

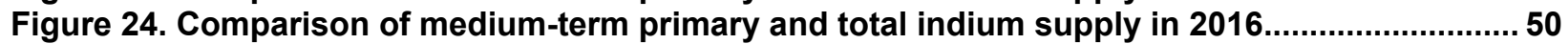

Figure 25. Market price versus concentration of metal in typical ore ................................................52

Figure 26. Market price versus concentration of metal in typical ore, including confidence intervals

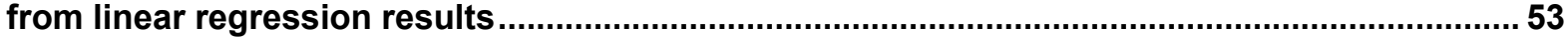

Figure 27. Historical zinc and tin prices in 2011 USD as indicated ..................................................6 66

Figure 28. Short-term primary indium supply curve ................................................................... 72

Figure 29. Short-term primary indium supply, including pipeline efficiency improvements............ 74

Figure 30. Medium-term base case primary indium supply projected to 2016 and 2031 .................76

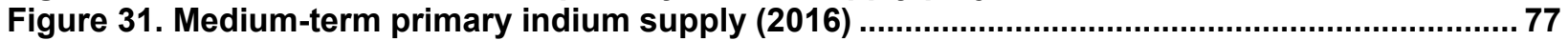

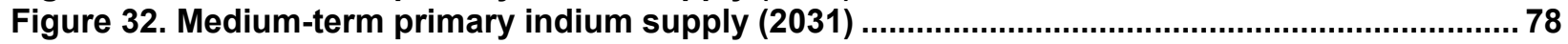

Figure 33. Medium-term primary indium supply (2016), including positioning of known potential

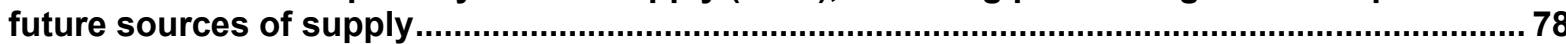

Figure 34. Abundance of elements in the Earth's upper continental crust as a function of atomic

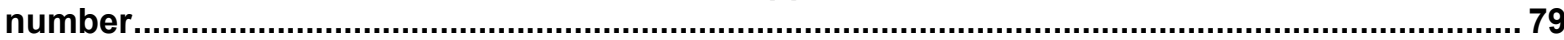




\section{List of Tables}

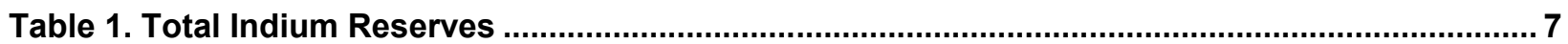

Table 2. Global Estimates of Mined Indium From Zinc Ores, 2009 and 2013 (tonnes) .................... 10

Table 3. Summary Estimate of Indium Content of Various Mined Ores ........................................... 10

Table 4. List of Prospective Buyers for Indium-Bearing Zinc Concentrates .................................. 12

Table 5. Estimate of Primary Indium Refinery Production (tonnes, 2009 to 2013).......................... 14

Table 6. China's Indium Export Quotas, 2010 and 2011 (tonnes) ................................................ 17

Table 7. Indium Refining Terms for Indium Sponge Revenue Calculations Used in NI 43-101 Report for Mount Pleasant Property ..................................................................................................... 21

Table 8. Estimates of Potential Indium Mined Along With Main Product Ores .............................. 23

Table 9. Overall Utilization of Indium in a Hypothetical ITO Sputtering Application With Closed

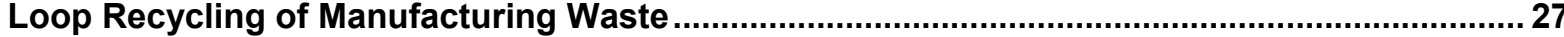

Table 10. Indium Recycling Capacity of Known Producers (2013) .....................................................29

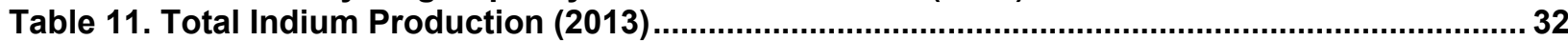

Table 12. Medium-Term Estimates of Indium Primary Refinery Production......................................35

Table 13. Summary of Indium Production From New Mine Production ............................................. 36

Table 14. Operational and Production Summary of Malku Khota Silver-Indium Project ................... 38

Table 15. Potential Indium-Bearing Mineral Resource at Pinguino .................................................... 39

Table 16. Potentially Recovered Metal and Revenue Contribution of Sulfide Ores (and Associated

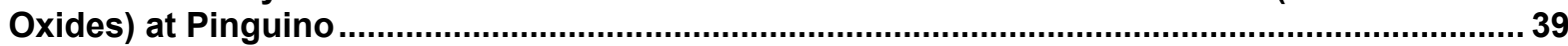

Table 17. South Crofty "Potential” Mineral Resource ...................................................................... 42

Table 18. Potential Expansion of Secondary Supply From Manufacturing Waste........................... 48

Table 19. Total Indium Production $(2011,2016$, and 2031) ............................................................ 49

Table 20. Long-Term Range of Potential Indium Prices (\$, 2011) .................................................53

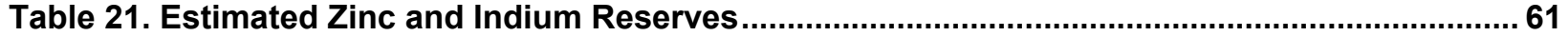

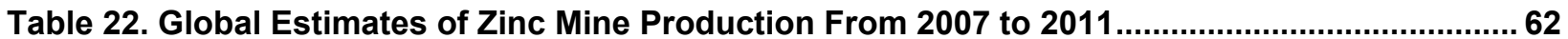

Table 23. Global Estimates of Copper Mine Production and Reserves From 2007 to $2011 \ldots \ldots \ldots \ldots . . . .63$

Table 24. Global Estimates of Tin Mine Production and Reserves From 2007 to 2011 ...................64

Table 25. Overall Recovery Efficiency of Indium Use in a Hypothetical ITO Sputtering Application With Closed Loop Recycling of Manufacturing Waste Where Total Measured Indium Recycled Is $~ 608.5$ Tonnes ......................................................................................................................... 65

Table 26. Mount Pleasant Production and Product Revenue Summary for Production Cases "A" Through "C"

Table 27. Summary of Cost Allocation Between Metals at Adex Mining's Mount Pleasant Project 69

Table 28. Monte Carlo Simulation Input Distributions for Grade, Recovery, and Costs ................... 71

Table 29. Short-Term Indium Supply Scenarios ................................................................................ 73

Table 30. Monte Carlo Simulation Input Distributions for Metal Prices ............................................. 75

Table 31. Main Product Growth and Associated Forecasted Byproduct Indium Production ............ 75

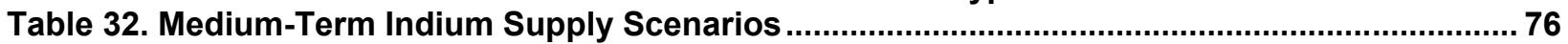




\section{Introduction}

Indium $^{5}$ was discovered in 1863 by Ferdinand Reich and Hieronymus Theodor Richter. Since indium's introduction as a commercial product in the 1930s, the indium market has had two key characteristics:

- It is produced primarily as a byproduct of zinc production, so its supply seriously depends on developments in zinc markets.

- It is used in niche electronic applications, so its demand is small relative to many other metals and is subject to shocks when new applications are developed.

The advent of flat-panel displays raised indium's commercial profile. Since 2002, annual indium production and recycling have increased. Its use as a transparent conducting oxide in the form of indium-tin oxide (ITO) and the lesser used indium-zinc oxide now represents the single largest use. As indium's use in photovoltaics (PV) and flat-panel displays continues to increase, analysts have become concerned about its future availability.

For several reasons, the indium market is fragile, fragmented, and prone to short-term shocks:

- Its short-term availability is tied closely to the level of zinc mining and processing, from which indium is produced as a byproduct. As such, an increase in indium's price will not lead to an appreciable increase in indium production in the short term, except in periods when significant quantities of indium are left unrecovered from zinc processing residues and other wastes.

- Also on the supply side, a relatively small number of firms and countries account for most indium production. This leads to a general lack of transparency in the indium market, because these firms tend to withhold information from the public domain for competitive reasons. This creates some possibility for opportunistic pricing. The small number of countries producing primary indium - and China's important role as the producer of about half of annual primary production — result in a market that is vulnerable to supply restriction if users operating in China benefit from preferential access to Chinese indium (such as when it is subject to export taxes or quotas).

- On the demand side, the small size of the market and the relatively small number of important applications mean that total demand can increase significantly in a short time if a new application emerges (such as what happened with ITO thin-films in flat-panel displays over the last decade).

- Also on the demand side, most indium users are not sensitive to changes in indium prices over the short term because the price of indium accounts for a very small share of total costs in the production of indium-containing products (such as flat-screen televisions).

Over the longer term, the indium market will be better able to adjust to shocks. If prices rise, for example, producers can invest in facilities to recover previously unrecovered indium, and users

\footnotetext{
${ }^{5}$ Atomic number 49 , atomic weight 114.82 , melting point $156.8^{\circ} \mathrm{C}$, boiling point $2073^{\circ} \mathrm{C}$, Mohs hardness 1.2 (Barbalace $1995-$ 2012).
} 
can invest in processes that use less indium, through either material substitution or more efficient manufacturing technologies. Perhaps the most important long-term response of a market to altered incentives is technological innovation; for example, improvements to the process of ITO sputtering (reducing the amount of waste created in sputtering) and improvements to techniques for recycling ITO waste (increasing the recovery of the indium from the wastes of the sputtering process).

Section 2 describes demand for indium, Section 3 examines indium supply at present, Section 4 describes indium supply in the in the medium term (5-20 years into the future), and Section 5 describes indium supply in the long term (beyond 20 years). 


\title{
2 Demand
}

Indium consumption in 2012 was estimated to be $\sim 1,550$ tonnes and was driven by the liquid crystal display (LCD) industry in the manufacturing of flat-panel, touch-screen, and plasma displays for televisions, computers, and handheld electronic devices. This market grew rapidly over the past 10 years to account for $\sim 56 \%$ of total annual consumption in the form of ITO. PV applications made up $\sim 8 \%$ of total consumption (Willis et al. 2012).

Indium's use in PV in the form of copper-indium-gallium-diselenide (CIGS) solar panels is relatively recent. Although it represents only a small fraction of current total indium demand, improvements in both the efficiency and material intensity of CIGS solar cells can propel this technology to be a major source of future indium demand. Currently, CIGS technology requires $\sim 23$ tonnes of indium per gigawatt (Woodhouse et al. 2012); hence, deployment of CIGS solar panels in the tens or hundreds of gigawatts per year would require substantial increases in indium production relative to current levels.

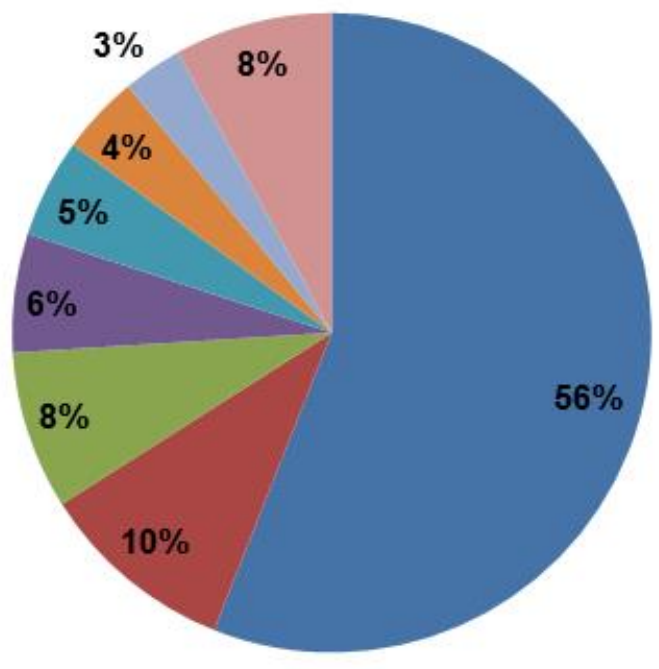

\author{
- Flat Panel Displays \\ घ Solders \\ - Photovoltaics \\ - Thermal Interface \\ Materials \\ Batteries \\ - Alloy/Compounds \\ - Compound Semis \& \\ LEDs \\ - Miscellaneous
}

Figure 1. End use applications of indium

(Willis et al. 2012)

Total consumption: $\sim 1,500$ tonnes.

The remaining $36 \%$ of indium is used in a variety of applications such as solders, thermal interface materials, batteries, compound semis, light-emitting diodes (LEDs), and other applications (Willis et al. 2012). According to Moss et al. (2011), other applications of indium include low-pressure sodium lamps, bearings, dental applications, nuclear reactor control rods, corrosion inhibitors, semiconductors for laser diodes, and low melting point alloys.

Future demand for indium likely will be driven by flat-panel displays and PV. Moss et al. (2011) expect the market to move from a small surplus to a significant deficit in 2020 (Figure 2). Gibson and Hayes (2011) estimate that increased demand in PV could cause indium demand to increase at a rate of $15 \%$ per year; expansion of zinc production (the source of indium) is estimated to increase at only $\sim 1 \%$ to $3 \%$ per year. 


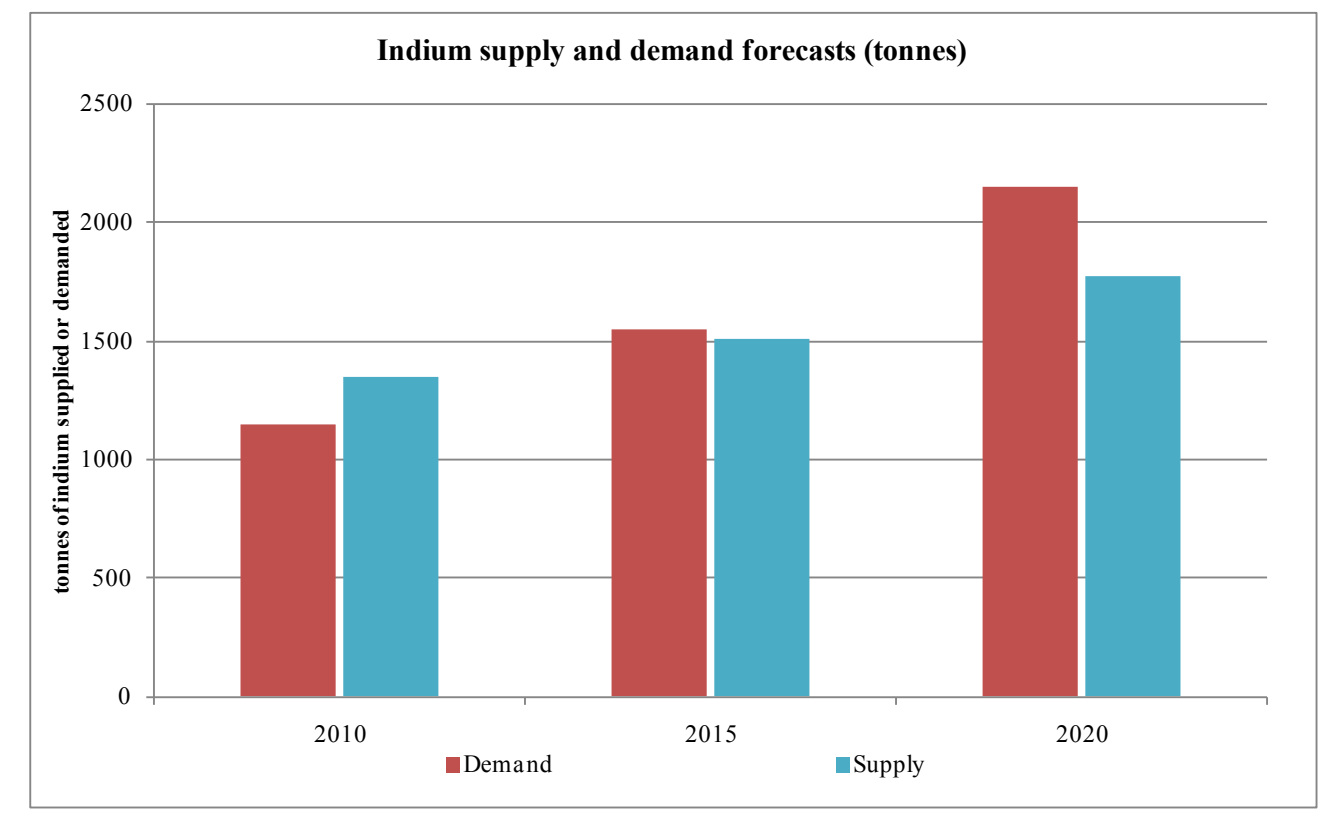

Figure 2. Indium supply and demand forecasts

(Moss et al. 2011)

SMG Indium Resources (SMG) believes demand is likely to persist because there is currently no large-scale substitute for indium in LCDs (Denina 2012). Even if indium prices increase, it comprises only a very small fraction of the materials used in an ITO target $(\sim 1 \%)$. Therefore, it represents only a small proportion of total input costs in manufacturing of LCDs, so manufacturers are likely to be able to absorb significant price increases before being required to: (1) reduce the quality of indium used; (2) find a substitute; or (3) change technologies.

Given the potential for significant demand growth and concerns about availability, speculation in indium markets has resulted in indium being increasingly bought as an investment mineral - a business model being pursued by SMG, which was formed to purchase and stockpile indium ingots with a minimum purity level of $99.99 \%$ (SMG Indium Resources 2010). Although indium will probably not develop into an exchange-traded fund, the attractive supply demand fundamentals have created a new type of consumer who is interested in investing in funds backed by indium. As of April 2014, SMG indium stockpiles were reported to be 21 tonnes (SMG Indium 2014). 


\section{Supply: A Snapshot of the Present}

\subsection{Introduction}

With rare exceptions, indium has not been mined as a main product, but rather as a byproduct from the refining of base metals. Almost all commercially produced indium is extracted from zinc refining. Indium often also occurs in deposits of silver, copper, lead, and tin; but in these instances, it normally occurs at subeconomic concentrations.

Indium's abundance in the Earth's crust ranges from 0.05 to 0.072 parts per million (ppm) (Schwarz-Schampera and Herzig 2002), and where it is economic to recover in zinc sulfide deposits, it often is concentrated in ranges from less than $1 \mathrm{ppm}$ to $100 \mathrm{ppm}$. However, not all zinc deposits contain indium, and for those that do, concentrations vary considerably.

A European Commission study into the availability of certain "critical minerals" recently estimated global production of refined indium at 1,345 tonnes per annum (tpa) from primary and secondary sources (Moss et al. 2011). The U.S. Geological Survey (USGS) estimates that primary indium refinery production was 770 tonnes in 2013 (Tolcin 2014a). China accounted for the largest proportion of this with 410 tonnes, which is consistent with China's leading position in zinc production (Tolcin 2014a, 2014b).

Figure 3 depicts indium's value chain. As mentioned earlier, primary indium is usually a byproduct from zinc mining. Zinc ores and indium-bearing zinc concentrate are generally concentrated at the mine site; then the zinc is shipped to smelters for further refining. If the zinc concentrate is shipped to an indium-capable smelter, the concentrated indium needs to be additionally refined by a special metals plant to upgrade it for commercial use. Once the required level of indium metal is produced, it can be formed into ingots, wires, or ITO powders. Where the indium is to be used in PV or LCDs, it is sputtered onto thin-films. The sputtering process is not very efficient: only about $30 \%$ of the indium is successfully deposited onto the thin-films when using the most typical sputtering targets that have a planar configuration. Given the low deposition efficiency of the planar sputtering targets, many manufacturers reuse the indium lost in the manufacturing process by sending the spent ITO targets and order residues to special recycling plants to recover the unused metal. The indium that is successfully deposited makes its way into consumer products and will once again be available for recovery at the end of the products' useful lives. Currently, the costs of waste separation are high and the fraction of indium (as a percentage of total mass) contained in many electrical devices is small; thus, recycled EOL products do not constitute a material source of indium supply.

The following subsections examine various aspects of indium's value chain in greater detail. 


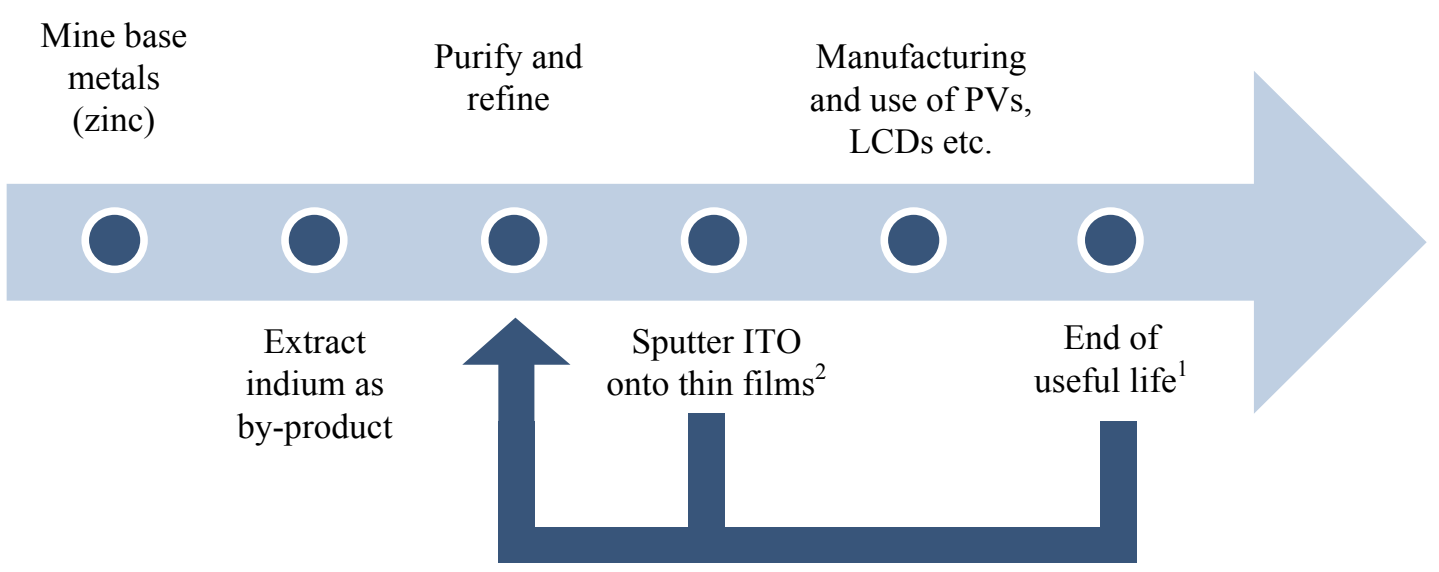

Figure 3. The high-level value chain for indium

${ }^{1}$ EOL recycling is not currently a significant source of supply.

${ }^{2}$ Recycling from manufacturing waste is better characterized as improved manufacturing efficiency than as a source of new supply.

\subsection{Deposits and Reserves}

Indium's average abundance is estimated to be approximately $0.05 \mathrm{ppm}$ in the continental crust and $0.072 \mathrm{ppm}$ in the oceanic crust. Indium is found in trace amounts in many minerals and base metal sulfides, particularly chalcopyrite, sphalerite, stannite, and cassiterite, where it deposits via ionic substitution. Although indium's concentration is highest within chalcopyrite, where concentrations are twice as high as in sphalerite, sphalerite remains the most important indiumbearing mineral where the indium is recovered as a byproduct from the zinc-sulfide ore (Tolcin 2012a; Schwarz-Schampera and Herzig 2002).

The average indium content of zinc deposits from which it is recovered ranges from less than 1 $\mathrm{ppm}$ to $100 \mathrm{ppm}$. Although the geochemical properties of indium are such that it occurs with other base metals - copper, lead, and tin, and to a lesser extent with bismuth, cadmium, and silver-at current indium prices most of these deposits are subeconomic.

Schwarz-Shampera and Herzig (2002) note three principal indium provinces:

- The subduction-related western Pacific plate boundaries, especially in east and southeast Asia

- The Nazca-South American plate boundary in Bolivia and Peru

- Various metallogenic epochs in central Europe covering the Hercynian and Alpine belts.

Other indium-rich areas are the Caledonian/Appalachian belt of North America (New Brunswick, Canada) and the Archean greenstone belts of Canada and South Africa.

Major geologic hosts for indium mineralization include volcanic-hosted massive sulfide deposits, sediment-hosted exhalative massive sulfide deposits, polymetallic vein-type deposits, epithermal deposits, active magmatic systems, porphyry copper deposits, and skarn deposits. The most important producers of indium today are the volcanic-hosted massive sulfide and the 
polymetallic vein-type deposits, which are mined for zinc, lead, tin, and other metals. For more detailed geologic information on indium, see Schwarz-Schampera and Herzig (2002).

Gibson and Hayes (2011) note that indium is also associated with some silver deposits. Because silver deposits are generally smaller than many large base metal deposits, indium may well make up a material part of the total revenue stream. Thus, they view indium production with silver as an attractive and stable alternative to byproduction from base metals.

Despite its association with a number of other metals, including silver, and because reported information is lacking, ${ }^{6}$ estimates of indium reserves are based on average indium content of zinc ores rather than direct assessment of indium reserves. Although these estimates represent only a small fraction of the total indium that is potentially recoverable from the Earth's crust, they provide a snapshot of known resources, their levels, and their locations. ${ }^{7}$ Indium reserves were $\sim 15,000$ tonnes in 2013; China has more than two thirds of the global reserves (Table 1 and Figure 4).

Table 1. Total Indium Reserves

\begin{tabular}{lcccc}
\hline & \multicolumn{2}{c}{$\begin{array}{c}\text { Indium Reserves } \\
\text { (tonnes indium metal) }\end{array}$} & \multicolumn{2}{c}{ Share of Indium Reserves } \\
\hline & $\mathbf{2 0 0 7}^{\mathbf{a}}$ & $\mathbf{2 0 1 3}^{\mathbf{b}}$ & $\mathbf{2 0 0 7}$ & $\mathbf{2 0 1 3}$ \\
\hline Canada $^{\mathrm{c}}$ & 150 & 180 & $1 \%$ & $1 \%$ \\
\hline China & 8,000 & 10,400 & $75 \%$ & $69 \%$ \\
\hline Peru & 360 & 480 & $3 \%$ & $3 \%$ \\
\hline Russia & 80 & 80 & $1 \%$ & $1 \%$ \\
\hline United States $^{\text {Other }}$ & 280 & 200 & $3 \%$ & $1 \%$ \\
\hline Total & 1,800 & 3,700 & $17 \%$ & $25 \%$ \\
\hline
\end{tabular}

${ }^{a}$ Represents the most recent available USGS estimate of indium reserves.

${ }^{\mathrm{b}}$ Based on a pro rata increase in global zinc reserves between 2007 and 2013. Information on the changes to zinc reserves over this period is included in Appendix A.

${ }^{\mathrm{c}}$ Zinc reserve data for 2007 from the Canadian Minerals Yearbook (Trelawny and Pearce 2009).

${ }^{d}$ Other countries include Australia, Bolivia, India, Ireland, Kazakhstan, and Mexico. Even though zinc reserves are available in these countries, no data were available to estimate the corresponding indium reserves. See Appendix A. Source: Own estimates; Tolcin 2008a, 2008b, and 2014a; Roskill 2010; Trelawny and Pearce 2009.

Not considered in these estimates is the recoverable indium in copper, lead, tin and silver deposits, or in discarded residues, slag, or tailings. Although the potential reserves and resources in these non-zinc deposits are not currently quantifiable, according to Indium Corporation of America (Indium Corp.) 15,000 tonnes of indium are contained residues, slag, and tailings, and annual increases from new residue generation are $~ 500$ tonnes (Mikolajczak 2009). Major quantities of indium are believed to lie in urban waste in discarded consumer products. In 2008, the Japanese National Institute for Materials Science estimated that Japan alone had more than 1,700 tonnes of indium in the form of consumer waste ${ }^{8}$ (Ogo and Takeishi 2010).

\footnotetext{
${ }^{6}$ Because indium has relatively low economic importance for most large mining companies, it bypasses disclosure requirements. ${ }^{7}$ The USGS defines reserves as the known metal content of ores or that is technically and economically capable of being mined and processed at a profit given conditions at the time of the reserve estimate (Jorgenson and George 2005).

${ }^{8}$ It is not known whether these resources would be economically recoverable given current technologies and prices.
} 


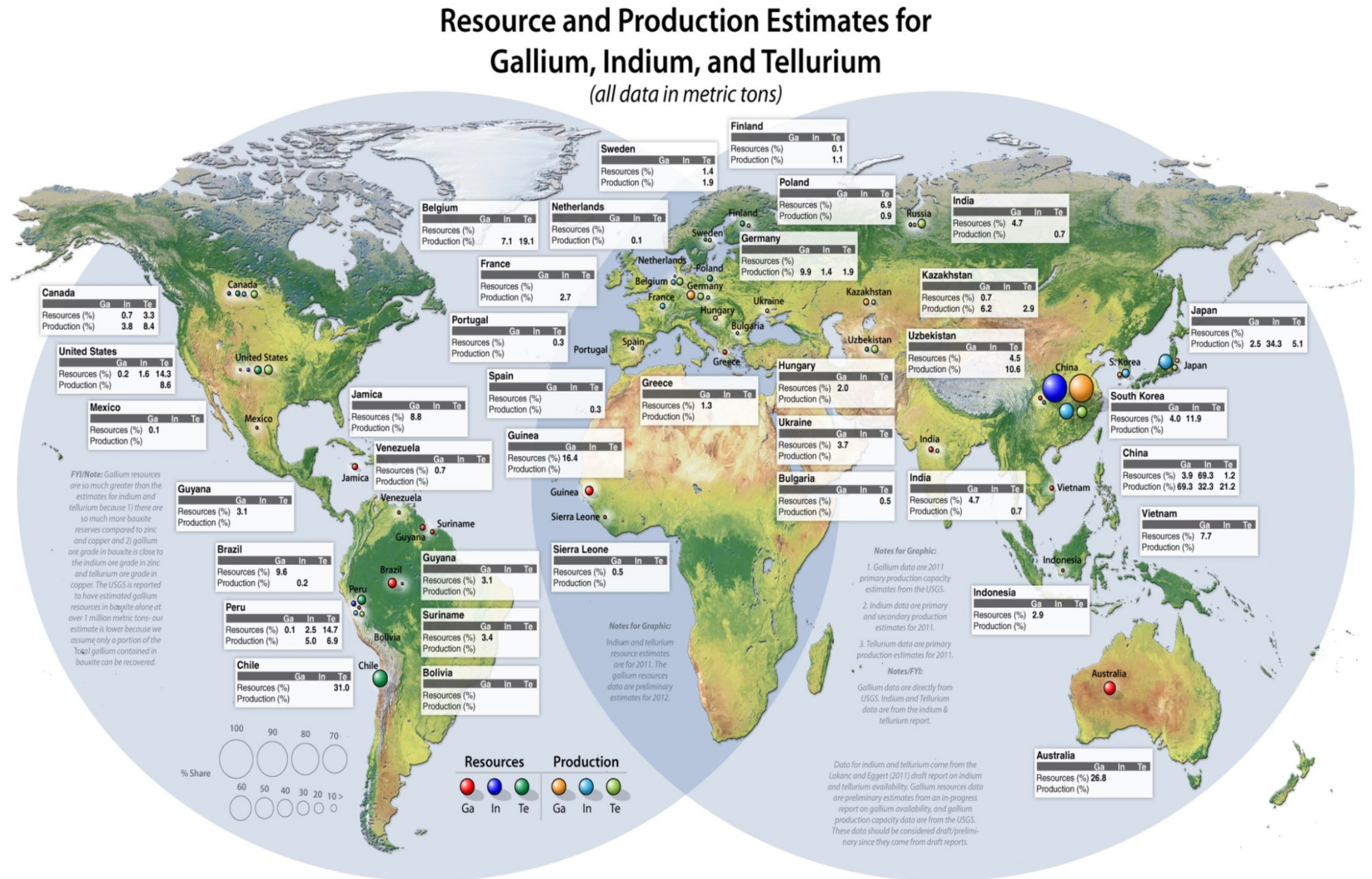

Figure 4. Distribution of world indium, gallium, and tellurium resources and production 
In comparison with the figures presented in Table 1, Indium Corp. states that total reserves and resources ${ }^{9}$ in 2009 were $\sim 50,000$ tonnes, distributed about evenly between Western countries $(26,000$ tonnes, $53 \%)$ and China, and the Commonwealth of Independent States $(23,000$ tonnes, 47\%) (Moss et al. 2011).

Given that current refined production is $\sim 770$ tpa (as discussed later in this report), the ratio of reserves to annual production is $\sim 20$, implying that these reserves would last $\sim 20$ years at current production rates. For many minerals, a reserve/production ratio of 10-20 is not uncommon, so indium's ratio is not unusual. One should not infer from this ratio that geologic sources of indium will be depleted in 2 decades. Reserves change over time. As mining depletes reserves, mining companies have an incentive to find and develop additional reserves - a process that results in reserve/production ratios that remain reasonably constant over time. For example, the USGS estimate of indium reserves at year-end 1997 was 2,600 tonnes, yielding a 1997 reserve/production ratio of 11 . Indium reserves at year-end 2013 were approximately six times larger than they were in 1997.

These are crude estimates of reserves; however, they provide a sense of where mining of indiumbearing ores is likely to be concentrated over the next several decades. Although most reserves and resources are in China, there is a significant diversity of other potential locations for mining indium-bearing ores. Also, the estimates of resources and reserves focus on primary sources of indium only; if one considers future increases in the recycling of consumer and manufacturing waste, the geographic dispersion of indium sources could diversify significantly.

\subsection{Mine Production}

Mine production figures are not publically available for indium as a byproduct of zinc mining and processing, but Roskill (2010) estimates global mine production of indium from zinc mine production statistics for 2009.

Table 2 shows the Roskill estimates for mine production of indium as well as our estimates for 2013. In arriving at these estimates, Roskill assumed that sphalerite ores contain $67 \%$ zinc and 15-50 ppm indium.

The indium content of zinc ores mined in 2009 and 2013 is 481 and 629 tonnes, respectively. Growth of indium production between 2009 and 2013 represents a compounded annual growth rate (CAGR) of $6.9 \%$. By comparison, zinc production grew at a CAGR of $4.8 \%$ over the same period (Appendix A), indicating that the production of indium-bearing zinc ores grew faster than non-indium-bearing ores.

The country concentration of mine production is similar to that of the concentration of reserves. The main sources of zinc ores are China, Peru, Canada, Australia, and the United States. These five countries accounted for $76 \%$ of the potentially recoverable indium from zinc ores in 2009 and $79 \%$ in 2013. These same countries represented $\sim 82 \%$ and $~ 75 \%$ of indium reserves in 2007

\footnotetext{
${ }^{9}$ Although reserves (classified as "proven" and "probable" by most reporting codes) are the fraction of known resources that are economically feasible for extraction given current prices and technologies, resources (classified as "measured," "indicated," and "inferred") represent known resources that are not economic to classify as reserves or are too speculative because the geological sampling information is preliminary.
} 
and 2013, respectively (Table 1). China has a lower market share with $59 \%$ of total mine production, compared to a $70 \%$ share of reserves.

Table 2. Global Estimates of Mined Indium From Zinc Ores, 2009 and 2013 (tonnes)

\begin{tabular}{|c|c|c|c|c|c|c|c|}
\hline & \multicolumn{2}{|c|}{$\begin{array}{c}\text { Mine Production } \\
\text { of Zinc } \\
\text { ('000s tonnes) }\end{array}$} & \multicolumn{2}{|c|}{$\begin{array}{l}\text { Estimated Sphalerite } \\
\text { (Zns) Production } \\
\text { ('000s tonnes) }\end{array}$} & \multicolumn{3}{|c|}{$\begin{array}{l}\text { Estimated Indium Content } \\
\text { of Mined Zinc Ores }\end{array}$} \\
\hline & 2009 & 2013 & 2009 & 2013 & $(p p m)^{b}$ & $2009(t)$ & $2013^{c}(t)$ \\
\hline Australia & 1,290 & 1,400 & 1,925 & 2,090 & 15 & 29 & 31 \\
\hline Bolivia $^{d}$ & 422 & 400 & 630 & 597 & 20 & 13 & 12 \\
\hline Canada $^{\mathrm{e}}$ & 702 & 550 & 1,048 & 821 & 37 & 39 & 30 \\
\hline China & 3,100 & 5,000 & 4,627 & 7,463 & 50 & 231 & 373 \\
\hline India $^{d}$ & 695 & 800 & 1,037 & 1,194 & 20 & 21 & 24 \\
\hline Ireland $^{d}$ & 386 & 330 & 576 & 493 & 20 & 12 & 10 \\
\hline Kazakhstan $^{d}$ & 480 & 370 & 716 & 552 & 20 & 14 & 11 \\
\hline Mexico & 390 & 600 & 582 & 896 & 20 & 12 & 18 \\
\hline Peru & 1,510 & 1,290 & 2,254 & 1,925 & 20 & 45 & 39 \\
\hline United States & 736 & 760 & 1,099 & 1,134 & 20 & 22 & 23 \\
\hline Other & 1,490 & 1,950 & 2,224 & 2,910 & 20 & 44 & 58 \\
\hline Total & 11,200 & 13,500 & 16,700 & 20,100 & & 481 & 629 \\
\hline \multicolumn{8}{|c|}{$\begin{array}{l}\text { a Estimates zinc content of concentrates and shipping ores. } \\
\text { b } \\
\text { Roskill (2010) believes that the actual amount of indium contained in the zinc ores may be much higher than estimated because } \\
\text { some deposits contain much higher levels of indium than assumed. } \\
\text { c } 2013 \text { estimates of indium production derived using Roskill (2010) estimates of indium concentration applied to } 2013 \text { USGS zinc } \\
\text { production data. } \\
{ }^{\mathrm{d}} \text { Roskill (2010) does not give an exact estimate of indium concentration in zinc ores. A value of } 20 \mathrm{ppm} \text { is used, because this } \\
\text { value is used most frequently in that particular study. } \\
{ }^{\mathrm{e}} \text { Estimates for } 2009 \text { zinc mine production from the Canadian Minerals Yearbook (Trelawny and Pearce 2009) and } 2013 \\
\text { estimates are from USGS mineral commodity surveys. } \\
\text { Source: Own calculations; Tolcin 2010a, 2010b, 2014b; Roskill 2010; Trelawny and Pearce } 2009\end{array}$} \\
\hline
\end{tabular}

As previously discussed, indium is also produced from metals such as copper, tin, and silver. As tabulated in Table 3, indium mined along with copper and tin ores is estimated to add a further 60-65 tonnes to annual global mine production (Roskill 2010). Potential known sources include copper ores mined in Russia and China, as well as tin ores mined in China. In addition, Falconbridge Ltd. produced indium from dusts recovered during copper smelting at its Canadian operations. Between 2009 and 2013, copper and tin production grew at rates of $\sim 3.2 \%$ and $7.0 \%$, respectively. Assuming that indium production from these sources has kept in line with main product production, total world mine production of indium from copper and tin resources was $\sim 68-74$ tonnes in 2013 (Table 3).

Table 3. Summary Estimate of Indium Content of Various Mined Ores

\begin{tabular}{lcc}
\hline & Estimate of Indium Mined From Zinc, Copper, and Tin Ores \\
\hline & $\mathbf{2 0 0 9}$ (tonnes) & $\mathbf{2 0 1 3}$ (tonnes) \\
\hline Zinc & 481 & 629 \\
\hline Copper and tin & $60-65$ & $68-74$ \\
\hline Total & $\mathbf{5 4 1 - 5 4 6}$ & $\mathbf{6 9 7 - 7 0 3}$ \\
\hline
\end{tabular}


Combining these estimates with the information from Table 1 yields total world mine production of indium of $\sim 550$ and $\sim 700$ tonnes in 2009 and 2013, respectively.

The methodology adopted herein to estimate total indium mined along with main product metals is highly subjective and is likely conservative.

\subsection{Smelting and Refining}

Indium is recovered from mine concentrates or from dusts and residues produced during smelting. It is then typically refined to a purity of $99.99 \%$ (known as $4 \mathrm{~N}$ or four "nines") and sent to a special metals refinery/plant and further refined to $6 \mathrm{~N}$ or $7 \mathrm{~N}$ purity, or manufactured into products such as ITOs, alloys, and compounds.

Few companies operate fully integrated indium recovery and refining facilities. Roskill (2010) identifies the following rare exceptions:

- Japan Energy Corp., the largest integrated indium producer in the world. It is a wholly owned subsidiary of JX Holding, which was established on April 1, 2010, through the merger of Nippon Oil Corporation and Nippon Mining Holdings, Inc.

- Canada's Teck Resources Limited (Teck). Teck produces copper, coal, zinc, lead, and energy as primary products. It produces molybdenum, silver, and various special metals such as indium and tellurium as byproducts. A key operation is its integrated smelting and refining complex at Trail in British Columbia, Canada, where its main products are refined zinc and lead; indium is a byproduct.

- Chinese state-owned Hunan Nonferrous Metals Corporation Limited, a large integrated producer of nonferrous metals. This corporation mines, processes, and sells nonferrous metals. It operates in three segments: (1) nonferrous metal mining; (2) nonferrous metal smelting; and (3) their compounds production.

Most indium producers are not fully integrated. A number of mining companies never recover refined metals at their own facilities and simply sell indium-bearing concentrates on the open market. Prospective buyers of zinc concentrates (and associated indium impurities) can be grouped into three major categories: commodity traders, smelters, and manufacturers of zinc end-use products. ${ }^{10}$ The main differences between these categories relate to the allocation of marketing and sales responsibilities and the price structure.

Smelters typically offer two options for processing concentrates:

1. Toll processing, where a company (which has specialized equipment) arranges to process the zinc concentrate on behalf of the owner of the concentrate. In this case, the owner of the concentrate has a set percentage (net smelter return) of the refined zinc produced by the smelter for which it is responsible for marketing and shipping to end users after processing (Thibault et al. 2010).

2. Alternatively, the miner can directly sell the zinc and indium contained in concentrates to the smelter and the smelter in turn sells the refined zinc to end users (Thibault et al 2010).

${ }^{10}$ Steel industry, brass manufacturers, and the die-casting industry, for example. 
Table 4 includes a non-exhaustive list of well-established prospective buyers for indium-bearing zinc concentrate.

Table 4. List of Prospective Buyers for Indium-Bearing Zinc Concentrates

\begin{tabular}{l|l}
\hline \multicolumn{1}{c|}{ Smelters } & \multicolumn{1}{c}{ Commodity Traders } \\
\hline Teck Resources (Canada) & $\begin{array}{l}\text { Amalgamated Metal Corporation (AMC) } \\
\text { Trading Group (Worldwide) }\end{array}$ \\
\hline Chelyabinsk Zinc (Russia) & Glencore International AG (Worldwide) \\
\hline Laibin Smeltery (China) & Euromin SA/Vitol (Worldwide) \\
\hline Dowa Mining (Japan) & ANI Metal and Chemicals (Turkey) \\
\hline Korea Zinc (South Korea) & Ocean Partners (United States) \\
\hline Lundin Mining (Portugal) & Traxys (Belgium) \\
\hline Mitsui Mining (Peru) & Marco International (United States) \\
\hline Nyrstar (France) & \\
\hline
\end{tabular}

Source: Thibault et al. 2010

Other mining companies produce standard-grade indium that is further upgraded by specialist refineries. To produce a metal that is high enough quality to be accepted by specialist refiners, these companies need to produce a high quality ( $+95 \%$ purity) indium at either the mine site or at their own smelting facilities. As an example, before its closure in May 2010, Xstrata (formerly Falconbridge Ltd.) produced indium at its Kidd Creek zinc-copper mining and refining division at Timmins, Ontario. $3 \mathrm{~N}$ indium (99.9\%) was produced at a refining plant built as a joint venture with Indium Corp., and the indium was shipped to Indium Corp.'s facilities in New York where it was refined to $4 \mathrm{~N}$ grade $(99.99 \%)$ or higher.

Not all indium that enters a zinc (or other metals) smelter is recovered. Once the indium has entered the smelting process there are three principal channels: (1) indium is discarded by the smelter operator ${ }^{11}$ either because the smelter lacks indium recovering capabilities or as normal losses in the recovery process; (2) indium is recovered in sponge or other impure form at a smelter and then sold to a third party refinery where it can be upgraded to commercial-grade indium; or (3) indium is recovered by the smelter and then refined to commercial grade in its own special metals processing refinery.

Where indium is a byproduct of zinc smelting, it is normally sold as a sponge. The typical minimum purity of indium in the sponge required by refineries is $95 \%$ where certain impurities may attract a penalty. ${ }^{12}$

In addition to being recovered from zinc concentrates, indium is also recovered by many refineries from fumes, dusts, slags, residues, and alloys from zinc, lead-zinc, or lead-tin-zinc smelting. ${ }^{13}$ The solutions are concentrated and crude indium is recovered as low-grade $99 \%$ purity metal. The impure indium can thereafter be refined to standard grade $(99.99 \%$ [4N]), high purity grade $(99.999 \%$ [ $5 \mathrm{~N}])$, or to grades up to $99.99999 \%(7 \mathrm{~N})$, and can then be produced in

\footnotetext{
${ }^{11}$ Approximately $30 \%$ of indium-bearing concentrates are not sent to indium-capable smelters (EU 2010a; Mikolajczak 2009).

${ }^{12}$ Typical impurities associated with the indium sponge that may attract a penalty charge by the refinery are arsenic, cadmium, thallium, lead, tin, and copper. As a result, care is normally taken in designing recovery processes to ensure that these impurities are extracted prior to the formation of a sponge.

${ }^{13}$ Normally these materials (as well as the slag) are leached with sulfuric or hydrochloric acid for indium recovery.
} 
various forms including ingots, foil, powder, ribbon, shot, and wire (Schwarz-Schampera and Herzig 2002).

A non-exhaustive list of potential buyers of indium sponge and end users follows:

- Indium Corp. of America (New York, United States)

- Umicore Group (Belgium)

- MCP Metal Specialties Inc. (Connecticut, United States)

- ESPI Corporation (Oregon, United States)

- AIM Specialty Materials Division (Rhode Island, United States) (Thibault et al. 2010).

Table 5 shows that third-party estimates put the refinery production of primary indium at $\sim 600$ 800 tpa over the last few years. The USGS stated that indium production was $\sim 770$ and $\sim 782$ tonnes in 2013 and 2012, respectively. In 2011, the USGS stated that indium production was $\sim 622$ tonnes. We estimate 822 tonnes. By comparison, the company 5NPlus stated that current global production of refined indium was $\sim 800$ tonnes (5NPlus 2011). The European Commission, which bases its estimates largely on those of the USGS, stated that global production of refined indium at $\sim 600$ tonnes in 2011 (Moss et al. 2011).

Figure 5 shows that China is the largest producer of refined indium with $50 \%-55 \%$ of global production, an outcome that is consistent with its share of global zinc production (see Appendix A). The remaining $45 \%-50 \%$ of primary indium production is distributed among countries such as Belgium (30-50 tpa, 4\%-6\%), Canada (41-67 tpa, 8\%-11\%), Japan (55-110 tpa, 9\%-11\%), and South Korea (70-165 tpa, 11\%-21\%). 
Table 5. Estimate of Primary Indium Refinery Production (tonnes, 2009 to 2013)

\begin{tabular}{lcccccc}
\hline & $\mathbf{2 0 0 9}^{\mathbf{b}}$ & $\mathbf{2 0 1 0}^{\mathbf{c}}$ & $\mathbf{2 0 1 1}^{\mathbf{c}}$ & $\mathbf{2 0 1 1}^{\mathbf{d}}$ & $\mathbf{2 0 1 2}^{\mathbf{e}}$ & $\mathbf{2 0 1 3}^{\mathbf{e}}$ \\
\hline Belgium & 30 & 30 & 30 & 50 & 30 & 30 \\
\hline Brazil & 5 & 5 & 5 & 4 & $\mathrm{~N} / \mathrm{A}$ & $\mathrm{N} / \mathrm{A}$ \\
\hline Canada & 41 & 67 & 65 & 52 & 62 & 65 \\
\hline China & 275 & 340 & 340 & 318 & 405 & 410 \\
\hline France & $\mathrm{N} / \mathrm{A}$ & $\mathrm{N} / \mathrm{A}$ & $\mathrm{N} / \mathrm{A}$ & 40 & $\mathrm{~N} / \mathrm{A}$ & $\mathrm{N} / \mathrm{A}$ \\
\hline Germany & 15 & $\mathrm{~N} / \mathrm{A}$ & $\mathrm{N} / \mathrm{A}$ & 20 & $\mathrm{~N} / \mathrm{A}$ & $\mathrm{N} / \mathrm{A}$ \\
\hline Japan & 55 & 70 & 70 & 110 & 71 & 71 \\
\hline Netherlands & $\mathrm{N} / \mathrm{A}$ & $\mathrm{N} / \mathrm{A}$ & $\mathrm{N} / \mathrm{A}$ & 2 & $\mathrm{~N} / \mathrm{A}$ & $\mathrm{N} / \mathrm{A}$ \\
\hline Peru & 5 & $\mathrm{~N} / \mathrm{A}$ & $\mathrm{N} / \mathrm{A}$ & 76 & 11 & 10 \\
\hline Russia & 20 & $\mathrm{~N} / \mathrm{A}$ & $\mathrm{N} / \mathrm{A}$ & 17 & 13 & 13 \\
\hline South Korea & 70 & 70 & 100 & 135 & 165 & 150 \\
\hline United States & 4 & $\mathrm{~N} / \mathrm{A}$ & $\mathrm{N} / \mathrm{A}$ & $\mathrm{N} / \mathrm{A}$ & $\mathrm{N} / \mathrm{A}$ & $\mathrm{N} / \mathrm{A}$ \\
\hline Other & 13 & 27 & 30 & N/A & 25 & 25 \\
\hline Total & 533 & 609 & 640 & 822 & 782 & 770 \\
\hline
\end{tabular}

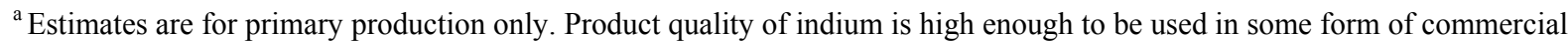
manufacturing or production process.

${ }^{\mathrm{b}}$ USGS (Tolcin 2008a to 2010a) or Roskill (2010). Average of both where two figures are available. "Other" production used as a balancing figure.

${ }^{\mathrm{c}}$ USGS estimates (Tolcin 2011a and 2012a).

${ }^{\mathrm{d}}$ Company reports, own estimates, Roskill 2010 and Tolcin 2008a to 2012a.

e USGS estimates (Tolcin 2014a).

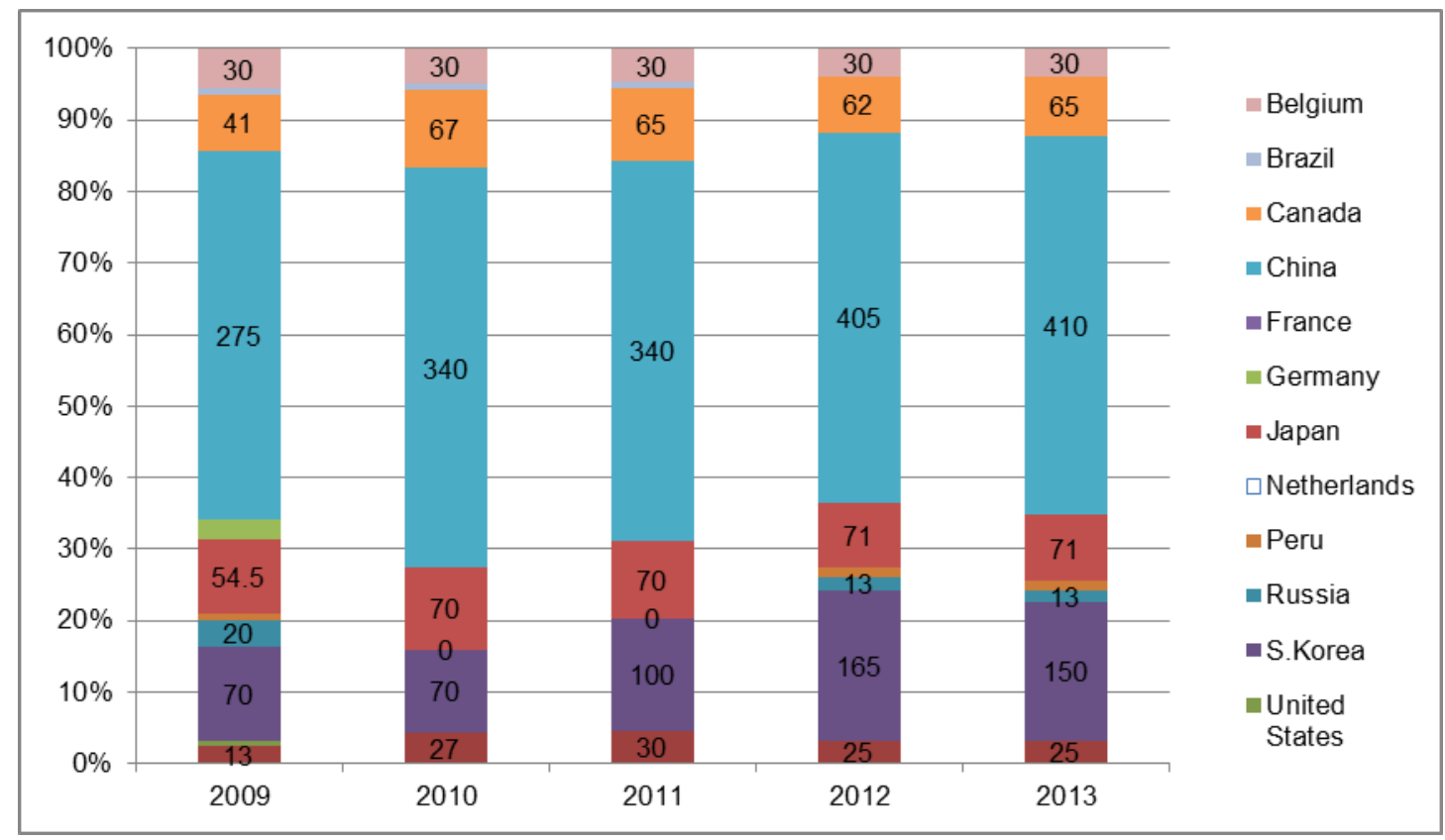

Figure 5. Share of primary indium refinery production by country (2009 to 2013)

(Created with data from Table 5) 


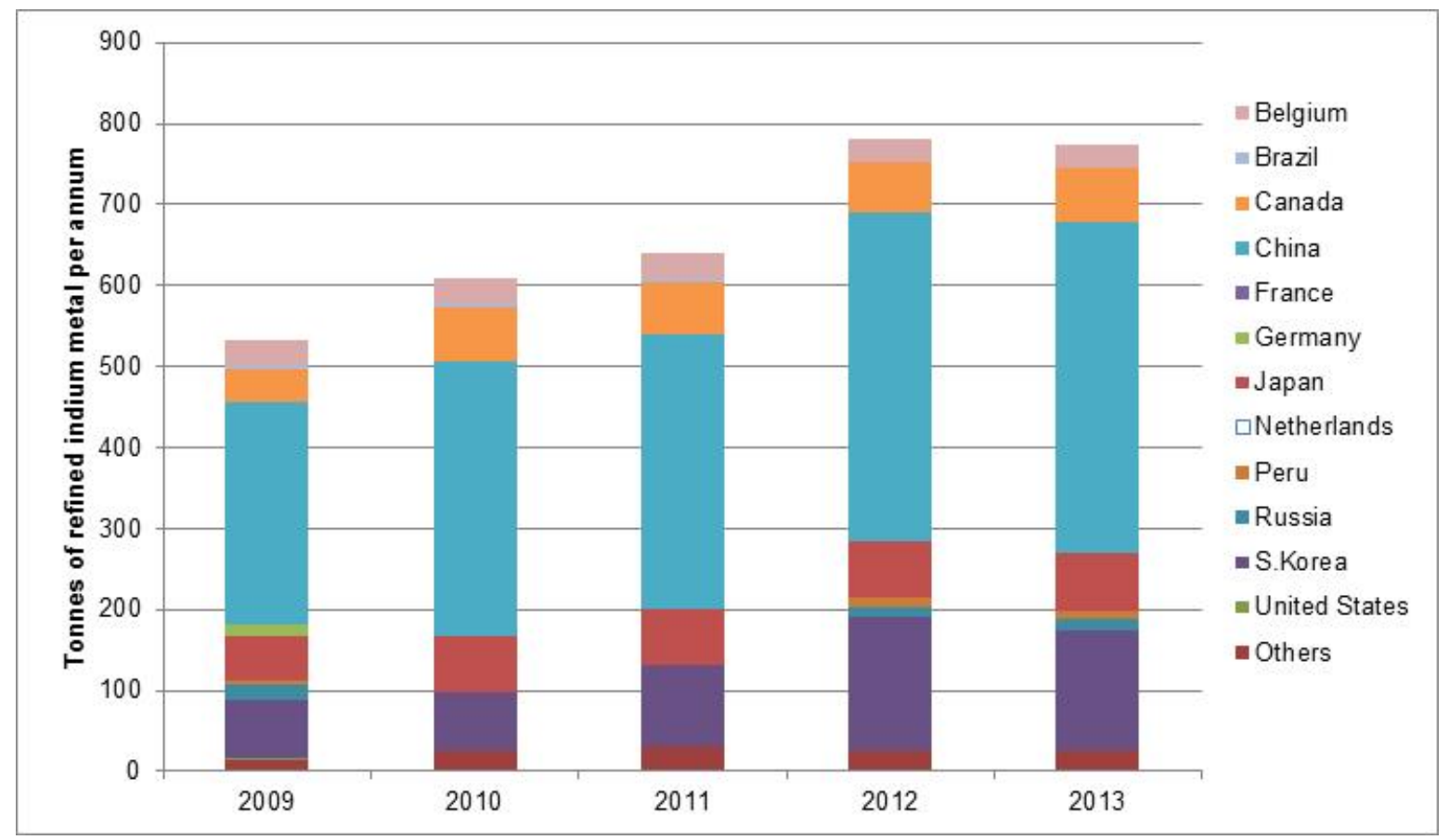

Figure 6. Tonnes of primary indium refinery production by country (2009 to 2013)

(Created with data from Table 5)

The risk to non-Chinese users associated with China's dominant position in the production of refined indium is compounded by the Chinese government's trade restrictions. Since June 2007 the China's Ministry of Commerce (MOFCOM) has required that an export license be issued to export indium metal with a purity of $99.995 \%$ or higher (Roskill 2010; MOFCOM 2012). Figure 7 shows that allowable indium exports have remained constant at $\sim 230$ tpa from 2008 to 2013 while production has grown, thereby allowing Chinese indium producers to export a lower share of refined indium to global markets. Exports were most restricted in 2009 when indium production was curtailed because of depressed indium and zinc prices associated with the 20082009 global recession. 


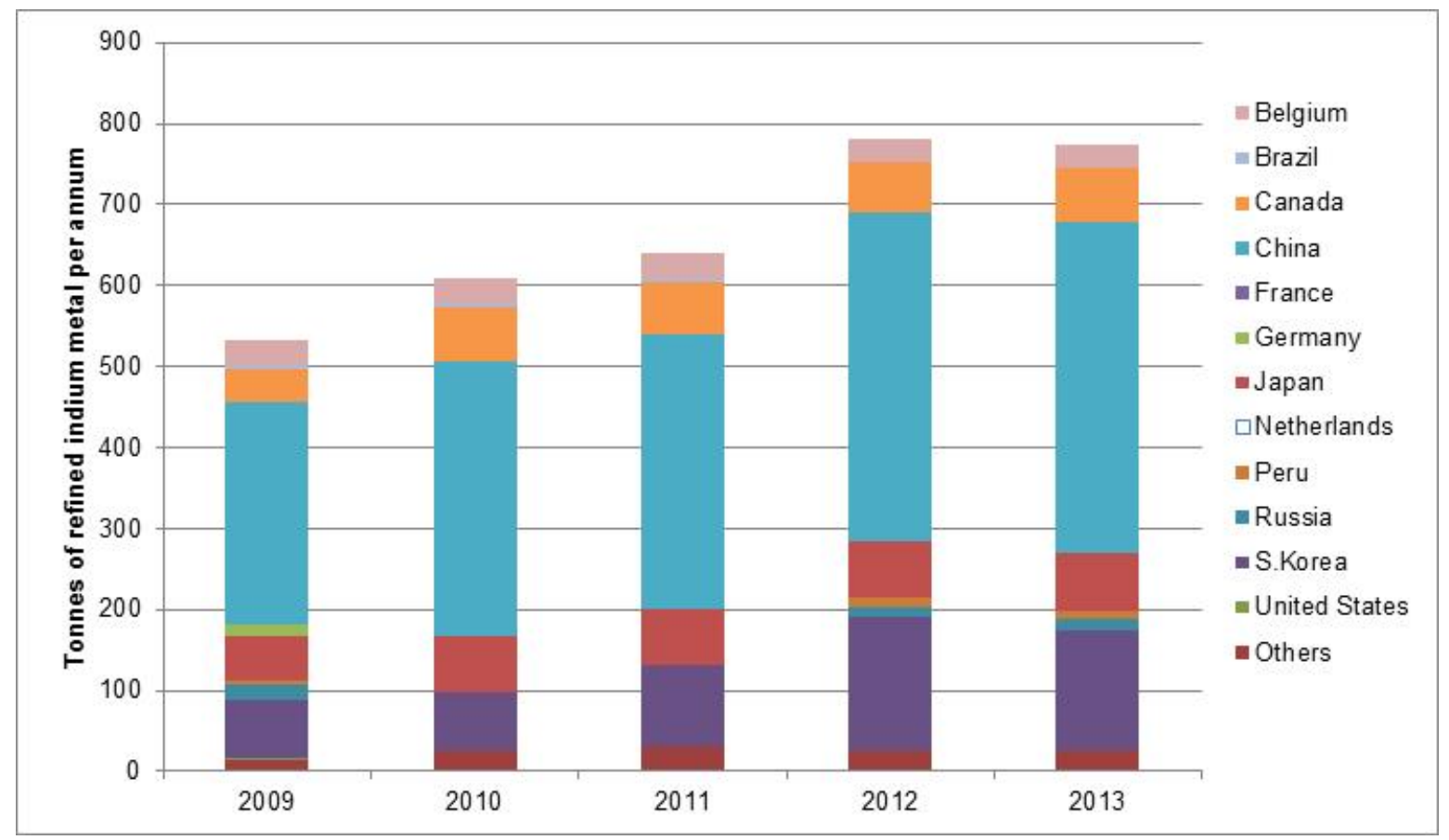

Figure 7. Permissible Chinese export levels from 2008 to 2013

Sources: MOFCOM (2012), Metal Bulletin (2012), and Yi (2013)

Issuance of an export license by the MOFCOM requires applicants to meet certain requirements, which in addition to compliance with local environmental regulations and minimum purity levels require exporters to ensure that the recovery rate of indium in the main producing metal residue is not less than $80 \%$ and that they have minimum registered capital of not less than 70 million Yuan $^{14}$ (MOFCOM 2012). Export quotas vary by company and are re-examined every 6 months. Table 6 contains a list of China's main indium exporters over 2010 and 2011.

\footnotetext{
${ }^{14}$ Enforcement of such regulations would prove difficult, particularly the minimum recovery requirement of $80 \%$.
} 
Table 6. China's Indium Export Quotas, 2010 and 2011 (tonnes)

\begin{tabular}{|c|c|c|c|c|c|c|}
\hline & $\begin{array}{c}\mathrm{H} 1 \\
2010\end{array}$ & $\begin{array}{c}\mathrm{H} 2 \\
2010\end{array}$ & $\begin{array}{c}\mathrm{H} 1 \\
2011\end{array}$ & $\begin{array}{c}\mathrm{H} 2 \\
2011\end{array}$ & $\begin{array}{l}\text { Total: } \\
2010+2011\end{array}$ & $\begin{array}{l}\text { Share of } \\
\text { exports }\end{array}$ \\
\hline $\begin{array}{l}\text { Guang Xi Debang Technology Co., } \\
\text { Ltd. }\end{array}$ & $\mathrm{N} / \mathrm{A}$ & 4.3 & 0.0 & 4.7 & 9.1 & $2 \%$ \\
\hline Guangxi China Tin Group Co., Ltd. & 15.3 & $\mathrm{~N} / \mathrm{A}$ & 6.4 & 13.8 & 35.5 & $8 \%$ \\
\hline Guangxi Indium Technology Co., Ltd. & 1.3 & 5.1 & 5.9 & 2.5 & 14.8 & $3 \%$ \\
\hline Guangxi Tanghanxinyin Ltd. & 0.5 & 0.4 & 0.5 & 1.2 & 2.6 & $1 \%$ \\
\hline $\begin{array}{l}\text { Huludao Nonferrous Metals (Group) } \\
\text { Import \& Export Co., Ltd. }\end{array}$ & 8.7 & 7.9 & $\mathrm{~N} / \mathrm{A}$ & N/A & 16.6 & $4 \%$ \\
\hline $\begin{array}{l}\text { Hunan Zhuzhou Smelter Torch Metals } \\
\text { Import and Export Ltd. }\end{array}$ & 29.4 & 19.2 & 4.7 & 2.2 & 55.6 & $12 \%$ \\
\hline $\begin{array}{l}\text { Jiangsu Sainty International Group } \\
\text { Co., Ltd. }\end{array}$ & 3.4 & 1.0 & 2.8 & 1.6 & 8.8 & $2 \%$ \\
\hline $\begin{array}{l}\text { Kunming hualian indium Industry Co., } \\
\text { Ltd. }\end{array}$ & 3.2 & 1.2 & 4.4 & 5.2 & 14.0 & $3 \%$ \\
\hline Liuzhou China Tin Group Co., Ltd. & N/A & 11.2 & $\mathrm{~N} / \mathrm{A}$ & N/A & 11.2 & $2 \%$ \\
\hline Minmetals Nonferrous Metals Co., Ltd. & N/A & 1.8 & 18.8 & 9.0 & 29.6 & $6 \%$ \\
\hline $\begin{array}{l}\text { Nanjing Foreign Economic and Trade } \\
\text { Development Co., Ltd. }\end{array}$ & 17.6 & 11.2 & 18.2 & 12.3 & 59.3 & $13 \%$ \\
\hline $\begin{array}{l}\text { Nanjing Germanium Technology Co., } \\
\text { Ltd. }\end{array}$ & 7.8 & 5.1 & 14.5 & 7.8 & 35.2 & $8 \%$ \\
\hline $\begin{array}{l}\text { Nanjing three Friends of the Electronic } \\
\text { Materials Co., Ltd. }\end{array}$ & 4.3 & 3.7 & 4.2 & 2.2 & 14.5 & $3 \%$ \\
\hline $\begin{array}{l}\text { Shuikoushan Nonferrous Metal Co., } \\
\text { Ltd. }\end{array}$ & 1.2 & 1.4 & 0.6 & 0.5 & 3.7 & $1 \%$ \\
\hline The Liuzhou Ingle metal Co., Ltd. & 5.9 & 2.8 & 5.8 & 3.8 & 18.3 & $4 \%$ \\
\hline $\begin{array}{l}\text { The Xiangtan positive Tan Non- } \\
\text { Ferrous Metals Ltd. }\end{array}$ & 6.7 & 4.8 & 7.5 & 6.1 & 25.1 & $5 \%$ \\
\hline $\begin{array}{l}\text { Western Qinghai indium Industry Co., } \\
\text { Ltd. }\end{array}$ & 2.7 & 0.5 & 2.6 & 3.0 & 8.7 & $2 \%$ \\
\hline Xikuangshan antimony industry Llc.. & 1.1 & 0.7 & 1.2 & 0.6 & 3.7 & $1 \%$ \\
\hline $\begin{array}{l}\text { Yunnan Chengo Nonferrous Metals } \\
\text { Corporation Ltd. }\end{array}$ & 2.0 & 1.7 & 2.2 & 1.3 & 7.3 & $2 \%$ \\
\hline $\begin{array}{l}\text { Zhuzhou Branch to New Materials } \\
\text { Co., Ltd. }\end{array}$ & 14.2 & 5.3 & 24.5 & 15.1 & 59.2 & $13 \%$ \\
\hline Other & 14.6 & 3.6 & 15.0 & 0.0 & 33.3 & $7 \%$ \\
\hline Total (6 months) & 139.8 & 93.2 & 140.0 & 93.0 & & \\
\hline Total & \multicolumn{2}{|c|}{233.0} & \multicolumn{2}{|c|}{233.0} & 466.0 & $100 \%$ \\
\hline
\end{tabular}

Note: Translation of company names from official documents was performed through Google Translate. As a result, translations may not be precise.

Source: Department of Foreign Trade, China Ministry of Commerce (MOFCOM 2012)

\subsection{Processing of Indium-Bearing Ores and Recovery of Indium}

As discussed later in this paper, improved recovery efficiency in processing is one of the main channels through which the indium supply may be increased. Generally speaking, mineral processing can be divided into four distinct phases: (1) comminution (crushing and grinding); (2) 
beneficiation (separation and concentration); (3) smelting; and (4) refining. Each stage is discussed in detail in Section 3.5.1 through 3.5.3.

\subsubsection{Comminution}

Comminution is the method by which the size of solid materials is reduced by crushing, grinding, and other processes. Breaking the rock into smaller fragments helps to either liberate certain particles of interest or increase the surface area to facilitate processing.

This part of the process occurs at the mine site, sometimes very early in the mining process, such as in the open pit or underground (with a crusher) to break the mineral-bearing ore to a small enough size to facilitate its transport to the treatment plant. Once the material is transported into the plant, several types of crushers, mills, and screens are often used in sequence (with feedback loops) to reduce the material to a fine enough fraction for recovery.

\subsubsection{Beneficiation}

The exact transition between comminution and beneficiation is not clearly defined, but generally, beneficiation is the process whereby extracted ore from mining is separated into mineral and gangue $^{15}$ (the former being suitable for further processing or direct use).

In the processing of many base metals, such as copper, lead, zinc, and nickel, this first stage of beneficiation occurs at the mine site. But full separation/beneficiation cannot be completed at the mine due to the metallurgical complexities and scale of operation required.

Instead, the mill (or treatment plant on site) separates the compounds from the ore by flotation to produce concentrates, which are the typical products from a base metal mine. The concentrates are then transported to a smelter that is usually a long distance from the mine. The concentrates often contain small quantities of precious or special metals such as gold, indium, or tellurium, which can improve the value, and may contain undesirable impurities such as mercury, sulfur, or arsenic, which reduce the value.

In the case of indium-bearing zinc sulfide ores (sphalerite), the indium may only be as concentrated as 1-100 ppm in the sphalerite; the zinc grade might be as low as $2 \%(20,000 \mathrm{ppm})$. After passing through the treatment plant, $50 \%-70 \%$ of the indium contained in the ore may report to the concentrate. Typically, indium occurs in the concentrate at $120 \mathrm{ppm}^{16}$ to $170 \mathrm{ppm}^{17}$ (Alfantazi and Moskalyk 2003). This concentration varies greatly by mine (i.e., the technology in use at a given mine) and by deposit (i.e., the grade and metallurgical complexity). For example, the Peruvian and Bolivian zinc concentrates have $187 \mathrm{ppm}$ and $630 \mathrm{ppm}$ of indium content, respectively, which makes these two countries major indium players compared to their share of world zinc production (Moss et al. 2011).

\footnotetext{
${ }^{15}$ Gangue refers to material of little to no economic value that surrounds, or is closely mixed with, a wanted mineral in an ore deposit.

${ }^{16}$ The zinc residues feeding the Akita plant in Japan are reported to have this indium concentration level (Alfantazi 2003).

${ }^{17}$ As anticipated by Ausmelt of Australia (Alfantazi and Moskalyk 2003).
} 


\subsubsection{Smelting}

Once zinc concentrate is transported to a smelter, zinc metal can be produced via either pyrometallurgical or hydrometallurgical processes. About $90 \%$ of total zinc refining is done through hydrometallurgical processes; thus, we describe and focus on this process.

The hydrometallurgical zinc smelting generally consists of four separate stages (see Figure 8):

1. The Waelz process (often referred to as calcining/roasting). A mixture of zinc concentrate and coal is heated at high temperatures to produce a calcine of impure zinc oxide.

2. Leaching. The calcine is then leached with sulfuric acid in either a single- or doubleleach process to produce a zinc sulfate solution.

3. Purification. The solution is purified with zinc dust to precipitate the impurities in the solution. During this stage indium and other elements such as copper or cadmium can be recovered.

4. Electrowinning. The aqueous zinc solution is contained in an electrolytic cell and an electric current from a lead-silver alloy anode is used to deposit zinc onto the aluminum cathode. Zinc can then be stripped from the aluminum cathodes and melted and cast into ingots (ILO 2012).

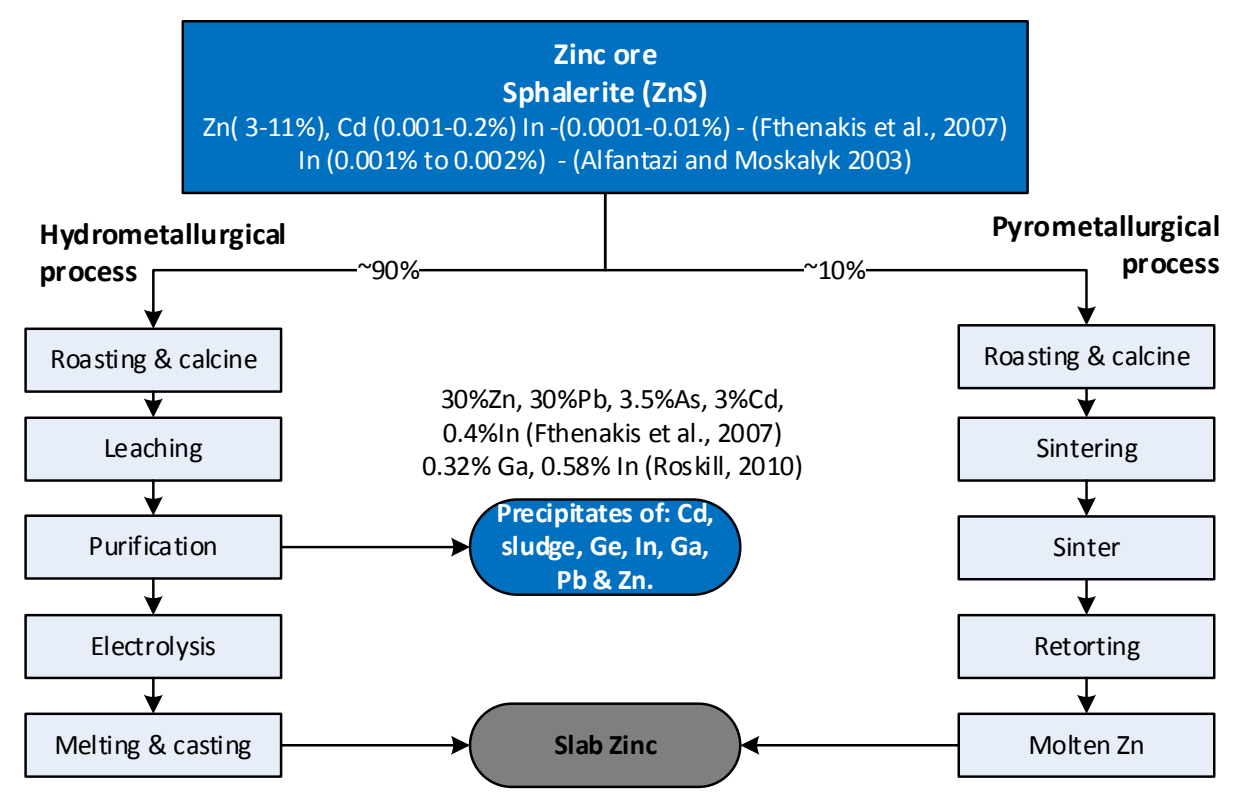

Figure 8. Smelting of zinc ores to yield zinc slabs and indium precipitate

\subsubsection{Refining}

The main source of indium for primary refining is from the fumes, dusts, slags, and residues in zinc smelting. Refineries can sometimes be located near the smelters in a "combined" metallurgical complex, as was the case with Xstrata's Kidd Creek smelter, or they can be separate standalone refineries that source their feed materials on global markets, as is the case 
with Umicore's Hoboken plant in Belgium. As with data on production, information on refinery technology and processing methodology is generally difficult to obtain, because processes are proprietary and a large part of the production is in China. Figure 9 summarizes the process described in Fthenakis et al. (2007), which is in turn based on Ullmann's encyclopedia and other information from manufacturers' reports.

As described in Section 3.5.3, after roasting the zinc oxides undergo leaching and purification, which precipitates indium in a solution pregnant with other minerals such as zinc, arsenic, and cadmium. As detailed in Figure 9, the precipitates formed in zinc refining undergo a series of leaching steps, followed by cementation. The cements are then washed and pressed to form briquettes that are refined in a furnace and poured into ingots (Fthenakis et al. 2009 and de Souza 2010).

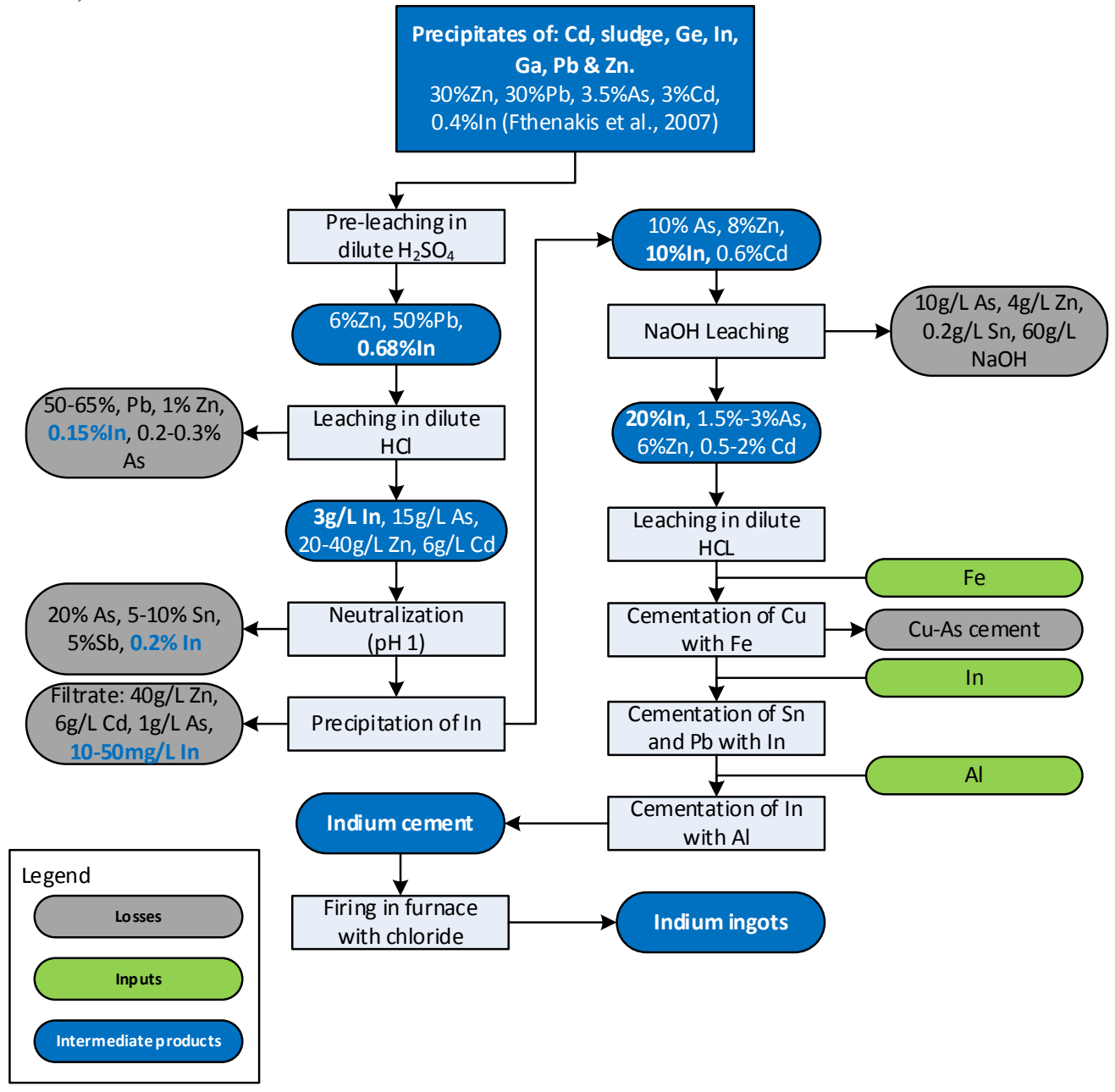

Figure 9. Advanced refining of indium from the precipitates of zinc smelting

Note: \% refers to the weight \% (i.e., concentration) of the output. Sources: Fthenakis et al. (2009) and de Souza (2011)

The product is normally at least $99.99 \%$ pure; however, at least $97 \%$ purity can also be achieved if the impurities are high; purities kept in check may have a final indium purity higher than $99.995 \%$. The total recovery of refining is $\sim 80 \%$ (Alfantazi 2003; de Souza 2011). 


\subsubsection{Costs of Refining}

Although the price structures for indium sponge and other forms of indium are negotiated with refineries on a case-by-case basis, sales contracts generally feature: (1) price discounts used in long-term off-take contract agreements; (2) refining charges for upgrading 95\% to $99 \%$ indium products to $4 \mathrm{~N} 8(99.998 \%)$ grade indium metal; and (3) terms will reflect refining yields (Thibault et al. 2010).

Based on a recent feasibility study for a mine in Canada, a toll treatment charge of approximately CAD $66 / \mathrm{kg}$ of $4 \mathrm{~N} 8$ indium produced from $95 \%$ pure indium sponge received is approximately representative of current refining costs and efficiencies (Table 7).

Table 7. Indium Refining Terms for Indium Sponge Revenue Calculations Used in NI 43-10118 Report for Mount Pleasant Property

\begin{tabular}{lccl}
\hline \multicolumn{1}{c}{ Parameter } & Units & Value & \multicolumn{1}{c}{ Notes } \\
\hline $\begin{array}{l}\text { Price discount factor for } \\
\text { indium sponge }\end{array}$ & $\%$ & $87.5 \%$ & $\begin{array}{l}\text { Typical discount used for pricing indium } \\
\text { sponge relative to 4N grade indium }\end{array}$ \\
\hline $\begin{array}{l}\text { Recovery of indium in } \\
\text { refining process }\end{array}$ & Wt\% & $93.0 \%$ & $\begin{array}{l}\text { No payment is received for indium lost } \\
\text { during refining process }\end{array}$ \\
\hline $\begin{array}{l}\text { Total refining and penalty } \\
\text { charge }\end{array}$ & $\begin{array}{c}\text { CAD/kg } \\
4 \mathrm{~N} 8 \\
\text { indium }\end{array}$ & $\$ 66$ & $\begin{array}{l}\text { Charge based on refining 95\% (by wt.) } \\
\text { indium sponge to 4N8 grade indium }\end{array}$ \\
\hline
\end{tabular}

Source: Thibault et al. (2010)

By comparison, when shipping concentrates for toll processing by refiners, one can expect to obtain $53 \%$ and $15 \%$ of the final market price of zinc and indium, respectively, because of deductions. (Exact figures will vary depending on the unique characteristics of the concentrate.) When shipping indium sponge, one would expect to achieve $71 \%$ credit of the final market price (Thibault et al. 2010).

\subsubsection{Overall Recovery Efficiency}

Principally because of its low economic contribution to zinc and other base metal producers and the complexity of metallurgical extraction, the overall recovery of primary indium over its value chain is poor. Typically, less than $20 \%$ of the indium content in concentrates is extracted to yield indium metal, but higher indium prices and technological developments can make it economically viable for mines, smelters, and refineries to invest to increase yields and capacities.

A study undertaken by Indium Corp. shows that only approximately $30 \%$ of the total indium mined annually becomes refined indium metal (Mikolajczak 2009). Our calculations put the overall recovery closer to $15 \%-20 \%$ and, as depicted in Figure 10, the major causes of the low overall recovery rate follow:

\footnotetext{
${ }^{18}$ NI 43-101 (or National Instrument 43-101) represents the Canadian standard for reporting economic and mineral resource information for companies traded on Canadian stock exchanges.

${ }^{19}$ One would expect the latest estimates of recovery efficiency to exceed industry averages ( $~ 80 \%$, Alfantazi and Moskalyk 2003 and de Souza 2011) as new or planned facilities would use the latest technologies.

${ }^{20}$ As of April 27, 2012, 1 CAD $=0.98$ USD.
} 
- Based on the process described for zinc mining and processing, only $50 \%-70 \%$ of the indium contained in the ores is recovered by the on-mine treatment plant and report to the zinc concentrate.

- Of these indium-pregnant zinc concentrates, 30\% are not sent to indium-capable smelters (Mikolajczak 2009) and are lost to smelter tailings or slag heaps.

- The indium in the remaining indium-pregnant concentrates that sent to indium-capable smelters is recovered at an average rate of $\sim 50 \%$ in an impure form (Mikolajczak 2009), such as a sponge.

- The impure indium is sent for advanced refining at various special metal refineries where the recovery rate averages $\sim 80 \%$.

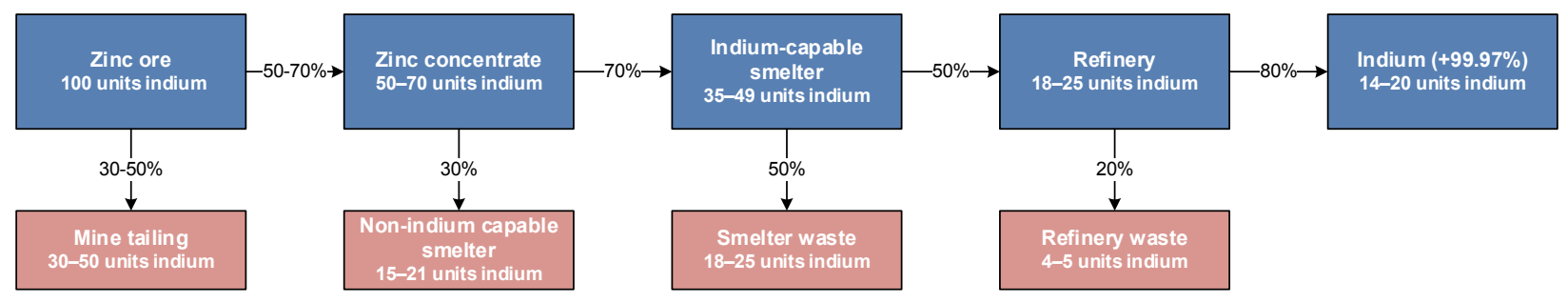

For every 100 units of indium metal mined along with zinc ores, only $\sim 15-20$ units is recovered as refined metal.

\section{Figure 10. Indium value chain and overall recovery efficiency}

(Schwarz-Schampera and Herzig 2002; Mikolajczak 2009)

Heath Steele reports that $35.8 \%$ of indium in ore is reported to tailings and $51.4 \%$ went to zinc tailings (SchwarzSchampera and Herzig 2002).

Brunswick 6 and 12 mills reportedly recovered only $58.9 \%$ of the indium in zinc concentrate (Schwarz-Schampera and Herzig 2002).

At Toyoha, the recovery of indium in zinc concentrates was $\sim 96 \%$ (same as estimated for zinc recovery in zinc concentrate). This mine was a main product indium producer, so these high recoveries are unlikely to be representative of byproduct indium producers.

Indium recovery in mine concentrates is $\sim 50 \%-70 \%$.

As detailed above, the cumulative effect of these losses results in only $15 \%-20 \%$ of mined indium being recovered. This suggests at least one explanation for the mismatch between our estimates of mined indium and those for refined metal production. Given the low overall recovery efficiency and cumulative losses of indium throughout the value chain, the figures for total mined indium production presented in Table 3 (629 tonnes in 2013) could be significantly underestimated.

The data on indium demand as well as primary refined indium provide useful benchmarks and support an estimate of primary refined metal of 640-822 tonnes. Furthermore, various sources tend to confirm an overall recovery efficiency of $15 \%-30 \%$. With this in mind, and assuming that the overall indium recovery efficiency corresponding with zinc ores is similar to those of other main product ores, the total potential tonnes of indium mined in 2011 could be 2,130-5,870 tonnes, as tabulated in Table 8. The upper end of this range is almost an order of magnitude 
greater than the estimate of 615 tonnes when using a methodology adopted by Roskill (2010). ${ }^{21}$ Because the data on indium content in base metals ores are (according to Roskill's own admission) highly uncertain, and because we have more data points and confidence in our estimates of overall recovery efficiency and levels of primary refined indium production, we believe the mined indium estimate to more likely be $\sim 5,200$ tpa, coinciding with the midpoint of the high scenario identified in Table 8 . We use this figure in subsequent calculations.

Table 8. Estimates of Potential Indium Mined Along With Main Product Ores

\begin{tabular}{lccc}
\hline & USGS & Own Estimates & Midpoint \\
\hline Refined metal production (tpa) & 640 & 822 & 730 \\
\hline Corresponding potential tonnes of contained indium mined per annum (tpa) & & \\
\hline Low $^{\mathrm{b}}$ & 2,133 & 2,740 & 2,437 \\
\hline Med $^{\mathrm{b}}$ & 3,265 & 4,194 & 3,730 \\
\hline High $^{\mathrm{b}}$ & 4,571 & 5,871 & 5,221 \\
\hline Range & 2,133 to 5,871 tpa & 5,221 \\
\hline
\end{tabular}

${ }^{\text {a }}$ Estimates of potential indium mined per annum are calculated as follows: tonnes mined per annum $=$ refined metal produced/overall recovery efficiencies.

${ }^{b}$ The corresponding recovery efficiencies for low, mid, and high estimates of tonnes indium mined are $30 \%, 20 \%$, and $14 \%$, respectively.

Sources: Own estimates; Mikolajczak (2009); USGS estimates (i.e., Tolcin 2011a and 2012a)

\subsection{Summary of Primary Production}

As noted in Table 8, total global production of primary refined indium metal in 2013 was 770 tonnes. In recent years primary indium production was $\sim 640-822$ tpa. China is the largest producer of refined indium with $\sim 50 \%-55 \%$ of global production. The remaining $45 \%-50 \%$ of primary indium production is distributed among countries such as Belgium Canada, Japan, and South Korea.

An analysis of overall indium recoveries has shown that significant losses of $70 \%-85 \%$ occur throughout the value chain, representing a significant opportunity for increasing indium supply in the short to medium term.

Until now, we have focused on summarizing existing supply characteristics of primary indium. We now turn to estimating a supply curve for current indium production, which involves not only estimates of indium quantities but the price at which indium can be produced. As is often the case with mineral properties, the best and most detailed information available for costs and efficiencies is contained in technical reports filed with the securities exchanges by midsized and junior mining companies as part of their disclosure requirements. ${ }^{22}$ Information in these reports can then be used together with the distribution of indium concentration in currently known

\footnotetext{
${ }^{21}$ This methodology is incompatible with the methodology adopted by Roskill, because recovery of indium from ores efficiency would need to be greater than $100 \%$. Alternatively, a significant amount of primary indium would have to be produced from nonmined sources, which represents an unlikely scenario.

${ }^{22}$ Often, large mining companies are not required to disclose detailed technical information about development projects or ongoing operations, because the performance of a single operation is, in many cases, not significant to the overall value of the company.
} 
deposits (Schwarz-Schampera and Herzig 2002), recovery efficiencies, costs of capital, etc., to generate a representative view of costs and production levels for various deposits. We adopt this approach when examining what a supply curve for indium might currently look like and how this might change going forward, and we use a Monte Carlo simulation to generate a short-term supply curve. A detailed description of the methodology used to generate these curves is included in Appendix D.

Figure 11 shows that producers require a minimum indium price of $\$ 100 / \mathrm{kg}$ (in $2011 \mathrm{U}$.S. dollar [USD] terms) to be incentivized to produce indium. Below this price level, even the highest grade deposits cannot economically recover indium. At prices of $\sim \$ 150 / \mathrm{kg}$ and $\sim \$ 300 / \mathrm{kg}$ of refined metal produced, indium supply is highly elastic. These two steps in the supply curve represent byproduct and coproduct production, respectively. ${ }^{23}$ As a result, changes to indium prices above or below $\$ 150$ and $\$ 300$ will trigger significant supply responses. At prices higher than $\$ 350 / \mathrm{kg}$, indium supply is highly inelastic in the short term where short run production is constrained by limitations at production facilities. As a result, an increase in price has virtually no effect on supply because producers need time to change metallurgical processes or plant capacities to deliver a supply response.

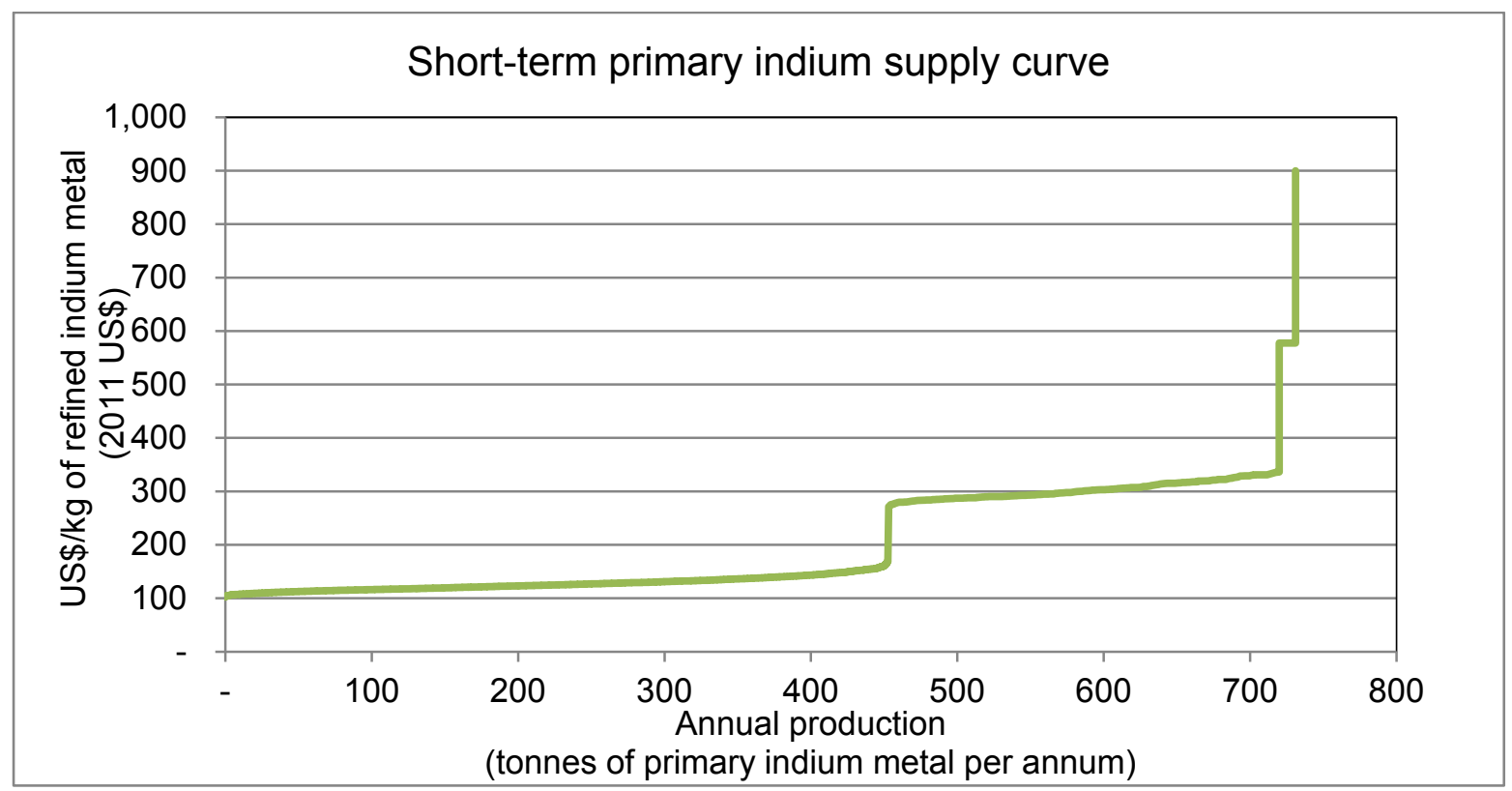

Figure 11. Indium supply (2011)

When considering overall recovery rates in the short term and the amount of indium that could potentially be recovered from current mining operations, we consider three scenarios:

1. Status quo. Estimates of refined primary indium from existing mines given recovery efficiencies throughout the value chain.

\footnotetext{
${ }^{23}$ We distinguish byproduct from coproduct producers as companies that produce indium but allocate no fixed or "common" costs to production versus those who allocate to indium production their share of fixed or common costs in addition to their own direct costs.
} 
2. Scenario 1. Estimates of refined primary indium if the pipeline were structured such that all indium-bearing concentrates were sent to indium-capable smelters, but assuming current recovery rates.

3. Scenario 2. Estimates of refined primary indium given in Scenario 1, but also assuming that recovery efficiencies reflect the latest technologies. This estimate also ignores any necessary investment and time delays.

These scenarios are discussed in significant detail in Appendix D. Figure 12 shows that, when varying efficiency across the pipeline such that all indium-bearing concentrates are shipped to indium-capable smelters, overall recovery of the refined metal increases from 731 tpa in the base case to 1,044 tpa, corresponding with overall recovery rates of $20 \%-28 \%$. Once we vary recovery efficiencies to correspond with current technologies, indium recovery increases to $2,710-3,348$ tpa with a midpoint of 2,976 tpa. This corresponds with overall recovery rates of $64 \%-73 \%$.

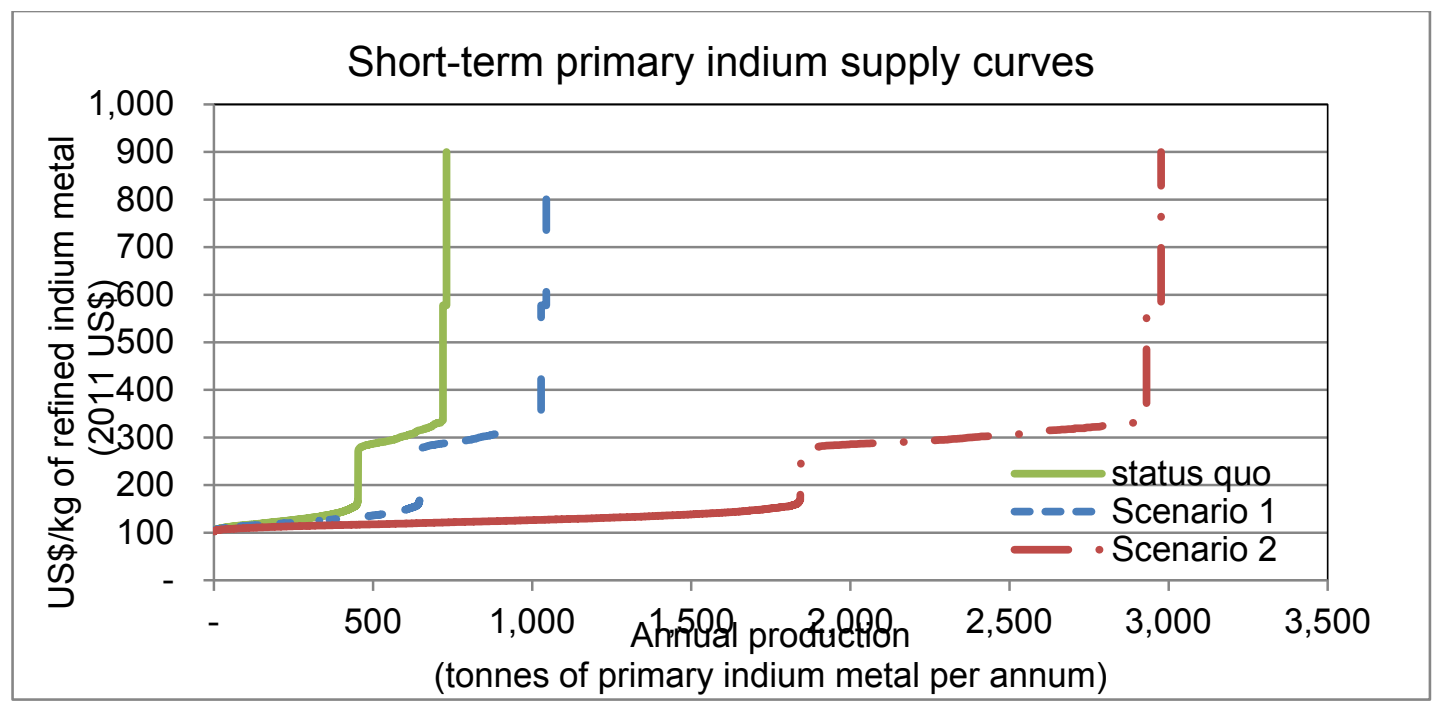

Figure 12. Short-term primary indium supply. including pipeline efficiency improvements

The general stepwise shapes of the three supply curves in Figure 12 are consistent with Figure 11 but have been stretched to match the corresponding total supply in each scenario. The three curves show the significant effect that increased indium recovery efficiency (either through technology or better management) can have on the total availability of primary indium in the short term.

\subsection{Secondary Production}

China, South Korea, and Japan have recently focused on recovering indium from manufacturing wastes and EOL products - a practice known collectively as secondary production. Secondary production of indium can result from two sources of supply: new scrap, which consists of waste generated in the manufacturing process; and old scrap, which consists of EOL consumer products. Significant indium recovery currently occurs from the recycling of new scrap (manufacturing waste), but the highly dissipative nature of indium in consumer products means that very little old scrap is currently recycled. 
At present, new scrap used in the secondary production of indium is mainly sourced from spent ITO sputtering targets. Sputtering is the process used in electronics manufacturing to apply ITO to transparent and conductive electrodes for use in LCD or flat-panel display applications. Moss et al. (2011) state that flat-panel displays and other ITO applications represent $\sim 84 \%$ of total indium demand. Due to inefficiencies in the current manufacturing process, only $\sim 30 \%$ of the indium is successfully deposited on the ITO thin-films when using planar sputtering targets. More expensive rotary targets can yield higher efficiencies (Gibson and Hayes 2011). Up to70\% of remaining indium is, therefore, conceivably available for recovery and reuse.

According to the USGS, before about $1996^{24}$ very little of the indium in ITO manufacturing waste was recycled (Brown 1996). Since then, ITO producers in Japan, China, and South Korea have installed significant recycling capacities. Unfortunately, because of metallurgical complexities, not all the indium in new scrap can be recycled and reused in the manufacturing process as losses. Overall, recovery is high and various estimates have placed the efficiency of the ITO recycling process at 60\%-70\% (Phipps et al. 2007; Mikolajczak 2009). The turnaround time for the recycling process is also an important consideration for recyclers, owing to potentially significant inventory carrying costs and maximization of plant throughput capacity. Market pressures and improvements in technology have enabled recyclers to decrease the recycle claim time to about 15 days. These improvements reduce the overall demand for primary indium.

Given this level of recycling efficiency, if we assume that new scrap is sent to a recycling plant and that the same indium continues to be used in a closed loop between the manufacturer and the recycler, the overall effective deposition of indium in ITO applications increases from $30 \%$ (in a single pass) to $\sim 55 \%^{25}$ (Table 9 ).

Of the 100 units of primary indium entering the manufacturing process, only 30 units are successfully deposited. With a closed-loop recycling process, manufacturers can increase the effective indium deposition from 30 units to 55 units. Therefore, of the total 55 units of indium used, 30 were sourced from primary supply and 25 were sourced from the new scrap. Had recycling not taken place, the manufacturer would have had to source an additional 25 units of primary indium, but recycling reduced the primary indium demand. For example, without recycling, manufacturers would have required an additional 83 units $^{26}$ of primary indium to successfully meet the demand of an additional 25 units. The introduction of a closed-loop recycling system enabled the 25 units to be produced and reduced potential demand for primary indium by 83 units.

\footnotetext{
${ }^{24}$ In 1996 , indium prices rose to $\sim \$ 175$ to $\sim \$ 550 / \mathrm{kg}$, indicating that at that point, indium could be recycled at a lower cost than primary indium could be produced. Since the peaks in 1996, prices of indium dropped but did not seem to affect recycling capacity, indicating that the recycling of indium remained profitable at prices of $\sim \$ 175 / \mathrm{kg}$.

${ }^{25}$ If 100 units of indium metal enter the manufacturing process, approximately 30 units (or 30\%) are deposited on thin-films in the first round of sputtering. If the manufacturer recycles its manufacturing waste, $\sim 65 \%$ of the 70 "wasted" units indium would be recovered through recycling. If the process repeats itself enough times and one assumes a closed-loop manufacturing and recycling process, the overall indium lost is $\sim 45 \%$ while $\sim 55 \%$ of the initial 100 units of indium is successfully deposited.

${ }^{26}$ Calculated as: $30 / 100=25 / \mathrm{s}$. Solving for 's' yields 83.333 .
} 
Table 9. Overall Utilization of Indium in a Hypothetical ITO Sputtering Application With Closed Loop Recycling of Manufacturing Waste

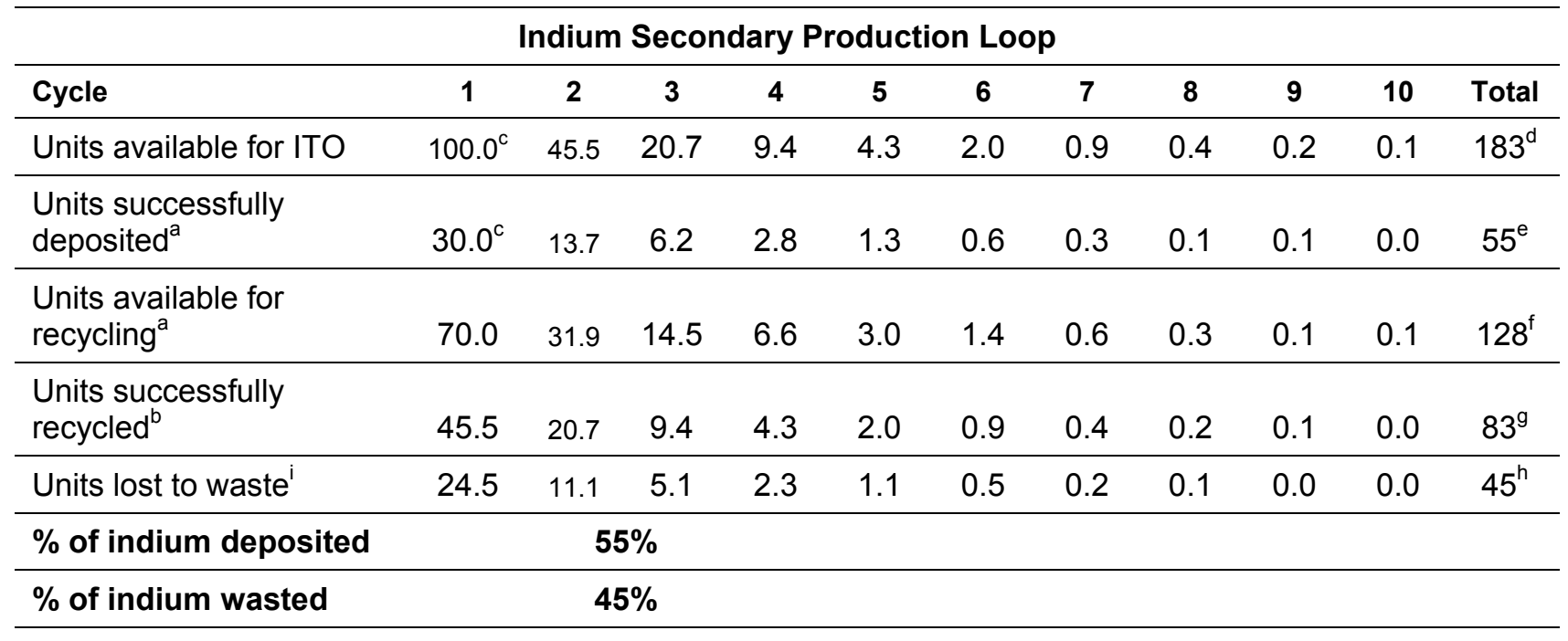

${ }^{a}$ The deposition success rate is assumed to be $30 \%$; therefore, $70 \%$ of indium is available for recycling. We assume that if indium is not successfully deposited upon application of ITO, it is available for recycling. In other words, there are no "losses" at the manufacturing stage, only at the recycling stage.

${ }^{\mathrm{b}}$ Indium recycling efficiency is estimated to be $65 \%$ per recycling cycle.

${ }^{\mathrm{c}}$ Primary indium. All other figures relate to indium that is either entering recycling or has been recycled.

${ }^{\mathrm{d}}$ If 100 units of primary indium are used in ITO applications with recycling, the ITO applications will appear to have consumed 100 units (primary) +83 units (secondary) indium. The figure of 183 units of indium likely represents the figure of indium demand reported by manufacturers.

${ }^{d}$ Of the original 100 units of primary indium entering the manufacturing process, 55 units $(55 \%)$ are effectively deposited when factoring in that spent ITO targets and other manufacturing wastes are recycled.

${ }^{\mathrm{f}}$ Of every 100 units of primary indium used in ITO applications, 128 units are a quantity that might appear to be entering the recycling plant because the same indium may enter the plant more than once per period.

${ }^{\mathrm{g}}$ Of every 100 units of primary indium used in ITO applications, 70 units enter the recycling plant. Because the 70 units enter more than once, the plant appears to produce 83 units of refined indium over 10 cycles. This figure of 83 units is most likely representative of recycling plant throughput as measured by producers.

${ }^{\mathrm{h}}$ Of the 100 units of primary indium entering the manufacturing process, 45 units (45\%) are forever lost. This is due to a combination of: deposition efficiency, which drives the number of times the same indium must be recycled, and recycling efficiency.

${ }^{\mathrm{i}}$ Units of indium discarded in the waste stream may be recoverable at some later stage. We do not, however, have information about the concentration of indium in the waste piles or the technical challenges of recovering this indium.

Source: Own calculations; Mikolajczak (2009)

The calculations in Table 9 also highlight the significant potential for inflated estimates of reported supply and demand from double counting. Because manufacturers are most likely reporting total consumption of indium in ITO applications by quoting the amount of indium purchased, they may indicate that they used 183 units of indium over the period. However, as we have shown, only 100 units entered the process, of which only 55 units were successfully deposited. Similarly, new scrap recyclers may report that they produced 83 units of indium over the period, because these would have been shipped from their facilities. Together with the 100 units reported by the primary producer, reported figures by all producers might lead one to believe, incorrectly, that total supply over the period was 183 units. Again, total supply was only 100 units, of which 55 were deposited ( 30 from primary sources) and 45 were lost. 
Finally, because secondary supply from new scrap decreases with each cycle of recycling, Table 9 also highlights that, if primary supply were to cease for whatever reason, secondary supply from new scrap would decrease geometrically and cease altogether within a very short period. Thus, although secondary supply from manufacturing waste can buffer market shocks in the short term, it does not isolate manufacturers from prolonged primary supply disruptions.

This sample analysis should lead readers to be cautious when estimating total demand and supply. As we have illustrated, when considering sources of supply, secondary production from new scrap introduces significant potential for double counting in estimates for both supply and demand. To eliminate this risk, secondary supply from new scrap should rather be seen as a reduction in the demand for primary indium.

\subsubsection{Recycling Process}

The technology used in recycling indium is mostly proprietary. Although recovery techniques differ, ${ }^{27}$ Roskill (2010) describes a process in which indium is recovered from spent ITO targets through the following steps:

1. Nitric acid is used to form indium nitrate, followed by neutralization, which produces indium hydroxide.

2. Indium oxide is formed through thermal decomposition and dissolved in sulfuric acid.

3. Metallic indium can be produced from the resulting solution electrolytically (Roskill 2010).

As previously discussed, refining capacity to reclaim spent ITO targets has expanded considerably since 1996 to reduce primary demand for indium. Japan, China, and to a lesser extent, South Korea and Belgium, have most of this capacity (Table 10 and Figure 13). The geographic dispersion of secondary production is expected, because recyclers of new scrap can reduce transportation costs and cycle times by locating close to high-tech manufacturing centers that sputter ITO in the manufacturing of LCDs or other applications.

\subsubsection{Estimates of Secondary Supply}

A bottom-up analysis of global secondary indium production indicates that $\sim 610$ tonnes of refined indium are "measured" as being produced through the recycling of manufacturing waste, most of which is sourced through the application of ITO in flat-panel displays. ${ }^{28}$

Roskill (2010) states that total secondary indium production was $\sim 602$ tonnes in 2009; Indium Corp. estimates that $\sim 1,000$ tonnes of indium is produced from new scrap every year (Mikolajczak 2009).

The geographic dispersion of secondary production (Figure 13) is located close to where most LCD manufacturing takes place: Japan, China, and South Korea.

\footnotetext{
${ }^{27}$ For example, Han et al. (2002) describe a process for the recovery of indium from ITO consisting of chemical precipitation followed by solvent extraction.

${ }^{28}$ As discussed earlier, it's important to highlight that "measured" secondary production from new scrap can be significantly overestimated because of the potential for double counting in a closed-loop recycling environment.
} 
Table 10. Indium Recycling Capacity of Known Producers (2013)

Source: Own estimates; Roskill (2010)

\begin{tabular}{lccc}
\hline \multicolumn{1}{c}{ Location } & Country & Operating Company/lnvestors & Indium (tpa) \\
\hline Hoboken & Belgium & Umicore & 50.00 \\
\hline $\begin{array}{l}\text { Hydrometal-Lien } \\
\text { plant }\end{array}$ & Belgium & $\begin{array}{c}\text { Hydrometal SA, Jean Goldschmidt } \\
\text { International S.A }\end{array}$ & 0.50 \\
\hline Trail Smelter & Canada & Teck Resources Limited & 5.00 \\
\hline Nanjing 718 factory & China & Nanjing Germanium Factory Co. Ltd. & 150.00 \\
\hline $\begin{array}{l}\text { Fremat Freiberg } \\
\text { plant }\end{array}$ & Germany & Gfe Fremat GmbH & 1.00 \\
\hline Fukuoka & Japan & Asahi Pretec Corp & 200.00 \\
\hline Kosaka plant & Japan & Akita Rare Metals, Dowa Holdings Co., Ltd & 150.00 \\
\hline $\begin{array}{l}\text { Hitachi metal } \\
\text { recycling complex }\end{array}$ & Japan & $\begin{array}{c}\text { Nikko Environmental Services Co, } \\
\text { Nippon Mining and Metals Co. Ltd. }\end{array}$ & 6.00 \\
\hline Onahama & Japan & $\begin{array}{c}\text { Onahama Smelting and Refining Co., Ltd, of } \\
\text { which Mitsubishi Materials Group owns 50\% }\end{array}$ & 6.00 \\
\hline Onsan & $\begin{array}{l}\text { South } \\
\text { Korea }\end{array}$ & Korea Zinc Co. Ltd. & 40.00 \\
\hline Total & & & $\mathbf{6 0 8 . 5 0}$ \\
\hline
\end{tabular}

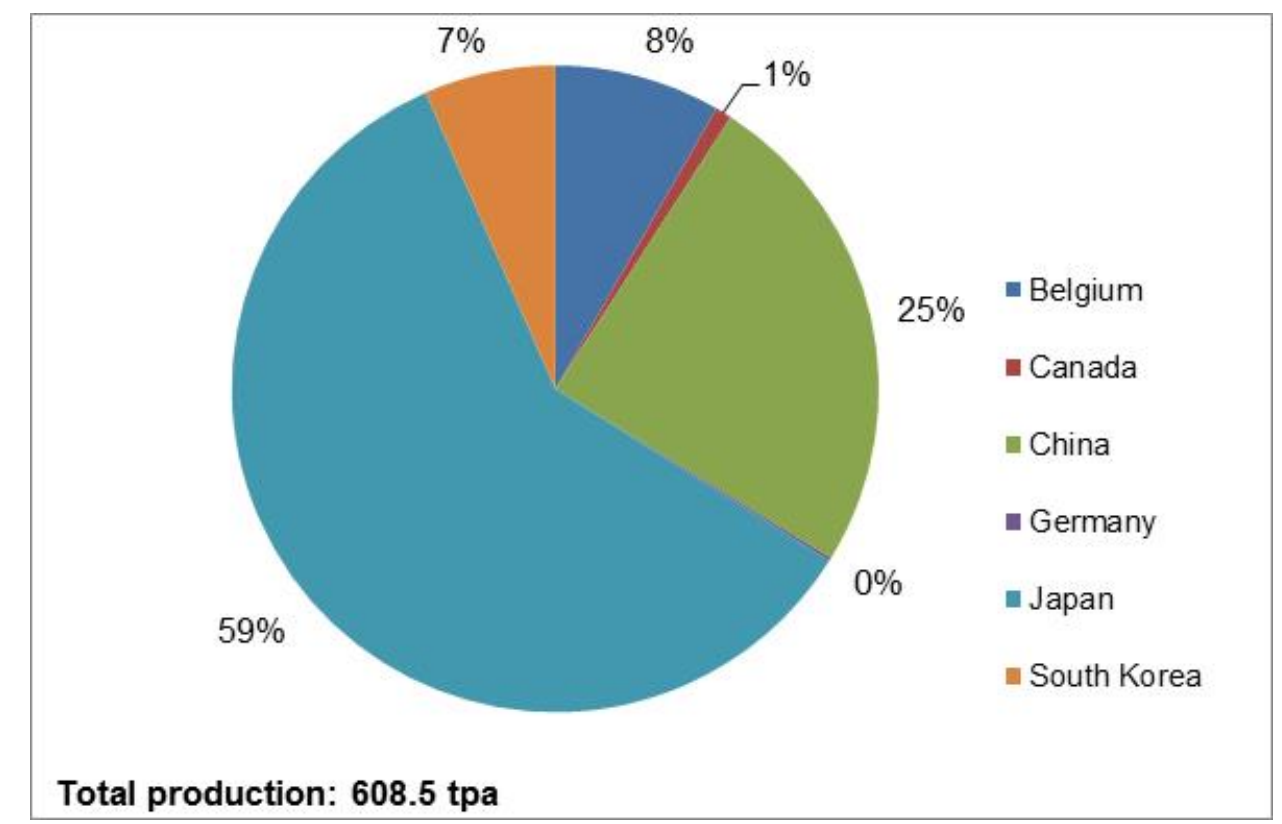

Figure 13. Geographic distribution of secondary refined indium

Source: Own estimates; company reports; Roskill 2010

Using the values from Table 10, if one assumes that 608.5 tpa of refined indium are produced, 938 tonnes $^{29}$ of indium enter the recycling process and approximately 330 tonnes are lost due to refining inefficiency any given year. Similarly, $\sim 1,341$ tonnes appears to be demanded by

\footnotetext{
${ }^{29}$ Calculated using the ratios in Table 10 as $608.5 / x=83 / 128$. Solving for ' $x$ ' yields $\sim 938$ tonnes. Similarly, solving for ' $y$ ' in $608.5 / 83=y / 183$., yields $\sim 1,341$ tonnes. More detail is provided in Appendix B.
} 
manufacturers. Assuming that most LCD/flat-panel display manufacturers now recycle manufacturing waste implies primary indium demand of $\sim 730$ tonnes and the successful deposition of $\sim 400$ tonnes, of which $\sim 220$ tonnes is from primary indium and $\sim 180$ tonnes is from new scrap recycling. The amount generated by new scrap recycling reduced primary indium demand by 608.5 tonnes (Appendix B reports these figures in detail).

When considering the cost of secondary supply, we note that before 1996, recycling was not a significant source of supply. Before 1995 , indium prices were $\$ 125-\$ 200 / \mathrm{kg}$. Increased demand caused prices to increase significantly in 1995 and 1996 to a peak of almost $\$ 600 / \mathrm{kg}$. This surge led manufacturers to rationalize their use of indium and incentivized producers to reclaim indium waste. These factors simultaneously increased supply, decreased demand, and together with other factors, resulted in reduced prices. Once prices relaxed, recycling of indium continued.

The response of secondary production to price fluctuations suggests that, in the medium term, indium prices higher than $\$ 300-\$ 400 / \mathrm{kg}$ are required to increase new scrap secondary production capacity. Once the capacity is installed, producers can profitably recycle indium at prices higher than about $\$ 175 / \mathrm{kg}$. With this in mind, we use a short-term production cost for secondary production of $\$ 175 / \mathrm{kg}$ and a medium-term cost of $\$ 350 / \mathrm{kg}$ in our analysis.

\subsubsection{Recycling From End-of-Life Products}

In addition to the recovery of indium from manufacturing waste, much research has been conducted into the secondary recovery of indium from consumer waste. According to Roskill (2010), a proprietary technique has been jointly developed between Sharp and Aqua Tech Co. to recycle indium from LCD panels. The recycling process can be broadly described as comprising two stages: (1) comminution, where consumer waste products are reduced into fine pieces; and (2) recovery by chemical leaching or vaporization.

In Sharp and Aqua's recycling process, high-purity indium can be recovered from a process that uses only common chemicals, thereby eliminating the need for possible high-cost energy resulting from a process dependent on high temperatures or pressures (Sharp Electronics UK 2012). The companies are continuing large-scale prototype studies to establish the viability of the technique to operate as a closed-loop recycling system.

As an additional example, Figure 14 depicts a process to recover indium from the LCDs of discarded cellular phones as described by Takahashi et al. (2009). The process is similar to that used by Sharp/Aqua in that it can broadly be split into the same two-step process of comminution and chemical concentration. In this proposed process, indium is recovered from discarded cellular phones through chloride-induced vaporization. Following the comminution stage, sieved material from discarded cell phones is treated with a solution of hydrochloric acid $(\mathrm{HCl})$, which alters the structure of the indium oxide and allows it to be vaporized at relatively low temperature. Next, the vaporized indium compound is condensed on a cooled surface and recovered. Takahashi et al. report that $84 \%$ of indium contained in LCDs is recovered. 


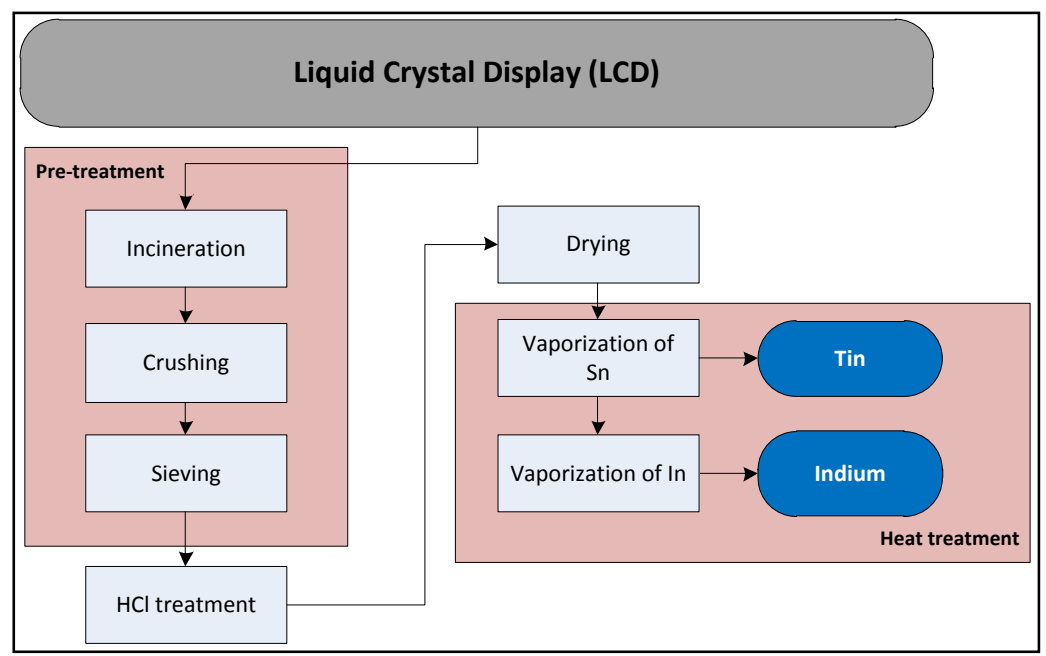

Figure 14. An example of recycling LCDs from discarded mobile phones using vaporization

(Takahashi et al. 2009)

Secondary production of indium from consumer waste is not a material source of supply because less than 1\% of indium contained in EOL products is recycled (Buchert et al. 2012). A key issue for consideration in the recycling of indium from consumer waste is the interaction between the value of the recycled material and the degree of dispersion of the raw material. A greater degree of dispersion implies that the cost of collecting, sorting, recycling, and refining is likely to be higher than if the raw material were concentrated within a single product at a single location and in large quantities. These costs are then compared to the value of the material that can be recovered to ascertain whether its recycling is economic. As discussed by Dahmus and Gutowski (2007), certain products, such as catalytic convertors, automobiles, and batteries, are economic to recycle. Other items such as computers, televisions, cell phones, and small electronic items fall beneath an apparent recycling boundary.

Although the recycling of indium from EOL products has significant potential, old scrap is not currently a significant source. The low recycling rate implies that the costs of collecting, sorting, and refining such scrap (because of the highly dissipative use of indium in consumer products) are still higher than long-term indium price expectations. In addition, dedicated recycling from concentrated sources of indium such as EOL solar panels is a supply source reserved for the future because the average solar panel has a life expectancy of approximately 20 years and recyclers are hesitant to commit capital to dedicated facilities until they can be assured that the base loads of plant feed are available (Van den Broeck 2010). Thus, because of its low contribution and high costs, we exclude consumer waste as a source of indium in our short-term analysis.

\subsection{Total Primary and Secondary Production}

In summary, indium primary production was approximately 770 tonnes in 2013 (Tolcin 2014a). Production is relatively concentrated, with about half currently in China. Since the indium price increases in 1995 and 1996, secondary production has been a significant contributor to overall supply, reducing primary indium demand by approximately 609 tonnes in 2013. Significant secondary supply of approximately 610 tonnes principally takes place close to high-tech manufacturing centers such as Japan (59\%, 300 tonnes), South Korea (7\%, 36 tonnes), and China 
(25\%, 128 tonnes). By comparison, Roskill (2010) estimates total secondary production at 602 tonnes and Gibson and Hayes (2011) estimate 630 tonnes.

As detailed in Table 11, after combining primary (770 tonnes) and secondary supply (610 tonnes), we estimate total global refined indium supply at 1,380 tonnes in 2013. After including secondary production, China's dominance in the sector is reduced from its $53 \%$ market share to $40 \%$ of overall supply. When using the Herfindahl-Hirschman Index (HHI) to estimate market concentration by country, we calculate an HHI of $\sim 2,870$ for total indium supply, compared to $\sim 3,370$ when estimating concentration for primary refinery production only. ${ }^{30}$ The decrease is principally due to the decreased market share of Chinese producers when including secondary supply.

Table 11. Total Indium Production (2013)

\begin{tabular}{|c|c|c|c|c|c|c|}
\hline \multicolumn{7}{|c|}{2013 Indium Refinery Production } \\
\hline & \multicolumn{2}{|c|}{ Primary Supply } & \multicolumn{2}{|c|}{$\begin{array}{l}\text { Secondary Supply } \\
\text { (i.e., Primary } \\
\text { Supply Abatement) }\end{array}$} & \multicolumn{2}{|c|}{ Total } \\
\hline & tonnes & $\%$ & tonnes & $\%$ & tonnes & $\%$ \\
\hline Belgium & 30 & $4 \%$ & 51 & $8 \%$ & 81 & $6 \%$ \\
\hline Canada & 65 & $8 \%$ & 5 & $1 \%$ & 70 & $5 \%$ \\
\hline China & 410 & $53 \%$ & 150 & $25 \%$ & 560 & $40 \%$ \\
\hline Germany & $\mathrm{n} / \mathrm{a}$ & $0 \%$ & 1 & $0 \%$ & 1 & $0 \%$ \\
\hline Japan & 71 & $9 \%$ & 362 & $59 \%$ & 433 & $31 \%$ \\
\hline Peru & 10 & $1 \%$ & $\mathrm{n} / \mathrm{a}$ & $n / a$ & 10 & $1 \%$ \\
\hline Russia & 13 & $2 \%$ & $\mathrm{n} / \mathrm{a}$ & $n / a$ & 13 & $1 \%$ \\
\hline South Korea & 150 & $19 \%$ & 40 & $7 \%$ & 190 & $14 \%$ \\
\hline Others & 25 & $3 \%$ & $\mathrm{n} / \mathrm{a}$ & $n / a$ & 25 & $2 \%$ \\
\hline Total & 770 & $100 \%$ & 610 & $100 \%$ & 1,380 & $100 \%$ \\
\hline
\end{tabular}

Source: Table 5 and Table 10

Figure 15 and Figure 16 show that the total indium supply curve keeps its general shape from Section 3.6. Supply is highly elastic at $\$ 150-\$ 300 / \mathrm{kg}$. That is, a small change in price induces a relatively large change in quantity supplied. This suggests a price floor for indium of $\sim \$ 150 / \mathrm{kg}$. At lower prices very little indium is produced, and at prices lower than $\$ 200$, virtually no secondary supply is produced. Short-term indium supply becomes inelastic at prices higher than $\$ 300 / \mathrm{kg}$ because of capacity constraints; a price increase thus induces little, if any, additional supply.

\footnotetext{
${ }^{30}$ The U.S. Department of Justice normally considers an HHI of 1,500-2,500 points to be moderately concentrated; markets in which the HHI exceeds 2,500 points are believed to be highly concentrated.
} 


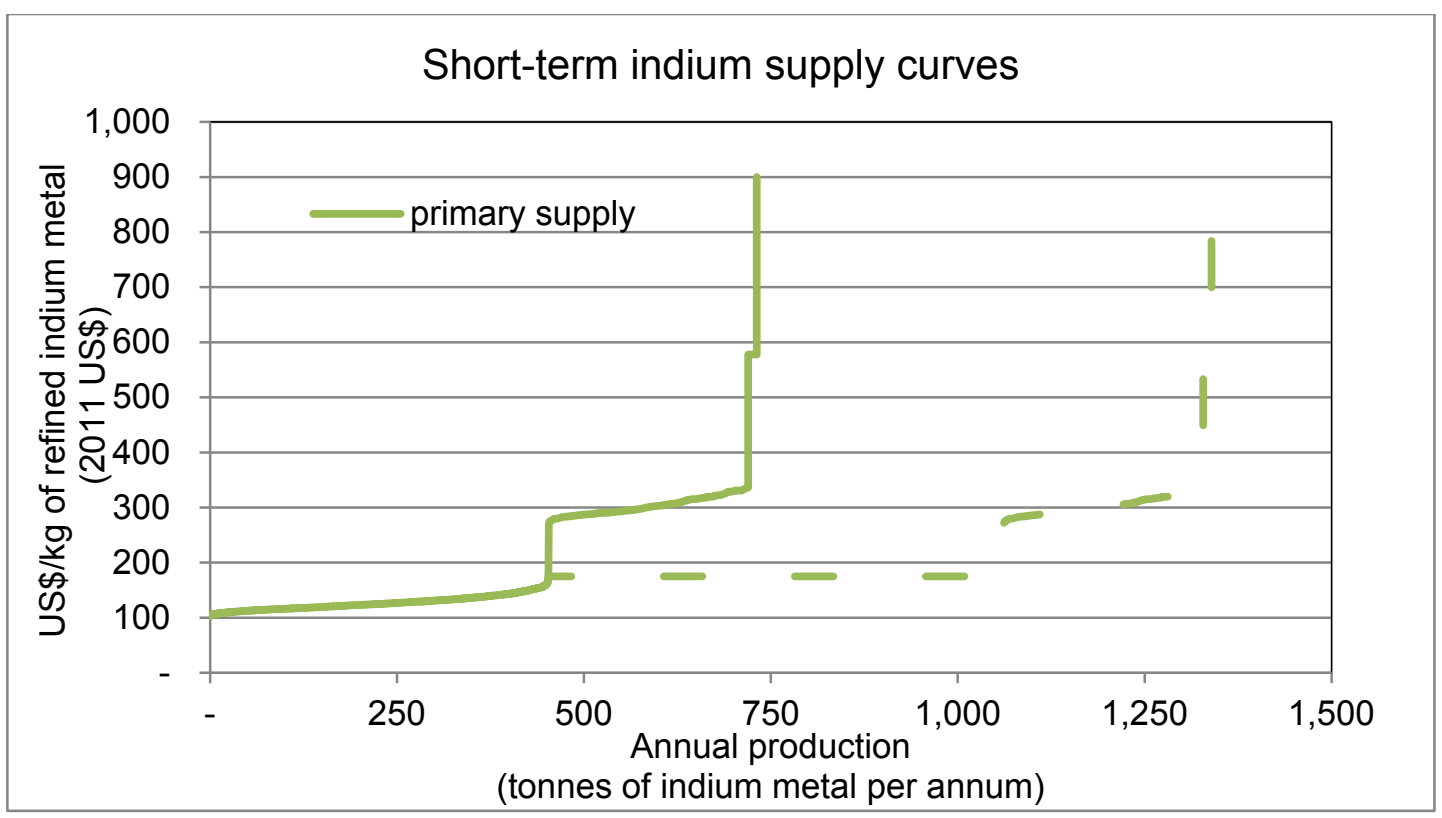

Figure 15. Comparison of short-term primary and total indium supply

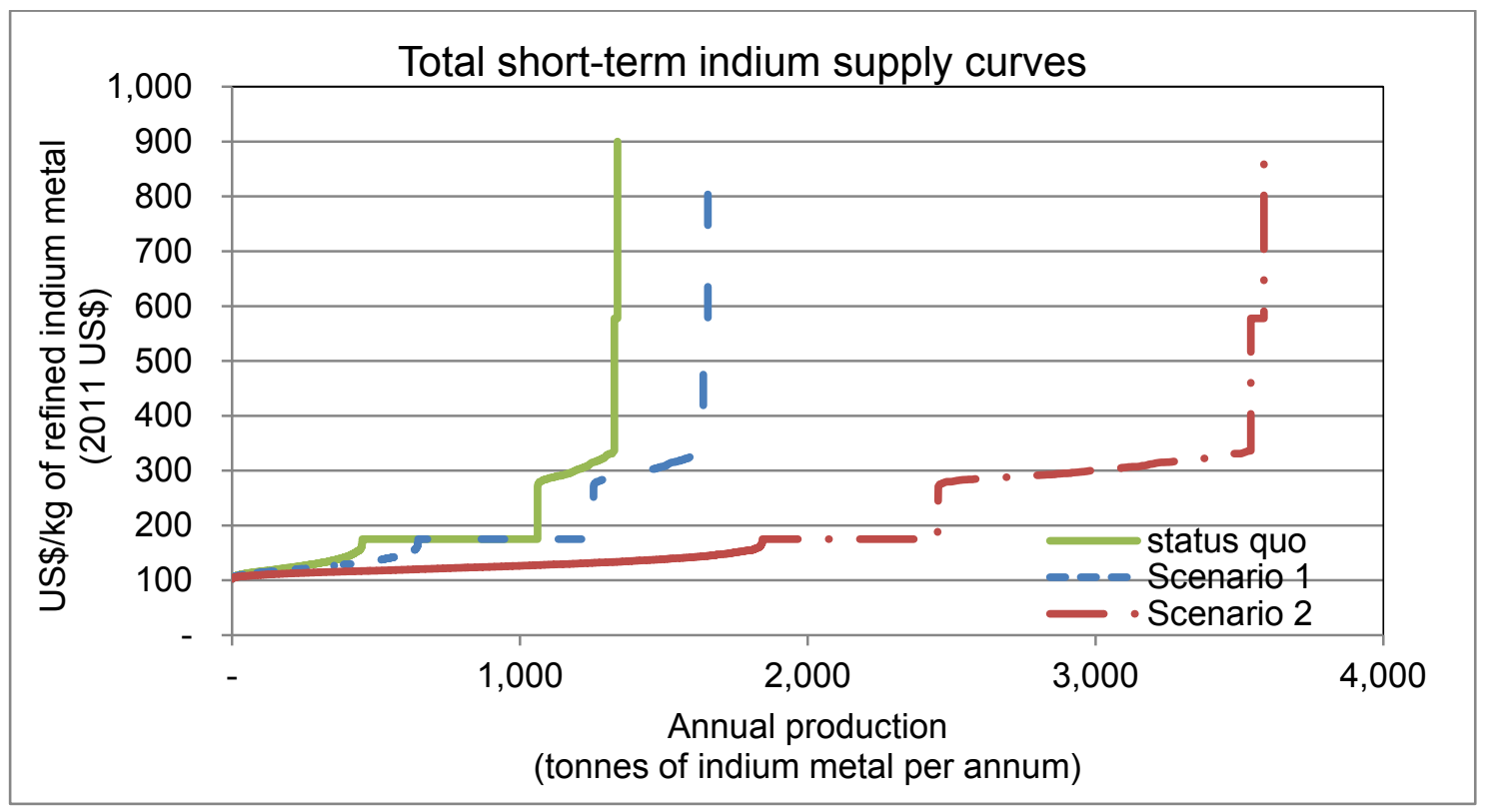

Figure 16. Comparison of short-term total indium supply under differing assumptions of pipeline efficiency 


\section{Supply: the Medium-Term Outlook (5-20 years)}

When thinking about supply in the medium term (loosely defined here to be 5-20 years), additional indium supply can come from several additional sources. As shown conceptually in Figure 17, these sources include:

- Increased recovery efficiency. This can be either through operational improvements, or by ensuring that indium contained in zinc or other base metal concentrates is shipped to indium-capable smelters and refineries.

- Operations that currently do not recover indium. This can occur by expanding or modifying processing facilities to recover indium that is currently not recovered. Because this option would require an investment in new technologies or capacity, it requires that prices and metal recoveries justify the additional capital and operating costs.

- New byproduct production. This could be through the byproduct recovery of indium from zinc (or other) mines that currently are not in production. Indium would be recovered as a byproduct in these cases, so the price required to justify its recovery would need to cover the incremental costs only; all other costs (such as mining, administration, and other fixed costs) would be allocated to main product production.

- Increased secondary production from EOL materials (i.e., recycling of consumer waste).

- Increased secondary production from the recycling of manufacturing waste. This can be done by: (1) increasing the efficiency of the secondary refining process; and (2) increasing the quantity of manufacturing waste being recycled.

- Recovery of indium through new main product supply, which might occur if indium deposits are discovered and developed where the principal metal of economic interest is indium. To our knowledge, there are currently no main product indium producers; however, the Toyoha mine in Japan has produced main product indium in the past. Main product indium is normally high-cost indium because the indium content of the deposit has to justify all costs associated with developing the property, including the initial discovery costs, mining, treatment, and administration costs as well as the costs of associated capital (i.e., the investment must earn a minimum required return on capital). 


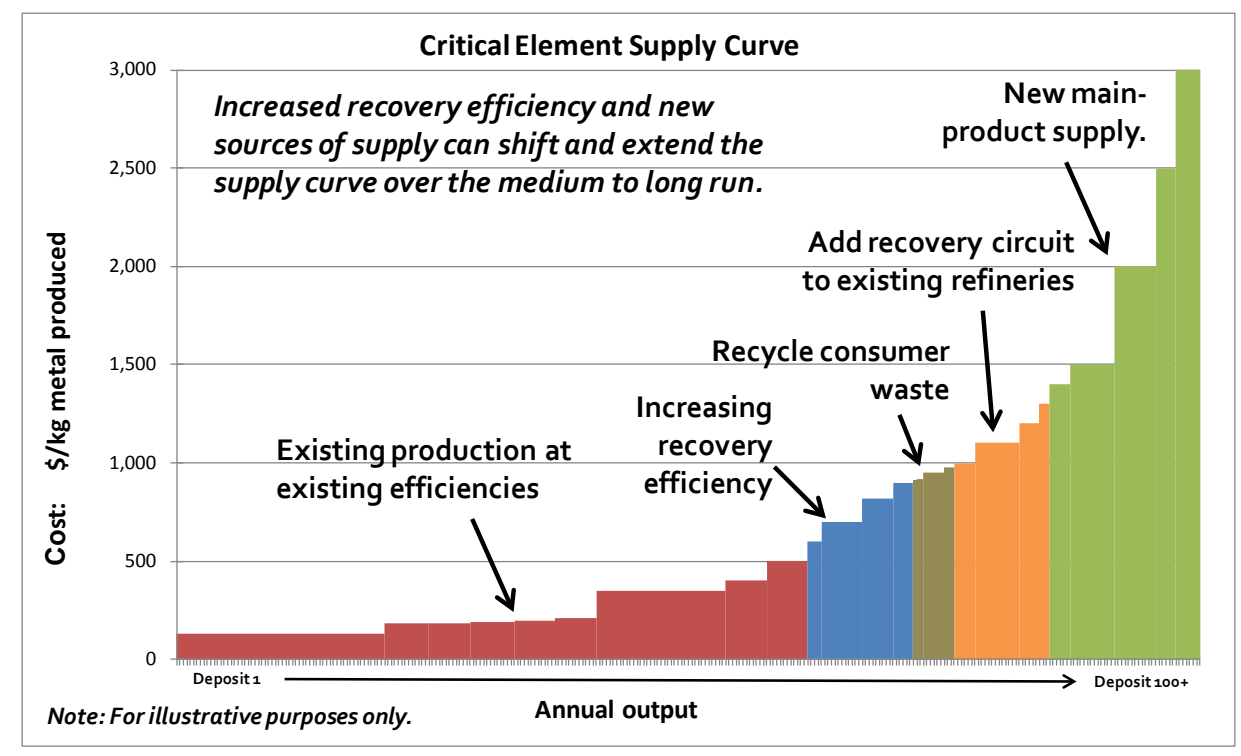

Figure 17. Illustrative medium-term indium supply curve

\subsection{Expansion of Zinc (or Other Main Product) Production}

Between 2007 and 2011, zinc production expanded at a CAGR of 2.4\% (Appendix A). The International Lead and Zinc Study Group forecast production growth at 3.9\% (White 2012), with increased output anticipated at a number of Peruvian, Bolivian, and Mexican mines. With these increases to zinc production in mind, and given production of $\sim 730$ tpa of indium (mainly derived as the byproduct from zinc production), we extrapolate medium-term indium production on the basis of historical expansion of zinc production. This is shown below for growth scenarios of $2 \%-3 \%$ annual expansion of zinc production. As Table 12 shows, on this basis, 2016 production could be 807-847 tonnes with an average of 827 tonnes. If this expansion continues until 2031, byproduct indium production could reach $\sim 1,200-1,531$ tonnes. For our estimates we use average values of 827 tonnes and 1,365 tonnes in 2016 and 2031, respectively.

Table 12. Medium-Term Estimates of Indium Primary Refinery Production

\begin{tabular}{|c|c|c|c|}
\hline Main product growth ${ }^{\mathrm{a}} \mathrm{CAGR}, \%$ & 2011 & $2016^{b}$ & $2031^{b}$ \\
\hline $2.0 \%$ & 731 & 807 & 1,199 \\
\hline $3.0 \%$ & 731 & 847 & 1,531 \\
\hline Average & 731 & 827 & 1,365 \\
\hline
\end{tabular}

\footnotetext{
${ }^{a}$ Main product CAGR ranged based on historical zinc production growth between 2007 and 2011 as calculated from USGS data and estimates from the International Lead and Zinc Study Group (White 2012).

${ }^{\mathrm{b}}$ Assumes that recovery rates continue and that the proportion of hydrometallurgical processing remains unchanged over the extrapolation period.
}

To identify individual producers that are likely to form part of medium-term supply, we surveyed company reports and identified the following six advanced stage deposits that have a potential combined supply contribution of 150-155 tpa. The two largest potential new sources of supply are the Mount Pleasant deposit in eastern Canada, with a potential to produce 38.5 tpa of indium, and the Maklu Khota deposit in Bolivia, with a potential production of 76 tpa. Summary 
characteristics for these deposits are presented in Table 13. Each deposit will now be discussed in greater detail.

Table 13. Summary of Indium Production From New Mine Production

\begin{tabular}{|c|c|c|c|c|c|c|c|}
\hline $\begin{array}{l}\text { Company } \\
\text { (Country) }\end{array}$ & Property & Resource & onnes) & $\begin{array}{l}\text { Potential } \\
\text { Production } \\
\text { (tpa) }\end{array}$ & $\begin{array}{l}\text { Indium } \\
\text { Purity }\end{array}$ & $\begin{array}{l}\text { Production } \\
\text { of Refined } \\
\text { Metal }^{\mathrm{e}} \text { (tpa) }\end{array}$ & $\begin{array}{l}\text { Actual or } \\
\text { Anticipated } \\
\text { Start Date }\end{array}$ \\
\hline \multirow{3}{*}{$\begin{array}{l}\text { Adex Mining Inc. } \\
\text { (Canada) }\end{array}$} & \multirow{3}{*}{$\begin{array}{l}\text { Mount } \\
\text { Pleasant, } \\
\text { North } \\
\text { Zone } \\
\end{array}$} & Indicated & 790 & \multirow{3}{*}{38.5} & \multirow{3}{*}{$\begin{array}{l}99.998 \% \\
(4 \mathrm{~N} 8)^{\mathrm{b}}\end{array}$} & \multirow{3}{*}{38.5} & \multirow{3}{*}{+2015} \\
\hline & & Inferred & 200 & & & & \\
\hline & & Total & 990 & & & & \\
\hline \multirow{3}{*}{$\begin{array}{l}\text { Government of } \\
\text { Bolivia' } \\
\text { (Bolivia) }\end{array}$} & \multirow{3}{*}{$\begin{array}{l}\text { Malku } \\
\text { Khota }\end{array}$} & Indicated & 190 & \multirow{3}{*}{80} & \multirow{3}{*}{$99.99 \%$} & \multirow{3}{*}{$76^{\mathrm{j}}$} & \multirow{3}{*}{+2015} \\
\hline & & Inferred & 1,290 & & & & \\
\hline & & Total & 1,480 & & & & \\
\hline \multirow{3}{*}{$\begin{array}{l}\text { Argentex } \\
\text { (Argentina) }\end{array}$} & \multirow{3}{*}{ Pinguino } & Indicated & 120 & \multirow{3}{*}{$8.0^{4}$} & \multirow{3}{*}{ Conc. $^{a}$} & \multirow{3}{*}{7.3} & \multirow{3}{*}{$+2017^{g}$} \\
\hline & & Inferred & 310 & & & & \\
\hline & & Total & 430 & & & & \\
\hline \multirow{3}{*}{$\begin{array}{l}\text { Silver Standard } \\
\text { Resources } \\
\text { (Argentina) }\end{array}$} & \multirow{3}{*}{ Pirquitas } & Reserves $^{\mathrm{e}}$ & 33 & \multirow{3}{*}{$18^{\mathrm{k}}$} & \multirow{3}{*}{ Conc. $^{c}$} & \multirow{3}{*}{$15.4^{\mathrm{k}}$} & \multirow{3}{*}{ 2009-2020 } \\
\hline & & Resources $^{\mathrm{e}}$ & 80 & & & & \\
\hline & & Total & 113 & & & & \\
\hline $\begin{array}{l}\text { Doe Run Peru } \\
\text { (Peru) }\end{array}$ & La Oroya & $\mathrm{N} / \mathrm{A}$ & N/A & 6.0 & $\begin{array}{c}99.991 \% \\
(4 \mathrm{~N} 1)\end{array}$ & 6.0 & 2013 \\
\hline $\begin{array}{l}\text { Western United } \\
\text { Mines Ltd./Celeste } \\
\text { Copper Corp. } \\
(\text { England) }\end{array}$ & $\begin{array}{l}\text { South } \\
\text { Crofty }\end{array}$ & $\begin{array}{l}\text { Potential } \\
\text { resource }^{h}\end{array}$ & 85 & 11.7 & Conc. ${ }^{\mathrm{h}}$ & 10.0 & $+2017^{\mathrm{h}}$ \\
\hline Total & & & 3,013 & & & 153 & \\
\hline
\end{tabular}

Figures may differ slightly from original sources due to rounding. "e" = estimate; "Conc." = concentrate

${ }^{\text {a }}$ Only $75 \%$ of indium will be recovered in the zinc concentrate (Argentex Mining 2012).

${ }^{\mathrm{b}}$ Assuming that Mount Pleasant produces indium sponge.

${ }^{\mathrm{c}}$ Concentrates of silver and zinc are expected to contain average indium concentrations of 450 and $1000 \mathrm{ppm}$, respectively (Board et al. 2011).

${ }^{\mathrm{d}}$ According to Argentex, $75 \%$ of indium will be recovered in the zinc concentrate (Argentex Mining 2012).

${ }^{\mathrm{e}}$ Based on an average indium content estimate of $2 \mathrm{ppm}$ (Schwarz-Schampera and Kerzig 2002) in total reserves and resources declared by Board et al.

(2011). Resources based on measured, indicated, and inferred resources. Reserves based on proven and probable reserves.

${ }_{\mathrm{f}}^{\mathrm{f}}$ Refers to the level of indium purity refined onsite.

${ }^{\mathrm{g}}$ The Pinguino Preliminary Economic Assessment is considered to be at the conceptual study level. Additional resource delineation and metallurgical tests need to be completed to support a pre-feasibility study and subsequent feasibility and detailed designs. Given the remote location of the site, it is not anticipated that first production would be achieved before 2017. Furthermore, as currently designed, Argentex plans to mine and treat the near surface oxide ores before treating the deeper sulfide ores. Because indium is believed to be recovered only through the sulfide ores, it may only commence indium production a number of years after commercial production of silver and gold.

${ }^{\mathrm{h}}$ Data for the South Crofty mine are preliminary. Conceptual mine planning and a preliminary economic assessment have not been performed. For the purpose of giving indicative results we have assumed: (1) that only the "potential resource" declared in Hogg (2011) is incorporated; (2) a life of mine of 12 years; (3) a recovery rate of $80 \%$ indium in the concentrate stage; (4) recoveries of $90 \%$ and $95 \%$ in converting the concentrate to sponge and then from sponge to refined metal; and (5) that because of ongoing dialogue with the nearby community and the preliminary stage of feasibility studies, production would not commence until after 2017.

${ }^{\mathrm{i}}$ Although commercial production has commenced at Pirquitas we do not believe the operation is currently recovering indium metal.

${ }^{j}$ Uses an average recovery of $95 \%$ in converting effectively smelter quality product (i.e., $99.99 \%$ ) to $+4 \mathrm{~N}$ metal.

${ }^{\mathrm{k}}$ Based on average silver and zinc concentrate production from 2012 to 2020 of 13,556 tonnes and 11,778 tonnes, respectively. Average indium concentrations in the respective concentrates of 450 and $1000 \mathrm{ppm}$ are used. Source: derived from Board et al. 2011. Indium is not currently believed to be recovered from these concentrates. Our own estimates indicate that 5.54 tpa indium metal may be contained in the silver concentrate and 10.69 tpa may be contained in the zinc concentrate.

${ }^{1}$ On July 10, 2012, the Government of Bolivia announced plans to nationalize South American Silver Corporation's interest in the Malku Khota deposit.

Sources: Own estimates; Adex Mining 2012a; Thibault et al. 2010; Armitage et al. 2011; Gibson and Hayes 2011; Argentex Mining 2009; Guido 2012; Board et al. 2011; Silver Standard 2012; Schwarz-Schampera and Herzig 2002; Hogg 2011 


\subsubsection{Mount Pleasant (North Zone), Canada}

Adex Mining Inc. ("Adex") is a Canadian junior mining company with $100 \%$ ownership in the Mount Pleasant Mine Property located in Charlotte County, New Brunswick, Canada. According to a Government of Canada report, Mount Pleasant is "North America's largest tin deposit and the world's largest reserve of indium" (Wright 1996, p. 61.1).

The North Zone contains an updated NI 43-101 resource estimate including 12.4 million indicated tonnes averaging $0.38 \%$ tin, $0.86 \%$ zinc, and $64 \mathrm{ppm}$ indium, as well as an inferred resource of 2.8 million tonnes averaging $0.30 \%$ tin, $1.13 \%$ zinc, and $70 \mathrm{ppm}$ indicum (Adex $2012 \mathrm{~b}$ ). It is not clear yet if Adex will build the mine with the capacity to produce indium sponge or whether it will produce an indium-rich zinc concentrate only. An NI 43-101 compliant report for the property contains preliminary economic estimates about the feasibility of three alternatives. The higher net present value (but also higher capital cost options) presented in the NI-43-101 report would see Adex produce refined zinc metal and indium sponge.

Should Adex develop the property to produce a final indium sponge, planned production of indium sponge of minimum $95 \%$ purity based on an 850 tpd nameplate capacity could be 40.5 tpa, equivalent to approximately 38.5 tpa at $99.998 \%$ (4N8) purity. We estimate that total indium production costs would be $\sim \$ 380 / \mathrm{kg}$ of refined metal based on analysis of preliminary economic estimates in Thibault et al. (2010) (see Appendix D for more information). The cost model for the Mount Pleasant deposits forms the backbone of our Monte Carlo simulation used to generate indium supply curves, so significant additional detail regarding this property is included in Appendix D.

\subsubsection{Malku Khota, Bolivia}

The silver-indium Malku Khota project, previously owned by South American Silver Corporation, is one of the world's largest undeveloped silver and indium resources with an NI 43-101 compliant indicated resource of 230.3 million ounces of silver and 1,481 tonnes of indium, and an inferred resource of 140 million ounces silver and 935 tonnes indium. An updated preliminary economic assessment was prepared in May 2011, which showed robust economics for a bulk mineable heap leach operation. Located in the eastern part of the Bolivian Altiplano at elevations of 3,800-4,600 meters above mean sea level, the project is accessible by dirt road and commercial power is within about 20 kilometers of the site (Armitage et al. 2011).

Silver and indium mineralization at Malku Khota begins at the surface and remains open at depth. The preliminary economic assessment contemplates the construction and operation of a 40,000 tpd open pit acid-chloride heap leach operation. As detailed in Table 14, 200 million tonnes of leach material are planned to be mined over a 15-year mine life, with production of 13.2 million ounces of silver per year for the first 5 years and more than 10.5 million ounces per year for the life of the mine. Additionally, the mine is anticipated to produce $\sim 80$ tpa of indium and $\sim 15$ tpa of gallium. The mine would also annually produce several million pounds of byproduct lead, copper, and zinc, contributing to the overall profitability of the project. When using the detailed cost assumptions contained within South American Silver's preliminary economic assessment, we estimate that Malku Khota could produce indium at approximately $\$ 330 / \mathrm{kg}$ of refined metal (Armitage et al. 2011). 
Despite the project being a potentially large supplier of indium in the future, South American Silver is considering an alternative design that uses cyanide heap leaching instead of acid-heap leaching. Under the cyanide heap leach option, the project would not recover indium but would instead focus on silver extraction with byproduct gold and copper production.

Table 14. Operational and Production Summary of Malku Khota Silver-Indium Project

Source: Armitage et al. 2011; South American Silver Corp. 2012

Malku Khota NI 43-101 Preliminary Economic Assessment

Acid-Heap Leaching Scenario

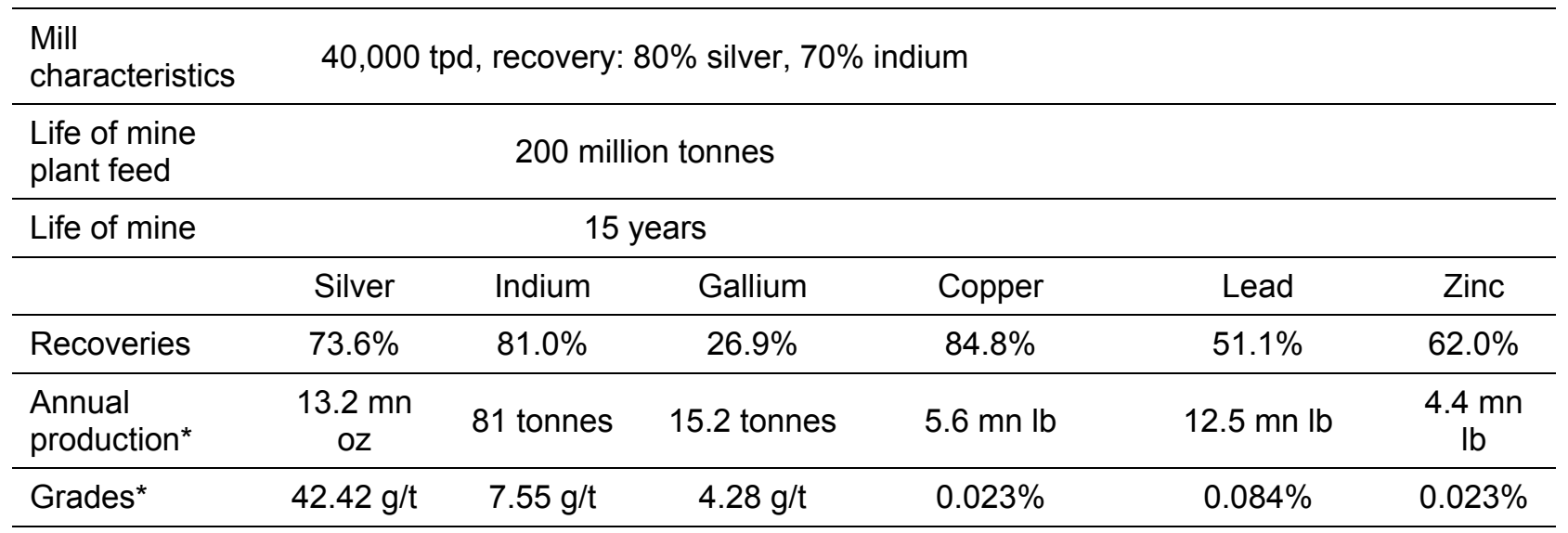

* Average annual production of recovered metal for the first 5 years. Figures do not vary significantly when examining life of mine averages, except that silver production reduced by about one third and zinc production doubles.

Under the pricing ${ }^{31}$ and grade assumptions used in Malku Khota's economic model, a comparison of the two cases shows that the indium, lead, zinc, and gallium contributions from the acid leach process are significant and allow "for greater exploitation of the deposits; longer mine life, higher metal production and higher [net present value]" (Armitage et al. 2011, p. 20). As a result, the acid leach option (with indium recovery) is the preferred option while the cyanide heap leach option is considered a fallback option in the event that the acid-chloride heap leach option proves not to be viable. ${ }^{32}$ The cyanide case will remain open for further study in subsequent project design phases.

According to the indicative timeline provided in South American Silver's preliminary assessment in 2011, if the feasibility study supported investment and if all permits and licenses were received, production at Malku Khota could begin as early as late 2015. The development timeline and production estimates are complicated by Bolivian president Evo Morales' nationalized South American Silver's interest in the property in July 2012 (Fraser 2012). South American Silver Corp. and the Bolivian government are currently involved in arbitration over the property (South American Silver Corp. 2014) and the future of the project appears to be unclear.

\footnotetext{
${ }^{31}$ Armitage et al. (2011) use base case pricing assumptions of $\$ 25 / \mathrm{oz}$ silver, $\$ 570 / \mathrm{kg}$ indium, $\$ 1 / \mathrm{lb}$ zinc and lead, $\$ 3.70 / \mathrm{lb}$ copper, and $\$ 570 / \mathrm{kg}$ gallium.

${ }^{32}$ Changes to the economics of the heap leach case could result from significant changes to the prices or grades of indium and other byproduct metals.
} 


\subsubsection{Pinguino, Argentina}

Canadian listed Argentex Mining Corporation's (Argentex) wholly owned Pinguino project is located in the Santa Cruz province of Argentina. Exploration is still at an early stage and Argentex has focused on defining an NI 43-101 compliant resource for the upper oxide ores. However, of interest to indium supply is the lower sulfide ores detailed in Table 15. Although the resource estimate presented in Table 15 is not NI 43-101 compliant, it gives an idea of the size of the potential indium resource.

Table 15. Potential Indium-Bearing Mineral Resource at Pinguino

(Gray et al. 2011)

\begin{tabular}{lccccccc}
\hline \multicolumn{7}{c}{ Sulfide Pit Resource Including Additional Oxide Ores } \\
\hline & $\begin{array}{c}\text { Resource } \\
\text { Class }\end{array}$ & $\begin{array}{c}\text { Resource } \\
\text { (tonnes) }\end{array}$ & Silver (gpt) & Gold (gpt) & $\begin{array}{c}\text { Lead } \\
\text { (\%) }\end{array}$ & Zinc (\%) & Indium (gpt) \\
\cline { 5 - 8 } Sulfide pit & Indicated & $5,220,000$ & 18.5 & 0.151 & $0.405 \%$ & $1.413 \%$ & 12.40 \\
\cline { 2 - 8 } & Inferred & $9,930,000$ & 17.2 & 0.113 & $0.420 \%$ & $1.336 \%$ & 8.28 \\
\hline Subtotal/average & & $15,150,000$ & 17.6 & 0.126 & $0.415 \%$ & $1.363 \%$ & 9.70 \\
\hline Associated oxides & Indicated & 710,000 & 14.0 & 0.111 & $0.126 \%$ & $0.077 \%$ & 4.92 \\
\cline { 2 - 8 } & Inferred & $2,170,000$ & 12.4 & 0.151 & $0.179 \%$ & $0.056 \%$ & 4.01 \\
\hline Subtotal/average & & $2,880,000$ & 12.8 & 0.141 & $0.166 \%$ & $0.061 \%$ & 4.23 \\
\hline Total/average & & $\mathbf{1 8 , 0 3 0 , 0 0 0}$ & $\mathbf{1 6 . 9}$ & $\mathbf{0 . 1 2 8}$ & $\mathbf{0 . 3 7 5 \%}$ & $\mathbf{1 . 1 5 5 \%}$ & $\mathbf{8 . 8 2}$ \\
\hline
\end{tabular}

* Despite the resource class terminology, figures do not represent an NI 43-101 compliant resource.

When using the metal prices adopted by Argentex in its preliminary economic assessment of the upper oxide portion of the deposit (Gray et al. 2011) and applying these to the lower sulfide zone, we calculate that indium comprises approximately $8 \%$ of total potentially recoverable revenue contained within an open pit mine that would target the sulfide ores (Table 16).

Based on figures in Argentex's preliminary economic assessment (Gray et al. 2011), we estimate that if mined over an 8-year period, Pinguino could produce approximately 7.3 tpa at a total cost of about $\$ 310 / \mathrm{kg}$ of refined indium metal.

Table 16. Potentially Recovered Metal and Revenue Contribution of Sulfide Ores (and Associated Oxides) at Pinguino

(Gray et al. 2011)

\begin{tabular}{|c|c|c|c|c|c|c|}
\hline \multicolumn{7}{|c|}{ Potentially Recovered Metal Content in Sulfide Pit and Associated Oxides } \\
\hline \multicolumn{2}{|l|}{ Midpoint metal recoveries } & $\begin{array}{c}\text { Silver } \\
(\mathrm{oz} .)\end{array}$ & $\begin{array}{l}\text { Gold } \\
\text { (oz.) }\end{array}$ & $\begin{array}{c}\text { Lead } \\
(\mathrm{t})\end{array}$ & $\begin{array}{c}\text { Zinc } \\
(\mathrm{t})\end{array}$ & $\begin{array}{c}\text { Indium } \\
(\mathrm{t})\end{array}$ \\
\hline \multicolumn{2}{|l|}{ Sulfide zone } & $60 \%$ & $0 \%$ & $90 \%$ & $90 \%$ & $75 \%$ \\
\hline \multicolumn{2}{|l|}{ Oxide layer/zone } & $85 \%$ & $96 \%$ & $0 \%$ & $0 \%$ & $0 \%$ \\
\hline & & \multicolumn{5}{|c|}{ Potentially Recovered Metal at Site } \\
\hline $\begin{array}{c}\text { Resource } \\
\text { Class }\end{array}$ & $\begin{array}{c}\text { Resource } \\
\text { (tonnes) }\end{array}$ & $\begin{array}{l}\text { Silver } \\
\text { (oz.) }\end{array}$ & $\begin{array}{l}\text { Gold } \\
\text { (oz.) }\end{array}$ & $\begin{array}{c}\text { Lead } \\
(\mathrm{t})\end{array}$ & $\begin{array}{c}\text { Zinc } \\
(\mathrm{t})\end{array}$ & $\begin{array}{c}\text { Indium } \\
(\mathrm{t})\end{array}$ \\
\hline \multirow{2}{*}{ Sulfide pit } & $5,220,000$ & $1,862,789$ & 0 & 19,027 & 66,383 & 49 \\
\hline & $9,930,000$ & $3,294,573$ & 0 & 37,535 & 119,398 & 62 \\
\hline Subtotal sulfide & $15,150,000$ & $5,157,362$ & 0 & 56,562 & 185,781 & 110 \\
\hline
\end{tabular}




\begin{tabular}{|c|c|c|c|c|c|c|c|}
\hline \multicolumn{8}{|c|}{ Potentially Recovered Metal Content in Sulfide Pit and Associated Oxides } \\
\hline \multirow{2}{*}{ Associated oxides } & Indicated & 710,000 & 271,629 & 2,420 & 0 & 0 & 0 \\
\hline & Inferred & $2,170,000$ & 735,310 & 10,060 & 0 & 0 & 0 \\
\hline \multicolumn{2}{|l|}{ Subtotal oxides } & $2,880,000$ & $1,006,939$ & 12,480 & 0 & 0 & 0 \\
\hline \multicolumn{2}{|l|}{ Total } & $18,030,000$ & $6,164,300$ & 12,480 & 56,562 & 185,781 & 110 \\
\hline \multicolumn{8}{|c|}{ Potential Revenue Contribution of Recovered Metal Content } \\
\hline & & & $\begin{array}{c}\text { Silver } \\
(\$ / \text { oz. })\end{array}$ & $\begin{array}{c}\text { Gold } \\
(\$ / o z)\end{array}$ & $\begin{array}{l}\text { Lead } \\
(\$ / / \mathrm{b})\end{array}$ & $\begin{array}{l}\text { Zinc } \\
(\$ / l b)\end{array}$ & $\begin{array}{c}\text { Indium } \\
(\$ / \mathrm{kg})\end{array}$ \\
\hline \multirow[t]{3}{*}{ Metal price } & & & 16.96 & 1,036 & 0.90 & 1.10 & 560 \\
\hline & & & \multicolumn{5}{|c|}{ Potential Revenue Contribution } \\
\hline & $\begin{array}{c}\text { Resource } \\
\text { Class }\end{array}$ & $\begin{array}{c}\text { Total } \\
(\$, \mathrm{mn})\end{array}$ & $\begin{array}{c}\text { Silver } \\
(\$, \mathrm{mn})\end{array}$ & $\begin{array}{c}\text { Gold } \\
(\$, \mathrm{mn})\end{array}$ & $\begin{array}{c}\text { Lead } \\
(\$, \mathrm{mn})\end{array}$ & $\begin{array}{c}\text { Zinc } \\
(\$, \mathrm{mn})\end{array}$ & $\begin{array}{l}\text { Indium } \\
(\$, \mathrm{mn})\end{array}$ \\
\hline \multirow{2}{*}{ Sulfide pit } & Indicated & 257.5 & 31.6 & 0.0 & 37.8 & 161.0 & 27.2 \\
\hline & Inferred & 454.4 & 55.9 & 0.0 & 74.5 & 289.6 & 34.5 \\
\hline Subtotal sulfide & & 711.9 & 87.5 & 0.0 & 112.2 & 450.5 & 61.7 \\
\hline Contribution (\%) & & $100 \%$ & $12 \%$ & $0 \%$ & $16 \%$ & $63 \%$ & $9 \%$ \\
\hline \multirow{2}{*}{ Associated oxides } & Indicated & 7.1 & 4.6 & 2.5 & 0.0 & 0.0 & 0.0 \\
\hline & Inferred & 22.9 & 12.5 & 10.4 & 0.0 & 0.0 & 0.0 \\
\hline Subtotal oxides & & 30.0 & 17.1 & 12.9 & 0.0 & 0.0 & 0.0 \\
\hline Contribution (\%) & & $100 \%$ & $57 \%$ & $43 \%$ & $0 \%$ & $0 \%$ & $0 \%$ \\
\hline Total & & 741.9 & 104.5 & 12.9 & 112.2 & 450.5 & 61.7 \\
\hline Contribution (\%) & & $100 \%$ & $14 \%$ & $2 \%$ & $15 \%$ & $61 \%$ & $8 \%$ \\
\hline
\end{tabular}

\subsubsection{Pirquitas, Argentina}

Silver Standard Resource Inc.'s (Silver Standard) wholly owned silver-zinc Pirquitas Property is located in the Puna de Jujeña region of northwestern Argentina, in the Province of Jujuy. The open pit mine was commissioned in 2009. The mine is at an elevation of 4,100 meters and is accessible by two all-weather roads. Ore is crushed and treated onsite to produce a concentrate via flotation techniques. The silver and zinc concentrates produced from the plant are then shipped to various third-party smelters around the world (Silver Standard 2012).

Based on an average indium concentration of 2 ppm (Schwarz-Schampera and Herzig 2002) and total resources of 39.8 million tonnes and reserves of 16.7 million tonnes (Board et al. 2011), the total indium content of Pirquitas resources and reserves could be $\sim 113$ tonnes.

Although commercial production at Pirquitas was achieved on December 1, 2009, comments made in Silver Standard's NI 43-101 Technical Report (Board et al. 2011) lead us to believe that indium is not currently being recovered at that site. Average indium concentrations reported in the separate silver and zinc concentrates are $450 \mathrm{ppm}$ and 1,000 ppm, respectively. Should these concentrates be shipped to indium-capable smelters, when using anticipated medium-term average smelter and refinery recoveries of $90 \%$ and $95 \%$, respectively, total supply of refined indium from Pirquitas could be $\sim 15$ tpa.

In 2013, 8.2 million ounces of silver and 27 million $1 \mathrm{~b}$ of zinc were produced and silver and zinc production in 2014 is expected to be $8.2-8.6$ million ounces and 25-30 million lb, respectively 
(Silver Standard 2013). The mine has a low cost base, principally because of the leaching recovery technique employed. Should Pirquitas recover the indium, we estimate that it would be an overall low cost producer at $\sim \$ 160 / \mathrm{kg}$ in 2011 USD.

\subsubsection{La Oroya, Peru}

Doe Run Peru, a wholly owned subsidiary of the U.S. company Renco Doe Run, is a mining and metallurgical company with operations located in the central highlands of Peru. The company has owned the La Oroya Metallurgical Complex since October 1997 and the Cobriza mine in Huancavelica since September 1998.

Doe Run Peru processes concentrates from third parties, most of which are Peruvian. The smelter and refineries of La Oroya extract and recover copper, zinc, silver, lead, indium, bismuth, gold, selenium, tellurium, and antimony, among others. The La Oroya Metallurgical Complex has the capacity to produce up to 6 tpa of 4N1 quality indium. The company also produces tellurium of 99.94\% (3N4) purity at La Oroya (Doe Run Peru 2012).

\subsubsection{South Crofty, England}

South Crofty is a metalliferous underground tin and copper mine located in the village of Pool. The mine has a long history and evidence of mining activity dating back to 1592; full-scale mining began in the mid-17th century. The mine extends almost $2 \frac{1}{2}$ miles across and 3,000 feet deep and mining has occurred in more than 40 different lodes ${ }^{33}$ (Hogg 2011).

South Crofty was the last remaining working mine in Cornwall, but a steep decline in the price of tin in 1985 and subsequent knock-on effects on viability caused it to decline after 1985 and to eventually close in 1998. The mine still possesses significant resources of tin, copper, and zinc.

Mineralization at South Crofty is in the form of lodes that occur within fracture zones and generally trend east-northeast to west-southwest. The lodes display a general moderate to steep dip to the southeast. Occasional opposite, moderate to steep dipping lodes are present in the system. A summary of the in situ classified inferred resource for the project, using a tin equivalent economic cutoff of $0.30 \%$, is estimated at approximately 1.331 million inferred tonnes of $0.44 \%$ tin, $1.08 \%$ copper, and $0.66 \%$ zinc. Although not forming part of the formal resource classification, total indium contained within the "potential resource" estimated in early 2011 for internal planning purposes and summarized in Table 17 is 85 tonnes, with an average grade of $\sim 36 \mathrm{ppm}$.

Data for the South Crofty mine are preliminary. Conceptual mine planning and a preliminary economic assessment have not been performed. For internal planning purposes, Celeste Copper Corporation, which in 2011 and 2012 evaluated possibly reopening the mine, stated that total costs could be $\sim \$ 50 /$ tonne mined by underground mining techniques, potentially through Alimak mining.

\footnotetext{
${ }^{33}$ In geology, a lode refers to a rich accumulation of minerals in solid rock, frequently in the form of a vein, layer, or an area with a large concentration of disseminated particles (Geology.com 2013).
} 
Table 17. South Crofty "Potential” Mineral Resource

Hogg 2011

\begin{tabular}{|c|c|c|c|c|c|c|}
\hline \multicolumn{7}{|c|}{ South Crofty Dolcoath-Potential Metal Content in Resource ${ }^{\mathrm{a}, \mathrm{c}}$} \\
\hline Wireframe Zone Name & $\begin{array}{c}\text { Tonnage } \\
(t)\end{array}$ & $\begin{array}{l}\text { Tin } \\
(t)\end{array}$ & $\begin{array}{c}\text { Copper } \\
(\mathrm{t})\end{array}$ & $\begin{array}{c}\operatorname{Zinc}_{(t)} \\
\text { (t) }\end{array}$ & $\begin{array}{c}\text { Lead } \\
(t)\end{array}$ & $\begin{array}{c}\text { Indium }_{(t)}^{b} \\
\text { (t) }\end{array}$ \\
\hline Dolcoath North & 20,538 & 18 & 136 & 45 & 0 & 0.75 \\
\hline Dolcoath Middle & 290,166 & 1,509 & 2,989 & 348 & 0 & 13.80 \\
\hline Dolcoath South & 385,921 & 2,470 & 1,582 & 2,007 & 39 & 16.53 \\
\hline Dolcoath South Branch & $1,508,864$ & 5,281 & 11,316 & 10,864 & 151 & 50.64 \\
\hline Dolcoath Flat & 115,798 & 683 & 718 & 1,818 & 23 & 3.32 \\
\hline Total & $2,321,287$ & 9,961 & 16,741 & 15,082 & 213 & 85 \\
\hline
\end{tabular}

To provide indicative results, we assume (1) an overall indium recovery rate of $80 \%$ at the concentrate stage; (2) a mine life of 12 years; (3) capital costs of $\$ 26$ million based on studies from similar scale operations; (4) sustaining capital equivalent to $10 \%$ of total operating costs; and (5) a contingency of $30 \%$ on all costs. With these assumptions, we calculate that 10 tpd of refined indium could be produced at a total cost of $\$ 342 / \mathrm{kg}$. Because dialogue with the nearby community is ongoing and the mine's reopening is uncertain, we do not believe that production could commence until 2017 at the earliest.

\subsection{Increased Recovery at Existing Facilities}

Recovery yields are another important contributor to increased outputs. In the medium term, higher indium prices make it economically viable for mines, smelters, and refineries to invest in increasing yields and capacities.

A study undertaken by Indium Corp. shows that only approximately $30 \%$ of the total indium mined worldwide every year is transformed into refined indium metal (Mikolajczak 2009). Our calculations put the overall recovery closer to $15 \%-20 \%$, and as depicted in Figure 18, the major causes of the low overall recovery rate are:

- Based on the process described for zinc ore mined, only $50 \%-70 \%$ of the indium contained in the ores is recovered by the on-mine treatment plant and contained in the zinc concentrate.

- Of these indium-pregnant zinc concentrates, $30 \%$ are not sent to "indium-capable" smelters (Mikolajczak 2009).

- The indium in the remaining indium-pregnant concentrates that are sent to indiumcapable smelters is recovered at a rate of 50\% (Mikolajczak 2009).

- The impure indium is sent for advanced refining at various special metal refineries where the recovery rate averages $\sim 80 \%$.

\footnotetext{
${ }^{34}$ JORC is the Australasian Joint Ore Reserves Committee. The JORC committee produces the JORC code, which is the Australasian code for public reporting of "exploration results, mineral resources and ore reserves" (JORC 2012).
} 


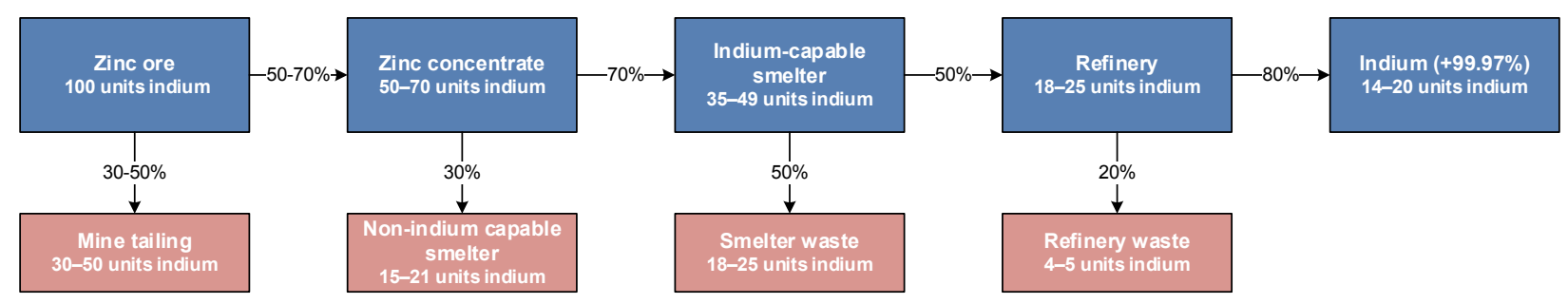

Figure 18. Indium value chain and overall recovery efficiency

For every 100 units of indium metal mined along with zinc ores, only $\sim 15$ to 20 units is recovered as refined metal Source: derived from Schwarz-Schampera and Herzig (2002) and Mikolajczak (2009)

${ }^{1}$ Heath Steele reports that $35.8 \%$ of indium in ore ended up in tailings and $51.4 \%$ went to zinc tailings (Schwartz-Schampera and Herzig 2002).

${ }^{2}$ Brunswick 6 and 12 mills reportedly recovered recovery of only $58.9 \%$ of In in Zn concentrate (Schwartz-Schampera and Herzig 2002).

${ }^{3}$ At Toyoha, the recovery of indium in zinc concentrates was $\sim 96 \%$ (same as estimated for zinc recovery in zinc concentrate). This mine was a main product indium producer, so these high recoveries are unlikely to be representative of byproduct indium producers.

${ }^{4}$ To allow for some upside, indium recovery in mine concentrates is estimated to fall be $50 \%-70 \%$.

The remaining $80 \%-85 \%$ that is not immediately recovered as indium metal and remains associated with other elements and impurities as residue accumulates in tailings and other dumps. These resources could be available for recovery at a later stage if prices and costs justify their extraction.

Although smelters are locked into current technologies, as they become due for rebuilds or upgrades newer technologies may be introduced that could significantly increase the recovery rate. For example, according to the NI 43-101 compliant ${ }^{35}$ Preliminary Assessment for Adex Mining's polymetallic Mount Pleasant property in New Brunswick, Canada, anticipated overall recovery efficiency of indium is expected to be $83.05 \%(\mathrm{wt} \%)$ at the point of zinc concentrate and $75.4 \%\left(\mathrm{wt}^{\%} \%\right)$ when indium is recovered in sponge form containing $\sim 95 \%$ purity indium ${ }^{36}$ (Thibault et al. 2010). By comparison, the recovery efficiency of indium is expected to be $\sim 75 \%$ at the point of zinc concentrate for Argentex's planned development of the Pinguino deposit in Argentina (Gray et al. 2011) and 81\% at the point of crude metal at South American Silver's Malku Khota deposit (Armitage et al. 2011).

The overall recovery of indium in zinc concentrates could thus conceivably be $75 \%-85 \%$ in the medium term. Such an increase would by itself increase the overall indium recovery rate from $14 \%-20 \%$ (Figure 18 ) to $\sim 21 \%-24 \%$. Assuming a further recovery efficiency improvement in new smelters of $90 \%$ efficiency (as implied by the Mount Pleasant estimate) the overall recovery increases from $21 \%-24 \%$ to $38 \%-43 \%$. Finally, assuming a further increase in recovery efficiency from $80 \%-95 \%$ at the refinery stage increases the overall indium recovery efficiency to $45 \%-51 \%$.

\footnotetext{
${ }^{35}$ NI 43-101 (or National Instrument 43-101) represents the Canadian standard for reporting economic and mineral resource information for companies traded on Canadian stock exchanges.

${ }^{36}$ This is the minimum specification for feed to conventional electro-refining circuit (Thibault et al. 2010).
} 


\subsection{Summary Expansion of Primary Supply}

The short-term supply curves presented earlier represent the quantities of indium currently available at prices sufficient to cover variable production costs. The medium-term curves that follow embody several adjustments:

- Capital costs are included. Because operators have the option to invest in new capacity or shut down in the medium term, we adjust costs to reflect returns to capital and eliminate all realizations in the simulation that would not generate positive returns for investors.

- Variation in the long-term main-product average prices is used in assessing feasibility. Readers should examine the long-term historical prices of tin and zinc in Figure 28 in 2011 U.S. dollars as indicated. More detail regarding how this is performed is included in Appendix D.

- Recoveries reflect latest commercially available technologies.

- Quantities reflect current production capacity and quantities contained in mineral deposits with published resources that could be in production over the medium term, as well as potential recovery improvements discussed above.

Using the projected byproduct indium supply levels summarized in Table 12, as well as the potential improvements to recovery efficiency details in Section 4.2, we generate a series of medium-term supply scenarios. Briefly, these are:

- Base case 2016. Based on current levels of recovery efficiency, 2011 production (731 tonnes) adjusted to reflect projected main product expansion (mainly zinc), and associated indium recovery.

- Adjusted 2016, base case + improved recovery and pipeline efficiency (2016). Uses the base case 2016 levels but builds in improved overall pipeline efficiency described in Section 4.2. This is similar to the approach taken in generating short-term primary supply scenarios. But because we now consider the medium term, capital costs associated with these efficiency improvements are reflected in the cost of indium.

- Base case 2031. Based on current levels of indium recovery efficiency, 2011 production (731 tonnes), and projected main product expansion (again, mainly zinc) between 2011 and 2031.

- Adjusted 2031, base case + improved recovery and pipeline efficiency (2031). Per the adjusted 2016 case, except byproduct indium production has been forecasted to 2031.

Figure 19 contains the supply curves for the base cases. Compared to the primary supply curve shown in Figure 11, the cost curves have shifted upward because capital costs are now included. In the medium term primary indium supply seems to be elastic at prices of $\$ 350-\$ 450 / \mathrm{kg}$ and inelastic at prices higher than $\$ 800$ and lower than $\sim \$ 275$. 


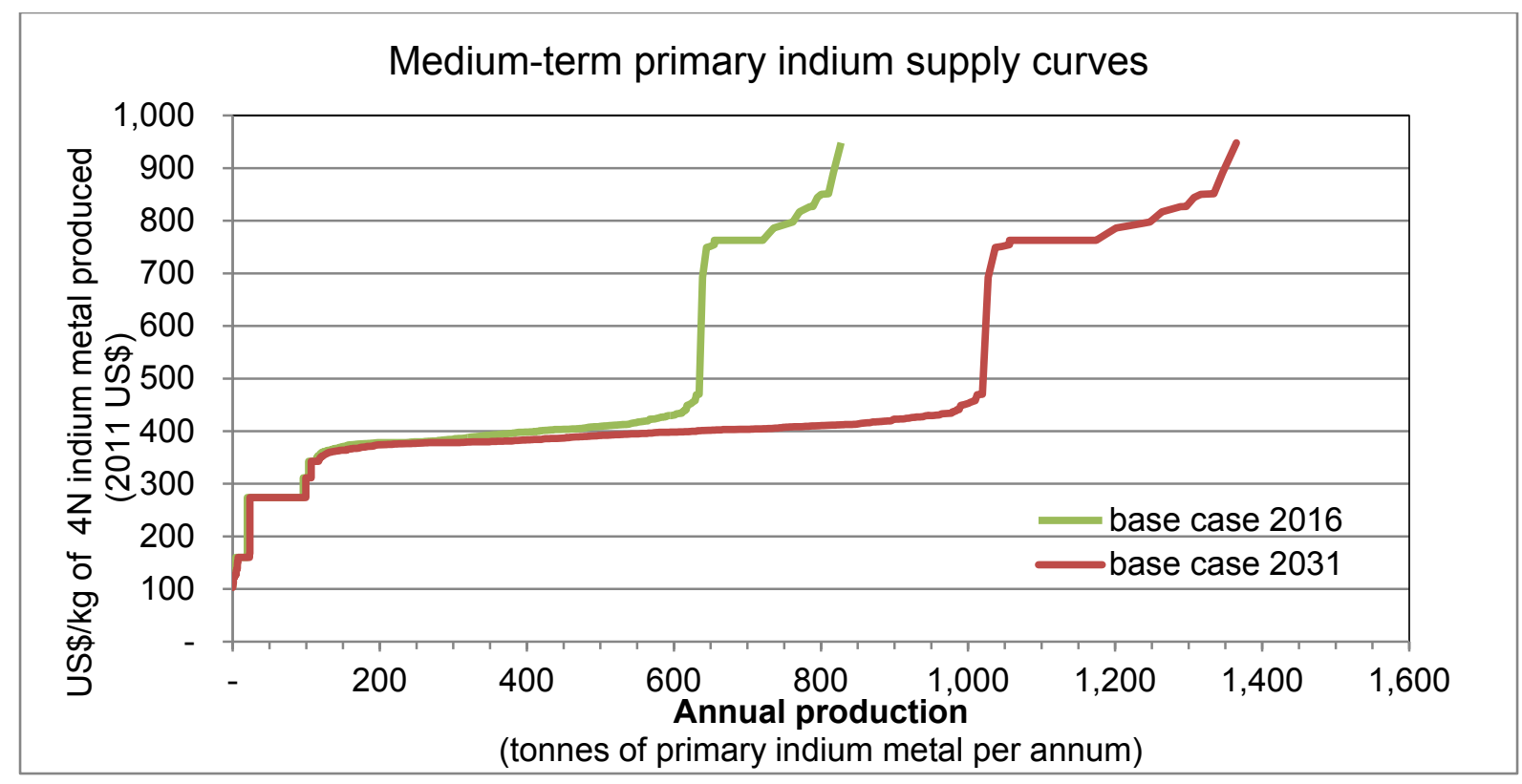

Figure 19. Medium-term base case primary indium supply projected to 2016 and 2031 (indium production growth in base case is solely due to zinc production growth)

The base case scenarios are self-explanatory, but the derivations of figures for the other two scenarios that examine improved recovery efficiency require more clarification. As discussed in the short-term supply curves, recovery inefficiency has two principal causes: (1) indium-bearing concentrates not being sent to indium-capable smelters; and (2) metallurgical losses through the recovery process, which may be caused by less efficient technologies being used at plants, smelters, and refineries. In deriving the medium-term supply curves, we assume that $100 \%$ of indium-bearing concentrates are sent to indium-capable smelters, which increases 2016 indium primary production from 827 tonnes to 1,182 tonnes and 2031 primary production from 1,365 tonnes to 1,950 tonnes. These calculations are detailed in Appendix D.

Examining potential indium supply where pipeline efficiencies are gained yields the primary indium supply curves depicted in Figure 20 and Figure 21 for 2016 and 2031, respectively. Costs are kept in 2011 US\$ terms to facilitate comparison across time, though one would expect costs to rise in nominal terms between 2016 and 2031. 


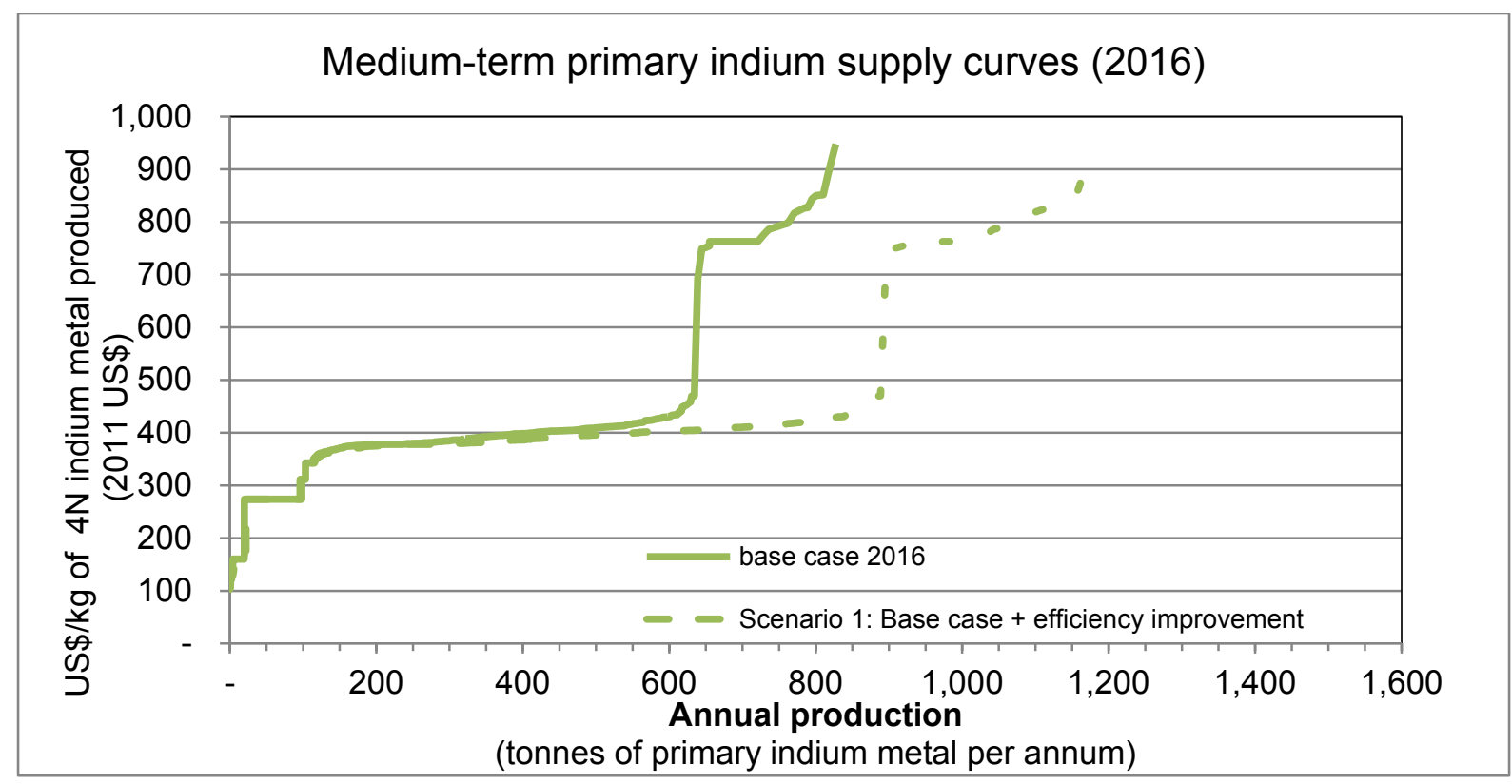

Figure 20. Medium-term primary indium supply (2016)

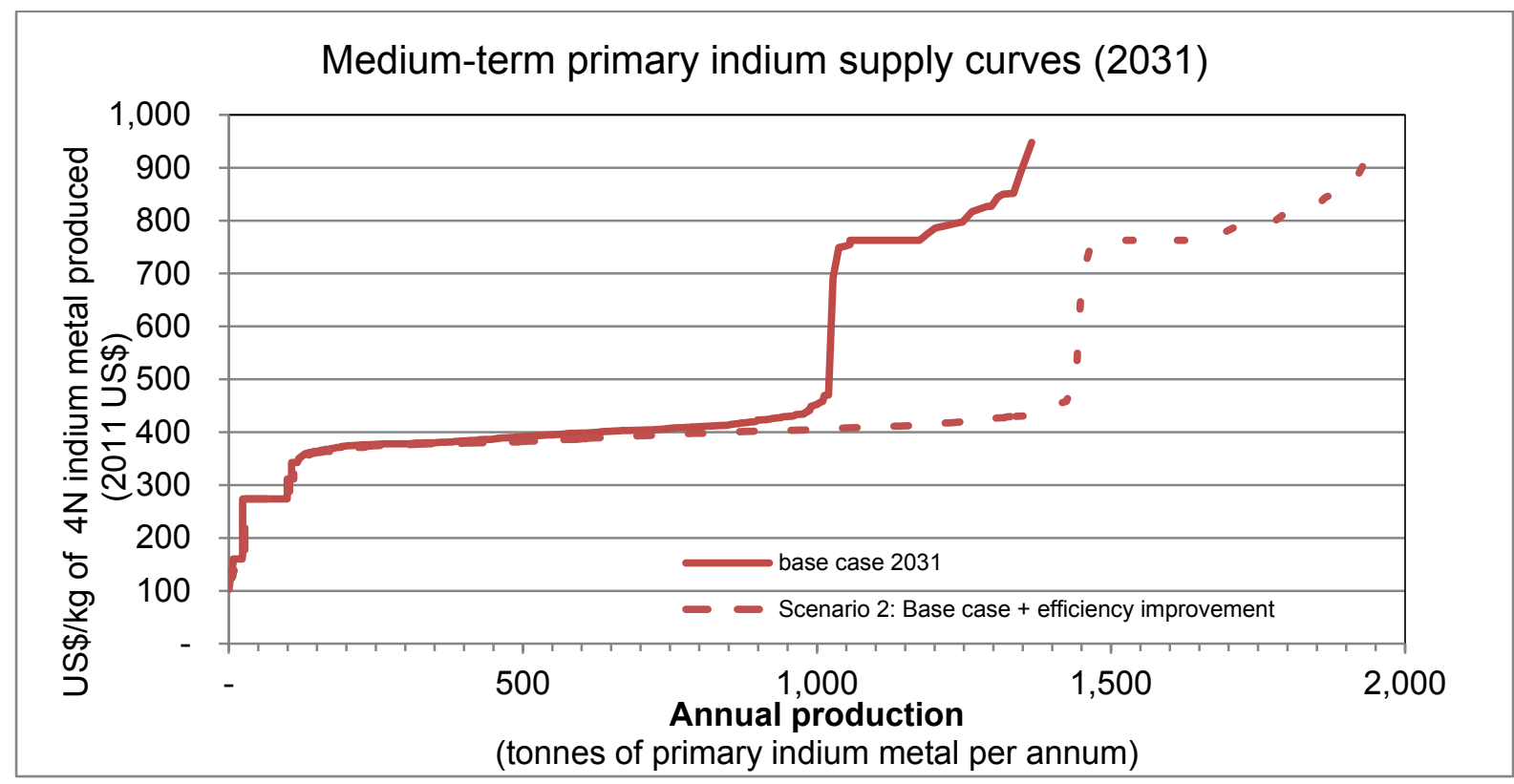

Figure 21. Medium-term primary indium supply (2031)

In all these scenarios, we include supply anticipated to come from known indium projects identified in Section 4.1, namely Mount Pleasant, Malku Khota, Pirquitas, Pinquito, and South Crofty. The La Oroya complex is not included because it is a metallurgical and refinery complex and we are hesitant to treat it as "new production." We believe that it may simply reflect a shift of production from a country that currently treats Peruvian concentrates. The positions of these potential new sources of supply are explicitly depicted in Figure 22 to indicate where these deposits might feature competitively and what fraction of primary indium they might contribute in 2016. 


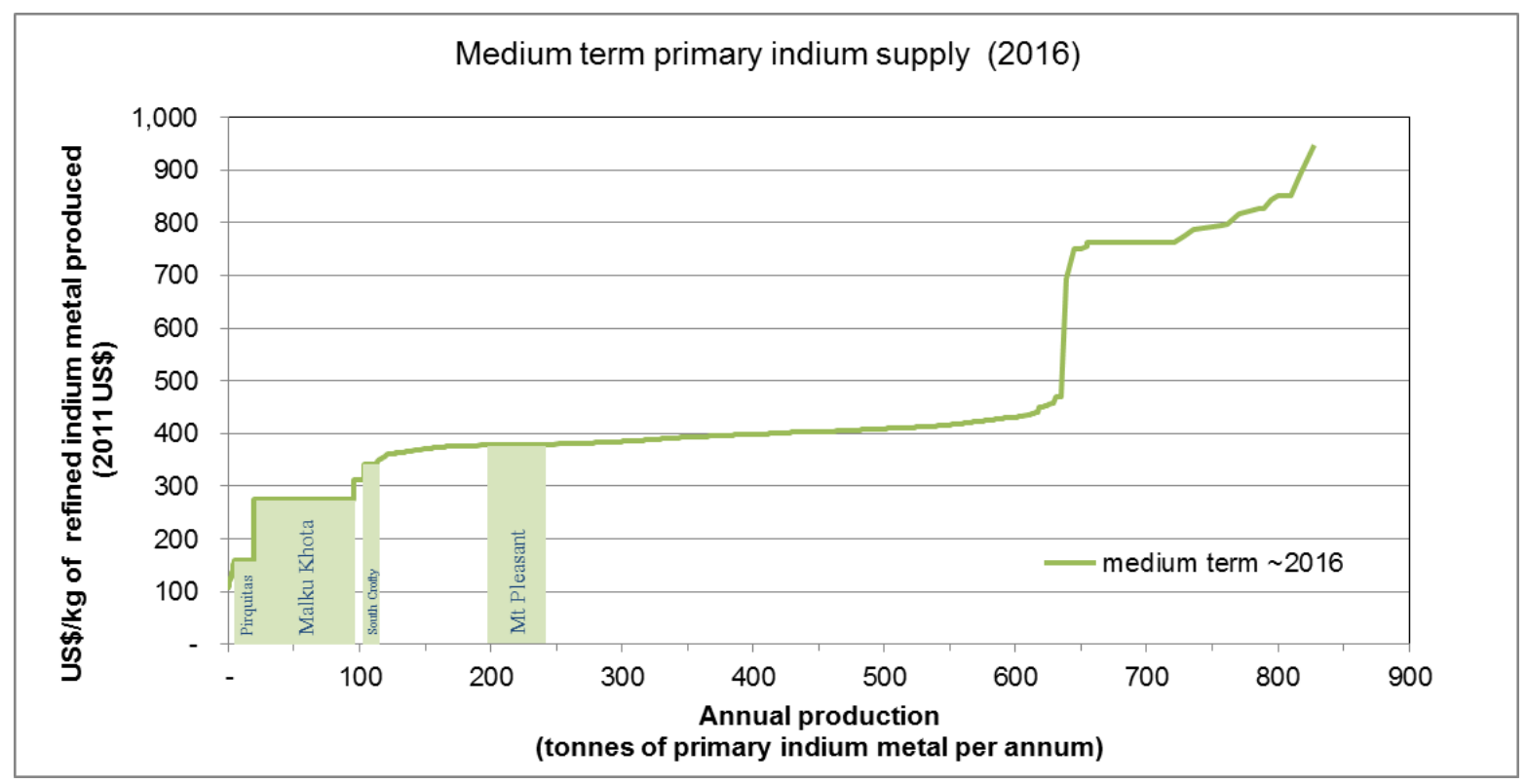

Figure 22. Medium-term primary indium supply (2016), including positioning of known potential future sources of supply

The costs and quantities for these deposits were determined using a bottom-up approach and using publically available information. The estimation methodology adopted to allocate costs to indium and other main products, coproducts, and byproduct metals was similar to that described in Appendix D for Adex's Mount Pleasant deposit.

\subsection{Expansion of Secondary Supply}

Recovery from mines and recyclers may well increase. Such recycling capacity would keep pace with manufacturing waste as demand for flat-panel displays (the leading user of ITO) expands. We model secondary supply as a function of ITO demand and efficiency improvements.

We use CAGRs of $3 \%, 5 \%$, and $7 \%$ when forecasting indium demand to 2031 . We also vary the efficiency of the recovery process to provide a range of potential medium-term secondary supply as detailed in Table 18.

The first set of numbers in Table 18 uses various demand growth rates to estimate the potential demand for indium for ITO applications in 2016 and 2031. The 2011 figures are derived using a linear extrapolation between the European Commission's 2010 and 2015 demand estimates (Moss et al. 2010). The panel of figures summarizes the amount of indium likely to be "fed" into the recycling plants; the third set presents secondary supply estimates if recovery efficiencies remained at the current level of $65 \%$. The final set of figures indicates secondary supply if overall recovery were increased to $90 \%$ from $65 \%$.

Table 18 shows that, without any improvements in recovery efficiency, secondary supply could expand from its current base of 609 tpa to 778 and 1,689 tpa in 2016 and 2031, respectively. This represents a CAGR of 5.2\% between 2011 and 2031 . When incorporating the potential increases in supply that result from improved recovery efficiencies, secondary supply almost doubles to 1,078 tpa and quadruples to 2,339 tpa in 2016 and 2031, respectively, representing a CAGR of $7 \%$. 
Table 18. Potential Expansion of Secondary Supply From Manufacturing Waste

\begin{tabular}{|c|c|c|c|}
\hline \multicolumn{4}{|c|}{ Potential Medium-Term Secondary Indium Supply } \\
\hline & 2011 & 2016 & 2031 \\
\hline \multicolumn{4}{|c|}{ Indium Demand in ITO Applications (Tonnes Indium) ${ }^{\mathrm{a}}$} \\
\hline Low: @3\% CAGR & 1,033 & 1,198 & 1,866 \\
\hline Medium: @5\% CAGR & 1,033 & 1,319 & 2,741 \\
\hline High: @7\% CAGR & 1,033 & 1,449 & 3,998 \\
\hline Average & 1,033 & 1,322 & 2,869 \\
\hline \multicolumn{4}{|c|}{ Tonnes of Indium Fed Into Recycling Plants ${ }^{b}$} \\
\hline Low & 936 & 1,085 & 1,691 \\
\hline Medium & 936 & 1,195 & 2,484 \\
\hline High & 936 & 1,313 & 3,623 \\
\hline Average & 936 & 1,198 & 2,599 \\
\hline \multicolumn{4}{|c|}{ Estimated Secondary Supply (Tonnes Indium @ 65\% Recycling Efficiency) } \\
\hline Low & 609 & 705 & 1,099 \\
\hline Medium & 609 & 777 & 1,615 \\
\hline High & 609 & 853 & 2,355 \\
\hline Average & 609 & 778 & 1,689 \\
\hline \multicolumn{4}{|c|}{ Scenario 1: Estimated Secondary Supply @ 90\% Efficiency } \\
\hline Low & 609 & 977 & 1,522 \\
\hline Medium & 609 & 1,075 & 2,236 \\
\hline High & 609 & 1,182 & 3,260 \\
\hline Average & 609 & 1,078 & 2,339 \\
\hline
\end{tabular}

\subsection{Summary of Medium-Term Supply}

Without any improvements to technology or pipeline efficiency, we estimate indium primary production to be approximately 730,830 , and 1,365 tpa in 2011,2016, and 2031, respectively (Table 19). Production is currently relatively concentrated, with about half in China, and we do not expect this to change significantly in the medium term. When including the possibility for greater recovery and pipeline efficiency, primary and secondary production could more than double to 3,370 and 5,560 tonnes, respectively, thus highlighting the significant impact that advancements in technology can have on supply.

Significant secondary supply of approximately 610 tonnes currently takes place close to hightech manufacturing centers such as Japan, South Korea, and China. As demand for flat-panel displays expands, we estimate that secondary supply could reach levels of 780 and 1,690 tonnes in 2016 and 2031. When considering the potential for improvements in recycling recovery rates, secondary supply could be as much as 1,080 and 2,340 tonnes over the same period. As previously noted, secondary supply from manufacturing waste is not a substitute for primary supply, and although recycling can significantly reduce primary indium demand (and thus reduce short-term supply shortages or risks), secondary supply from manufacturing waste does not address long-term supply risks. 
Table 19. Total Indium Production (2011, 2016, and 2031)

\begin{tabular}{|c|c|c|c|c|c|c|}
\hline & \multicolumn{2}{|c|}{2011} & \multicolumn{2}{|c|}{2016} & \multicolumn{2}{|c|}{2031} \\
\hline & tonnes & $\%$ of total & tonnes & $\%$ of total & tonnes & $\%$ of total \\
\hline \multicolumn{7}{|c|}{ Base Case Scenario } \\
\hline Primary & 731 & $55 \%$ & 827 & $52 \%$ & 1,365 & $45 \%$ \\
\hline Secondary & 609 & $45 \%$ & 778 & $48 \%$ & 1,689 & $55 \%$ \\
\hline Total & 1,340 & $100 \%$ & 1,606 & $100 \%$ & 2,143 & $100 \%$ \\
\hline \multicolumn{7}{|c|}{ Adjusted Scenario: Improved Recovery and Pipeline Efficiency } \\
\hline Primary & & & 3,368 & $76 \%$ & 5,557 & $70 \%$ \\
\hline Secondary & & & 1,078 & $24 \%$ & 2,339 & $30 \%$ \\
\hline Total & 3,819 & $100 \%$ & 4,446 & $100 \%$ & 7,896 & $100 \%$ \\
\hline $\begin{array}{l}\text { Adjusted scenario/ } \\
\text { base case }\end{array}$ & & & $2.8 x$ & & $3.4 x$ & \\
\hline
\end{tabular}

As shown in Figure 24 (2016) and Figure 25 (2031), the total indium supply curve keeps its general shape from Section 3.6, but the curves are shifted upward because the direct and opportunity costs of capital are now included in the curve. This increase to overall cost is somewhat offset by projected efficiency improvements that spread fixed costs over more units of recovered indium, and therefore lead to a lower average cost for indium production.

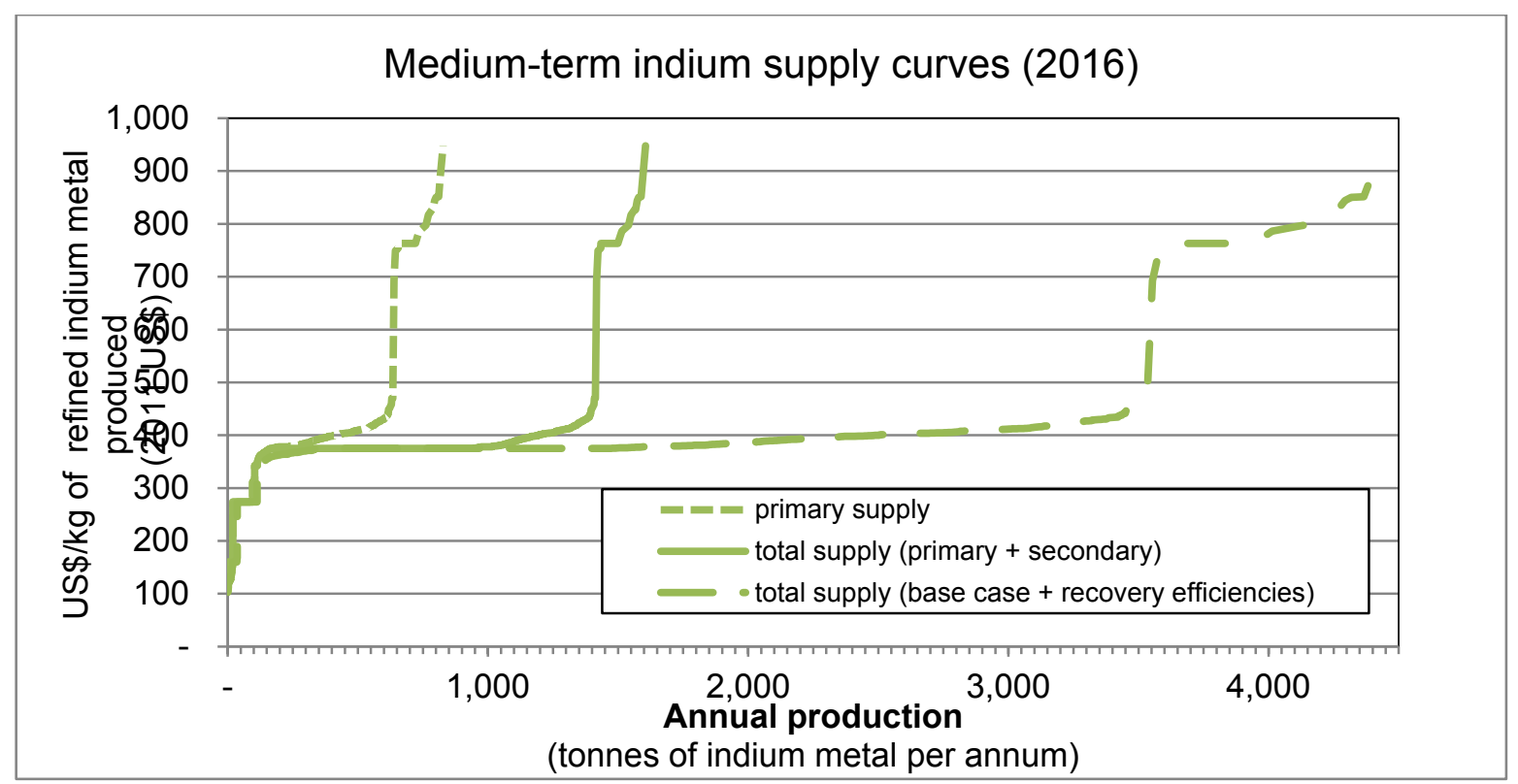

Figure 23. Comparison of medium-term primary and total indium supply in 2016 


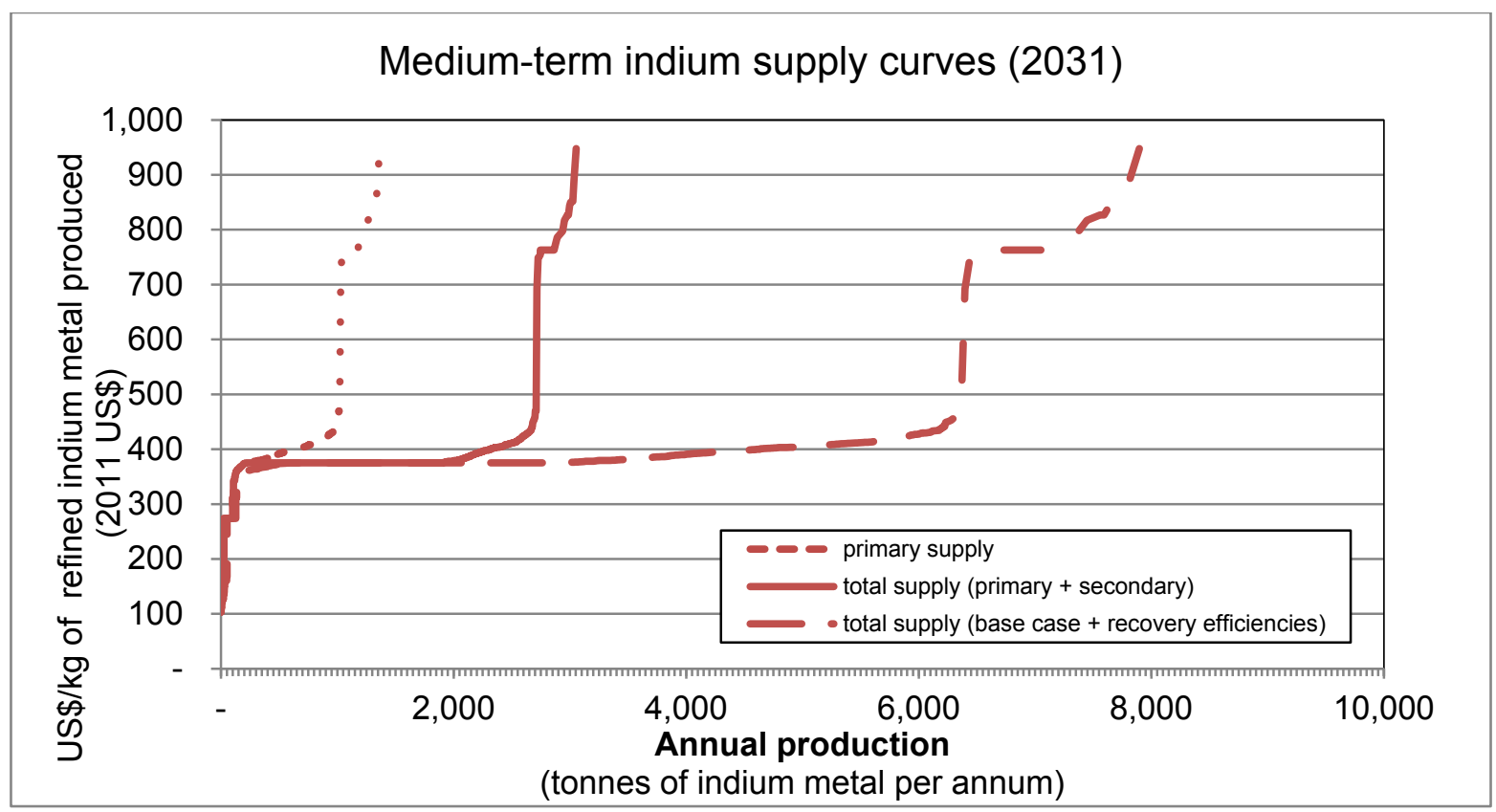

Figure 24. Comparison of medium-term primary and total indium supply in 2016

The significant range of total supply between the various scenarios leads to some preliminary conclusions about the medium term:

- The biggest medium-term supply opportunity is recovery efficiency. A focus on metallurgical efficiency as well as pipeline efficiency (i.e., ensuring that indium-bearing concentrates are shipped to indium-capable smelters) could increase total supply by a factor of $2.8 \mathrm{X}$ in 2016 and $3.4 \mathrm{X}$ in 2031.

- Higher recovery efficiency increases supply and lowers the average production cost.

- Although short-term market conditions might allow prices to drop to a $\$ 150-\$ 200 / \mathrm{kg}$ level, prices are unlikely to be lower than $\$ 400 / \mathrm{kg}$ for any prolonged period. At prices lower than $\$ 400 / \mathrm{kg}$, primary and secondary suppliers are unlikely to continue investing to maintain productive capacity.

Furthermore, although not explicitly modeled as part of this exercise, secondary supply from consumer waste (old scrap) could become a source of additional supply in the medium term. It is difficult to estimate the cost of such supply, but given that current price levels have not justified the recovery of indium from laptops, cellular phones, and other electronic devices (mostly because these items are so widely dispersed), prices would likely need to exceed $\$ 700 / \mathrm{kg}$ to make recovery from these sources profitable. Furthermore, although a less disperse and possibly more profitable source of old scrap could be found in EOL solar panels, we do not expect this to contribute to supply until the 2030s, because the average expected life of solar panels is approximately 20 years and only at this point would this potential resource would become available. 


\section{Supply: The Long Term (Beyond 20 Years)}

When thinking about the long term, it is helpful to keep in mind that all factors are flexible (capital, labor, technology, and our level of geological knowledge). That is, new discoveries are possible, and there are no constraints to production beyond the amount of resource in the Earth's crust and human ingenuity. Economists and others thus find it difficult to make accurate longterm forecasts.

A complete analysis of supply requires estimates of both price (on the vertical axis of a supply curve) and quantity (on the horizontal axis). Our analysis here is limited to price and builds on Green (2009), who argues there is a fundamental relationship between price and concentration (or weight percent) of an element in a mineral deposit. A lower mineral concentration implies more difficult extraction and higher production costs, and thus a higher price to justify investment in a mine and associated facilities. To be sure, factors other than concentration influence production costs, but the lower the concentration, the larger the quantity of unwanted material that must be separated from the desired element.

Largely derived from Green (2009), Figure 26 plots average mineral concentration in typical ores $^{37}$ against average price over the period of 2005 to $2009^{38,39}$ for different minerals. By deriving a general relationship between the market price of metals and the quality of ores from which they are mined, estimates of the market price of indium (if mined from available ores) can be obtained. When plotted in a log-log scale, a strong linear relationship and good fit $\left(\mathrm{R}^{2}\right.$ of $0.84)^{40}$ can be seen. If one believes that minerals will generally follow this relationship in the long term, this analysis can be used to provide a range of potential long-term indium prices.

\footnotetext{
${ }^{37}$ By using the terminology of "ores" in line with Green (2009), we explicitly rule out deposits of no economic interest.

${ }^{38}$ For $4 \mathrm{~N}$ quality indium we use a more recent price of $\$ 600 / \mathrm{kg}$.

${ }^{39}$ For a long-term analysis, it would be ideal to use longer term prices (i.e., average over the past $\sim 20$ years).

${ }^{40}$ A simple linear regression of the data in Figure 26 where $\log ($ price $)=\alpha_{1}+\alpha_{2} \log ($ concentration $)+\varepsilon$ yields highly significant estimates for the regression coefficients as summarized below where values in brackets below the regression equation represents the t-statistic:

$$
(13.89) \quad(-9.62)
$$$$
\log (\text { price })=4.776 \quad-0.834 * \log (\text { concentration })
$$

A plot of the residuals indicates the presence of heteroskedasticity, which may indicate that the standard errors for our coefficients are biased. Although the sample size of 20 is small, a normality plot of the residuals indicates that residuals are normally distributed, thus support our use of the t-statistics in determining the significance of the estimators for our coefficients.
} 


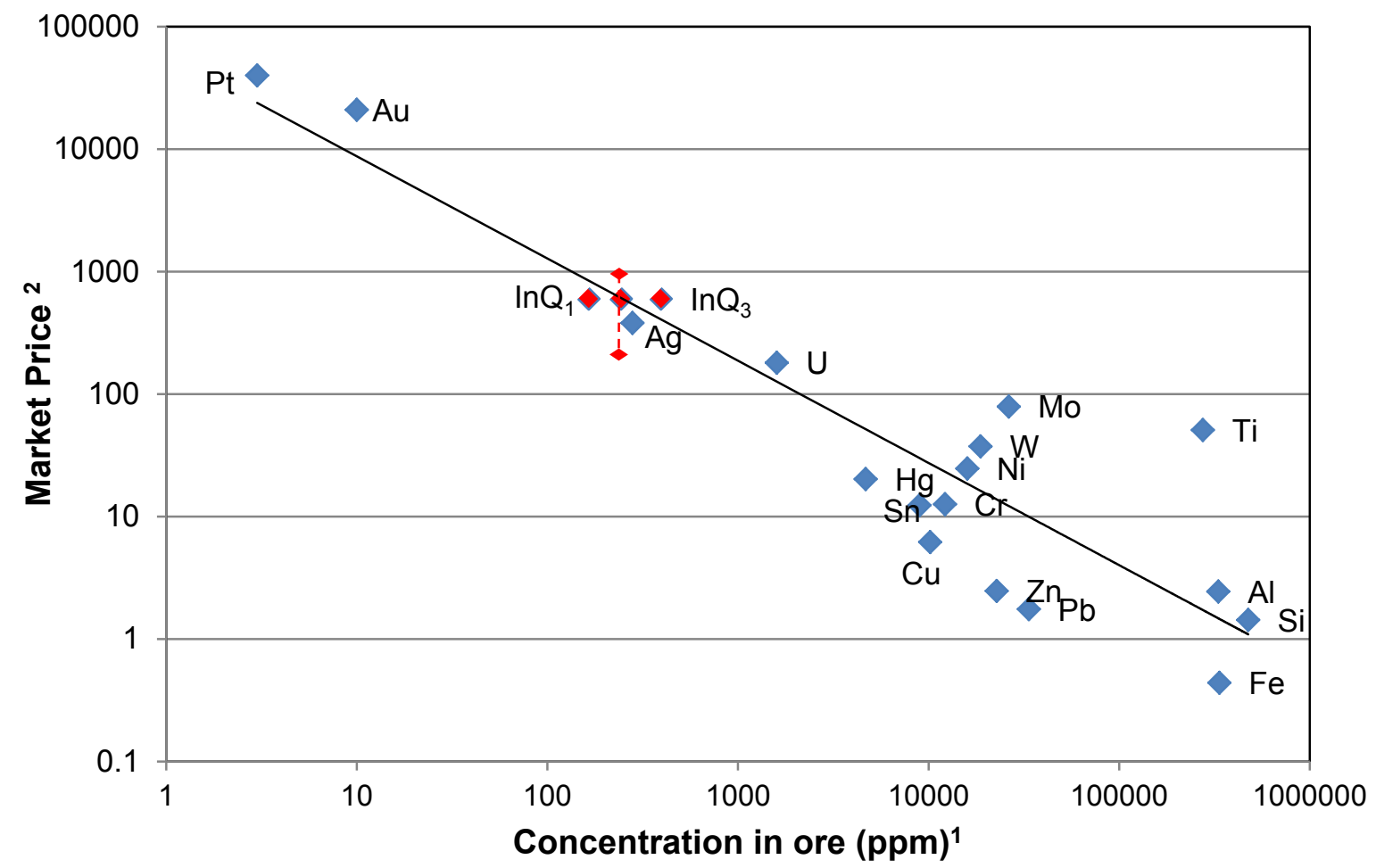

Figure 25. Market price versus concentration of metal in typical ore

${ }^{1}$ Concentration in ore is the product of estimated crustal abundance (ppm) and estimated ore enrichment factors. Values for all data except indium are obtained from Green (2009). Concentration and enrichment factors are based on median estimates. Indium concentrations in ore are based on the first, second, and third quartile indium concentrations used to generate the medium-term primary supply curve.

${ }^{2}$ All prices except those for indium are from Green (2009) and are based on the average monthly prices from January 2005 to November 2008. The iron quote is based on the Pittsburgh pig iron price and uranium quoted as $\$ / \mathrm{kg}$ triuranium octoxide ( $84.8 \%$ uranium). Price range indicated for indium based on observed prices over a 20 -year period.

Our base-point estimate of indium concentration against an average recent market price of $\$ 600 / \mathrm{kg}$ fits very well with the trend line in Figure 26. In order to plot indium with the other data, we use first quartile, median, and third quartile values of indium concentrations in economically feasible deposits that form part of our medium-term primary supply curves. First and third quartile data points are indicated in Figure 27 by the labels $\operatorname{InQ}_{1}$ and InQ $\mathrm{Q}_{3}$, respectively. We then overlay the range of indium prices observed over the past 20 years to indicate how tightly indium may have tracked the line over this period.

Again, we note that even when incorporating a range of potential indium ore concentrations and highlighting the historical range of indium prices, indium still appears to fit well within the model and a long-term price of $\$ 600-\$ 1,000 / \mathrm{kg}$ appears to be supported.

Recognizing that the log-log scale may lead one to conclude a better fit than justified, we use the results from the simple linear regression described in footnote 40 , and plot the $\pm 95 \%$ and $\pm 80 \%$ confidence intervals (Figure 27). Given the range of indium's concentration in ores (165-394 ppm), the 95\% confidence intervals reported in Table 20 and displayed in Figure 27 support a 
wide price range of $\$ 26-\$ 11,262 / \mathrm{kg}$. Instead, examining the $80 \%$ confidence intervals yields a narrower price range of $\$ 163-\$ 4,353 / \mathrm{kg}$. The historical prices suggest that indium came close to the lower $80 \%$ confidence interval in 1994. This can also be observed visually in Figure 27.

Table 20. Long-Term Range of Potential Indium Prices (\$, 2011)

\begin{tabular}{|c|c|c|c|c|c|c|c|}
\hline & \multirow{2}{*}{$\begin{array}{c}\text { Ore } \\
\text { Abundance } \\
\text { (ppm) }\end{array}$} & \multirow{2}{*}{$\begin{array}{c}\text { Market } \\
\text { Price }\end{array}$} & \multirow{2}{*}{$\begin{array}{l}\text { Expected } \\
\text { Price } \\
\text { (p50) }\end{array}$} & \multicolumn{4}{|c|}{ Confidence Intervals for Price } \\
\hline & & & & $(-95 \%)$ & $(+95 \%)$ & $(-80 \%)$ & $(+80 \%)$ \\
\hline Indium (low) & 165 & \multirow{3}{*}{$\$ 600 / \mathrm{kg}$} & $\$ 843 / \mathrm{kg}$ & 63 & 11,262 & 163 & 4,353 \\
\hline Indium (mid) & 243 & & $\$ 609 / \mathrm{kg}$ & 42 & 8,729 & 113 & 3,287 \\
\hline Indium (low) & 394 & & $\$ 407 / \mathrm{kg}$ & 26 & 6,374 & 71 & 2,324 \\
\hline
\end{tabular}

Because indium is principally produced as a byproduct, while the other minerals included in the regression have more significant main product supply, we would naturally expect indium to trend within the lower bounds of the confidence intervals provided. So unless prices induced a change in indium production from principally byproduct to main product production, we would not expect indium prices near the upper end of our confidence intervals.

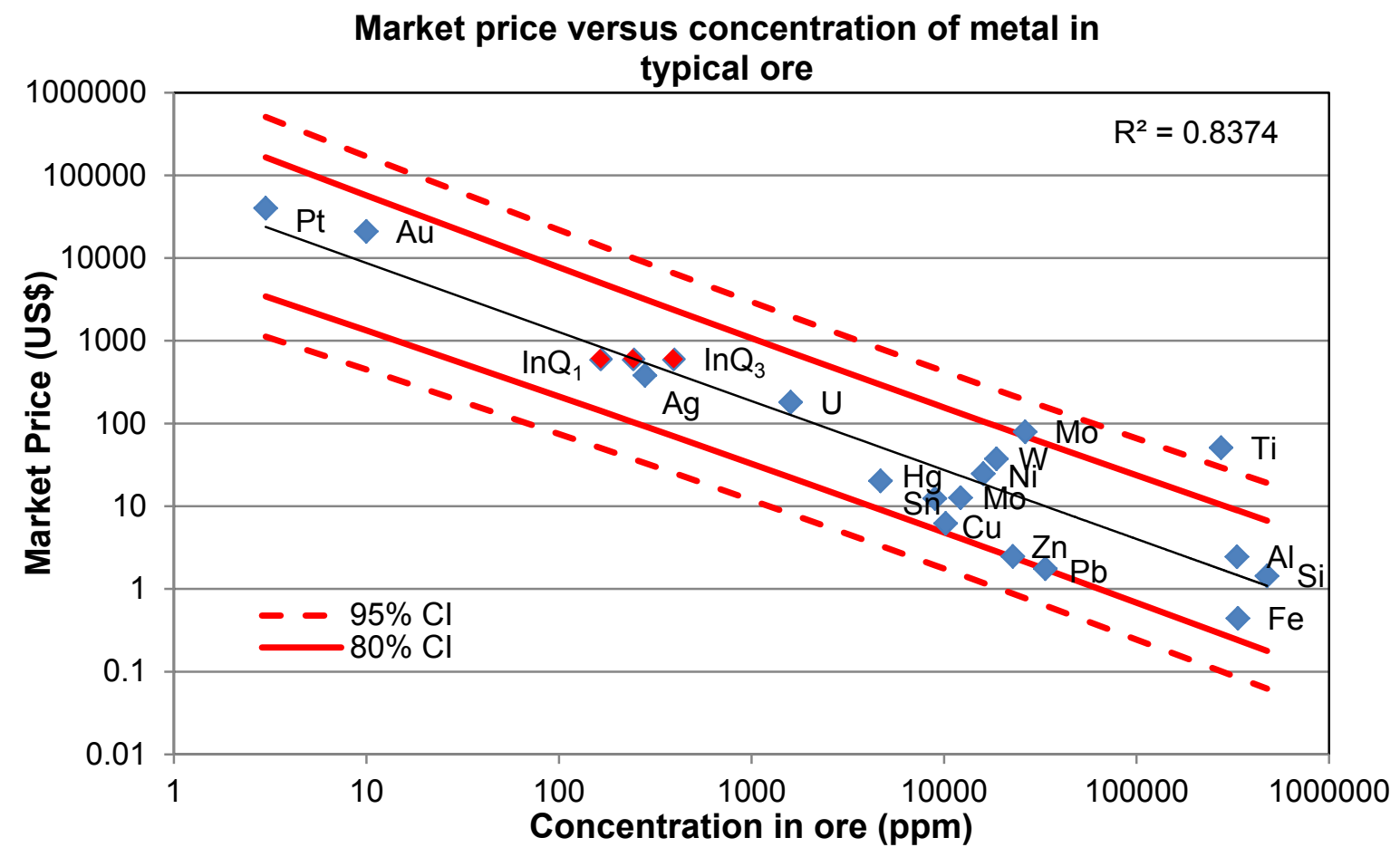

Figure 26. Market price versus concentration of metal in typical ore, including confidence intervals from linear regression results

\footnotetext{
${ }^{1} 95 \%$ and $80 \%$ confidence intervals for the in-sample forecasts are represented by dashed and solid red lines, respectively.

${ }^{2}$ Regression statistics: Multiple R 0.915, R²: 0.837; Adj. R²0.828; SE 0.553; N: 20.

${ }^{3}$ Regression equation: $\log ($ price $)=4.776-0.834 * \log ($ concentration $)$ t-stat (13.89) (-9.62) s.e $(0.344)(0.0867)$.
} 
As indicated by the wide range of possible values contained within the confidence intervals, this analysis is a very crude approximation of indium's long-term price. Although additional data or different techniques may help to reduce the variation in the estimates, these would not address some of the underlying weaknesses with this approach. For example, although the plots in Figure 26 and Figure 27 can be intuitively appealing, the methodology ignores specific features of minerals that complicate such a broad-brush comparison:

- Various minerals and types of ore bodies are associated with varying degrees of metallurgical complexity. This complexity directly affects costs and yields, which in turn affect historical supply and prices.

- Various types of deposits are found in various types of mines The depth and geometry of these deposits can affect mining-specific costs and recoveries or add dilution. External dilution tends to not be reported in company resource estimates and would therefore potentially bias the ore concentration calculation.

- Many deposits contain more than one mineral. A mineral's association with other metals (i.e., whether it is a main product, coproduct, or byproduct) and its overall contribution to a mine's profitability will directly affect the level of costs and therefore the price required to recover that mineral.

Despite these shortcomings, these estimates provide an important starting point for assessing the long-term supply of indium. Further work is needed to estimate the quantities of indium likely contained in deposits of different concentrations, mineralogies, and geographic locations. 


\section{References}

5NPlus. (2011). "Short form prospectus - New Issue: 13,590,000 Subscription Receipts, each representing the right to receive one common share." Available at www.sedar.com.

Adex. (2012a). "Adex reports updated mineral resource estimate for North Zone at Mount Pleasant." Adex Mining Incorporated. Accessed on March 31, 2012: www.adexmining.com/fileupload/pdf/2012-03-

01 Adex reports updated mineral resource estimate at NZ.pdf.

Adex. (2012b). "Mount Pleasant property overview.” Adex Mining Incorporated. Accessed on April 27, 2012: www.adexmining.com/overview.php.

Alfantazi, A.M.; Moskalyk, R.R. (2003). "Processing of Indium: a Review." Minerals Engineering 16 (8); pp. 687-694.

Anderson, R.W.; Gilbert, C.L. (1988). “Commodity Agreements and Commodity Markets: Lessons From Tin.” The Economic Journal 98 (389); pp. 1-15.

Argentex Mining. (2009). “Argentex Receives First Mineral Resource Estimate for Pinguino; Recommendation for Preliminary Economic Assessment (PEA) and New Exploration Program." Accessed on March 3,1

2012: www.argentexmining.com/s/NewsReleases.asp?ReportID=451856.

Argentex Mining. (2012). "Advancing the silver/gold Pinguino project in Santa Cruz Province, Argentina." Argentex Mining Corporate Presentation. Accessed on March 31, 2012: www.argentexmining.com/i/pdf/March-2012-Argentex-Presentation.pdf.

Armitage, A.; Desautels, P.; Zurowski, G.; Pennstrom, W.; Malbran, F.; Fitch, R. (2011). Preliminary Economic Assessment Update Technical Report for the Malku Khota Project Department of Potosi, Bolivia. Preliminary Economic Assessment Update. Toronto, Canada: Prepared on behalf of South American Silver Corp., www.soamsilver.com/upload/Technical_Reports/110511_MK_PEA_Update_SEDAR.pdf

Barbalace, K. (1995a.) "Periodic Table of Elements - Indium - In." EnvironmentalChemistry.com. http://EnvironmentalChemistry.com/yogi/periodic/In.html.

Board, W.S.; Kennedy, R.B.; Yeomans, T.J. (2011). NI 43-101 Technical Report on the Pirquitas Mine, Jujuy Province, Argentina. Technical Report. Vancouver, Canada: Silver Standard Resources Inc., www.silverstandard.com/_resources/Pirquitas Technical Report Dec 23 FINAL_v2.pdf.

Brown, R.D. (1996). "Indium.” Minerals Yearbook, USGS. Accessed on June 7, 2012: http://minerals.usgs.gov/minerals/pubs/commodity/indium/490496.pdf. 
Buchert, M.; Manhart, A.; Bleher, D.; Pingel, D. (2012). Recycling critical raw materials from waste electronic equipment. Darmstadt, Germany: Oeko-Institute V, www.oeko.de/oekodoc/1375/2012-010-en.pdf.

Carlin, J.F. (2008). “Tin.” Mineral Commodity Summary, USGS. Accessed on March 31, 2012: http://minerals.usgs.gov/minerals/pubs/commodity/tin/mcs-2008-tin.pdf.

Carlin, J.F. (2010). “Tin.” Mineral Commodity Summary, USGS. Accessed on March 31, 2012: http://minerals.usgs.gov/minerals/pubs/commodity/tin/mcs-2010-tin.pdf.

Carlin, J.F. (2012). “Tin.” Mineral Commodity Summary, USGS. Accessed on March 31, 2012: http://minerals.usgs.gov/minerals/pubs/commodity/tin/mcs-2012-tin.pdf.

Dahmus, J.B.; Gutowski, T.G. (2007). "What Gets Recycled: An Information Theory Based Model for Product Recycling.” Environ Sci Technol 41 (21); pp. 7543-7550.

De Souza, A.D. (2010). "Process for producing pure metallic indium from zinc oxide and/or solution containing the metal." United States Patent Application Publication, US 2010/0167077 A1, 01-July-2010. Accessed on April 27, 2012: www.google.com/patents/US20100167077.

Denina, C. (2012). "MB MINOR METALS CONFERENCE - Indium to compete with gold on investment qualities - SMG Indium Resources.” Fast Markets

Ltd., http://minormetals.com/scoop/?id=36382\&v=0\&lang=en\&cid=152925\&type=1.

Doe Run Peru. (2012). "Doe Run Peru: The Company." Corporate Web site, Doe Run Peru, www.doerun.com.pe/content/pagina.php?pID=153.

Edelstein, D.L. (2008). "Mineral Commodity Summary: Copper.” USGS, Mineral Commodity Summaries. USGS, http://minerals.usgs.gov/minerals/pubs/commodity/copper/mcs-2008coppe.pdf.

Edelstein, D.L. (2010). “Mineral Commodity Summary: Copper.” USGS, Mineral Commodity Summaries. USGS, http://minerals.usgs.gov/minerals/pubs/commodity/copper/mcs-2010coppe.pdf.

Edelstein, D.L. (2012.) “Mineral Commodity Summary: Copper.” USGS, Mineral Commodity Summaries. USGS, http://minerals.usgs.gov/minerals/pubs/commodity/copper/mcs-2012coppe.pdf.

EU. (2010a). Annex $V$ to the Report of the Ad-hoc Working Group on defining critical raw materials. European Commission, http://ec.europa.eu/enterprise/policies/rawmaterials/files/docs/annex-v-b en.pdf.

EU. (2010b). Report of the Ad-hoc Working Group on defining critical raw materials. European Commission, http://ec.europa.eu/enterprise/policies/raw-materials/files/docs/report-b_en.pdf. 
Fraser, C. (2012). "Expropriation: A Growing Threat to the Mining Industry?" Resource Investing News, http://resourceinvestingnews.com/41354-expropriation-mining-industry-southamerican-silver-bolivia-venezuela-rusoro-first-quantum.html.

Fthenakis, V.M.; Kim H.C.; Wang W. (2007). Life Cycle Inventory Analysis in the Production of Metals Used in Photovoltaics. BNL-77919-2007 Formal Report.

www.bnl.gov/isd/documents/35413.pdf

Geology.com. (2013). Geological Terms Beginning With "L". Retrieved August 2013, from Geology.com: http:/geology.com/dictionary/glossary-l.shtml

Gibson, C.; Hayes, T. (2011). "Indium and gallium overview." Sector Report, Edison Investment Research. Accessed on March 19,

2012: www.edisoninvestmentresearch.co.uk/sectorreports/IndiumGalliumOverview071011.pdf.

Gray, J.H.; Morris, R.J.; Bird, S.B. (2011). Pinguino Property Preliminary Economic Assessment 2011. Preliminary Economic Assessment. Vancouver, Canada: Moose Mountain Technical Services on behalf of Argentex Mining Corporation. www.argentexmining.com/i/pdf/ATX_PEA_AUG_2011.pdf.

Green, M.A. (2009). "Estimates of Te and In Prices from Direct Mining of Known Ores." Progress in Photovoltaics: Research and Applications 17 (5); pp. 347-359.

Guido, D. (2012). "Pinguino silver-gold epithermal deposit, Deseado Massif, Santa Cruz Province, Argentina - PDAC 2012 Open Session." Argentex Mining Corporate Presentation. Accessed on May 1, 2014: www.argentexmining.com/i/pdf/2012-PDAC-Presentation.pdf.

Han, K.N.; Kondoju, S.; Park, K.; Kang, H. (2002). "Recovery of Indium from Indium/Tin Oxides Scrap by Chemical Precipitation.” Geosystem Eng 5(4); pp.93-98.

Haxel, G.B.; Hedrick, J.B.; Orris, G.J. (2002). "Rare Earth Elements-Critical Resources for High Technology; Supporting Sound Management of Our Mineral Resources." USGS Fact Sheet, http://pubs.usgs.gov/fs/2002/fs087-02/.

Hogg, J.N. (2011). National Instrument 43-101 Technical Report for Celeste Copper

Corporation Dolcoath Resource Estimation South Crofty Mine. Cornwall, UK Technical Report. London, England: Micromine Limited on behalf of Celeste Copper Corporation. ww.sedar.com.

ILO. (2012). "Copper, Lead and Zinc Smelting and Refining." Ed. Jeanne Stellman. Encyclopaedia of Occupational Health and Safety. Geneva, Switzerland: International Labour Office. www.ilo.org/safework/cis/WCMS_113329/lang--en/index.htm.

JORC. (2012). The JORC Code 2012 Edition. Retrieved from Joint Ore Reserve Committee: www.jorc.org/docs/JORC_code_2012.pdf

Metal Bulletin (2012). "China confirms indium export quotas for H1 2013" Metal Bulletin. www.metalbulletin.com/Article/3134974/China-confims-indium-export-quotas-for-H12013.html\#axzz3A6PIvPbD. Accessed August 11, 2014. 
Mikolajczak, C. (2009). “Availability of Indium and Gallium”. Indium Corporation of America, www.commodityintelligence.com/images/2010/jan/11\%20jan/availability of indium and galliumwhite papermikolajczak sept09.pdf.

MOFCOM. (2012). "Ministry of Commerce of the People's Republic of China No. 79 of 2011, published in 2012, indium, molybdenum, tin export quotas to application requirements and reporting procedures." Notice No. 79 of 2011, Issued: 13-January-2012. Accessed April 8, 2012: www.mofcom.gov.cn/aarticle/b/g/201201/20120107927498.html.

Moss, R.L.; Kara, H.; Willis, P.; Kooroshy, J. (2011). Critical Metals in Strategic Energy Technologies Assessing Rare Metals as Supply-Chain Bottlenecks in Low-Carbon Energy Technologies. JRD Scientific and Technical Reports. Netherlands: European Commission Joint Research Centre, http://publications.jrc.ec.europa.eu/repository/handle/111111111/22726.

Ogo, S.; Takeishi, M., 2010 “'Urban mining recycles rare metals in Japan.” The Brunei Times. Accessed April 7, 2012: www.bt.com.bn/science-technology/2010/05/11/urban-mining-recyclesrare-metals-japan.

Phipps, G.; Mikolajczak, C.; Guckes, T. (2007). "Indium and Gallium Supply Sustainability, September 2007 Update.” Paper presented at 22nd EU PV Solar Conference, Milan, Italy, September 4.

Roskill. (2010). Indium: Global industry markets and outlook. $9^{\text {th }}$ ed. London, England: Roskill Information Services.

Schwarz-Schampera, U.; Herzig. P.M. (2002). Indium: Geology, Mineralogy, and Economics. Berlin, Germany: Springer-Verlag. ISBN 3-540-43135-7.

Sharp Electronics (UK). (2012). "Sharp and the environment: recycling technologies". Corporate Web site. Recycling technologies at Sharp Electronics

(UK), www.sharpdirect.co.uk/environment/recycling-technologies/page/recyclingtechnologies/.

Silver Standard. (2012). "Pirquitas Mine”. Corporate Web site. Silver Standard Projects:

Pirquitas Mine, www.silverstandard.com/projects/pirquitas/.

Silver Standard. (2013). "Silver Standard Corporate Presentation" Accessed October 19, 2013: http://files.shareholder.com/downloads/SSRI/2742003884x0x689509/3a298ef4-519642c1-a1f3-01cfb10776a6/SSRI_Corp._Pres.___090613.pdf

SMG Indium. (2010). “About SMG Indium -> Our Strategy.” Accessed March 9, 2012: www.smg-indium.com/Strategy.html.

SMG Indium. (2014). "NMV, Inventory \& Metal Bulletin's Price of 99.99\% Purity Indium." Accessed May 1, 2014: www.smg-indium.com/Docs/SMG_NMV_Current_Price.pdf

South American Silver Corp. (2012). "Malku Khota Property.” South American Silver Corp., www.soamsilver.com/malku-khota.asp. 
South American Silver Corp. (2014). “Arbitration Timeline.” South American Silver Corp., www.soamsilver.com/arbitration-timeline.asp.

Takahashi, K.O.; Sasaki, A.; Dodbiba, G.; Sadaki, J.; Sato, N., Fujita, T. (2009) "Recovering Indium from the Liquid Crystal Display of Discarded Cellular Phones by Means of ChlorideInduced Vaporization at Relatively Low Temperature" Metallurgical and Materials Transactions 40; pp.891-900

Thibault, J.; Dean, T.R.; McKeen, S.M.; Scott, T.B.; Hara, A. (2010). NI 43-101 Independent Technical Report: Mount Pleasant North Zone. Preliminary Economic Assessment. Toronto, Canada: Thibault \& Associates Inc. on behalf of Adex Mining Inc., www.adexmining.com/financial/pdf/Adex $\% 2043-$ 101\%20Technical $\% 20$ Report $\% 20$ for $\% 20$ NZ\%20Jan. $\% 2025, \% 202010$.pdf.

Tolcin, A.C. (2008a). "Indium.” Mineral Commodity Summary, USGS. Accessed March 23, 2012: http://minerals.usgs.gov/minerals/pubs/commodity/indium/mcs-2008-indiu.pdf .

Tolcin, A.C. (2008b). "Zinc.” Mineral Commodity Summary, USGS. Accessed March 23, 2012: http://minerals.usgs.gov/minerals/pubs/commodity/zinc/mcs-2008-zinc.pdf.

Tolcin, A.C. (2009a). "Indium.” Mineral Commodity Summary, USGS. Accessed March 23, 2012: http://minerals.usgs.gov/minerals/pubs/commodity/indium/mcs-2009-indiu.pdf.

Tolcin, A.C. (2009b). “Zinc.” Mineral Commodity Summary, USGS. Accessed March 23, 2012: http://minerals.usgs.gov/minerals/pubs/commodity/zinc/mcs-2009-zinc.pdf.

Tolcin, A.C. (2010a). "Indium.” Mineral Commodity Summary, USGS. Accessed March 23, 2012: http://minerals.usgs.gov/minerals/pubs/commodity/indium/mcs-2010-indiu.pdf

Tolcin, A.C. (2010b). “Zinc.” Mineral Commodity Summary, USGS. Accessed March 23, 2012: http://minerals.usgs.gov/minerals/pubs/commodity/zinc/mcs-2010-zinc.pdf.

Tolcin, A.C. (2011a). "Indium.” Mineral Commodity Summary, USGS. Accessed March 23, 2012: http://minerals.usgs.gov/minerals/pubs/commodity/indium/mcs-2011-indiu.pdf.

Tolcin, A.C. (2011b). "Zinc.” Mineral Commodity Summary, USGS. Accessed March 23, 2012: http://minerals.usgs.gov/minerals/pubs/commodity/zinc/mcs-2011-zinc.pdf.

Tolcin, A.C. (2012a). "Indium.” Mineral Commodity Summary, USGS. Accessed March 23, 2012: http://minerals.usgs.gov/minerals/pubs/commodity/indium/mcs-2012-indiu.pdf.

Tolcin, A.C. (2012b). "Zinc.” Mineral Commodity Summary, USGS. Accessed March 23, 2012: http://minerals.usgs.gov/minerals/pubs/commodity/zinc/mcs-2012-zinc.pdf.

Tolcin, A.C. (2012b). "Zinc.” Mineral Commodity Summary, USGS. Accessed October 19, 2013: http://minerals.usgs.gov/minerals/pubs/commodity/zinc/mcs-2013-zinc.pdf 
Tolcin, A.C. (2014a). “Indium.” Mineral Commodity Summary, USGS. Accessed May 1, 2014: http://minerals.usgs.gov/minerals/pubs/commodity/indium/mcs-2014-indiu.pdf.

Tolcin, A.C. (2014b). “Zinc.” Mineral Commodity Summary, USGS. Accessed May 1, 2014: http://minerals.usgs.gov/minerals/pubs/commodity/zinc/mcs-2014-zinc.pdf.

Trelawny. P.; Pearce, P. (2009). “Canadian Minerals Yearbook - 2009.” Natural Resources Canada. Accessed March 31, 2012: www.nrcan.gc.ca/minerals-metals/business-market/canadianminerals-yearbook/4033.

Van den Broeck, K. (2010). "Exploring the challenges in closing the loop for special metals." Presentation presented at the Metal Pages International Minor Metals Conference, October 19, Xiamen, www.preciousmetals.umicore.com/PMR/Media/specialMetals/show_exploringTheChal lenges.pdf.

Willis, P; Chapman, A.; Fryer, A.; (2012) "Study of By-products of Copper, Lead, Zinc, and Nickel" A reported prepared by Oakdene Hollins for International Lead Zinc Study Group, International Nickel Study Group, and International Copper Study Group.

White, P. (2012). "Review of the current lead and zinc situation and outlook for 2012." Presentation April 25, Lisbon, Portugal, www.ilzsg.org/generic/pages/file.aspx?file id $=1171 \&$ field name $=$ document $\% 20$ aa fil e id 0 .

Woodhouse, M.; Goodrich, A.; Margolis, R.; James, T.; Lokanc, M.; Eggert, R. (2012). "SupplyChain Dynamics of Tellurium, Indium, and Gallium Within the Context of PV Module Manufacturing Costs." IEEE Journal of Photovoltaics 3(2); pp. 833-837.

World Bank. 2012. "World Bank Commodity Price Data (Pink Sheet)". The World Bank Group. http://siteresources.worldbank.org/INTPROSPECTS/Resources/3349341304428586133/PINK DATA.xlsx.

Wright, P. (1996). Mineral and Metal Commodity Reviews: Tin. Retrieved from Library and Archives

Canada: www.collectionscanada.gc.ca/webarchives/20061104000927/www.nrcan.gc.ca/mms/cm $\mathrm{y} /$ content/1996/61.pdf

Yi, Zhuge (2013). "China export quotas allocated, players care about qualification" MetalPages. https://www.metal-pages.com/news/story/71985/china-h2-indium-export-quotasallocated-players-care-about-qualification/ Accessed August 11, 2014. 


\section{Appendix A: Zinc, Copper, and Tin Reserves and Production Estimates}

Table 21. Estimated Zinc and Indium Reserves

\begin{tabular}{|c|c|c|c|c|c|c|c|c|}
\hline & \multicolumn{5}{|c|}{$\begin{array}{l}\text { Zinc Reserves } \\
\text { ('000s tonnes) }^{\mathrm{a}, \mathrm{d}}\end{array}$} & \multicolumn{3}{|c|}{ Indium Reserves } \\
\hline & 2007 & 2008 & 2009 & 2010 & 2011 & 2012 & $2007^{b}$ & $2012^{c}$ \\
\hline Australia & 42,000 & 42,000 & 21,000 & 56,000 & 56,000 & 70,000 & N/A & $\mathrm{N} / \mathrm{A}$ \\
\hline Bolivia & $N / A$ & $N / A$ & $N / A$ & 5,000 & 5,000 & 6,000 & $\mathrm{~N} / \mathrm{A}$ & $N / A$ \\
\hline Canada & 6,000 & 5,000 & 8,000 & 4,200 & 4,200 & 7,800 & 150 & 230 \\
\hline China & 33,000 & 33,000 & 33,000 & 43,000 & 43,000 & 43,000 & 8,000 & 10,400 \\
\hline India & $\mathrm{N} / \mathrm{A}$ & $N / A$ & 10,000 & 12,000 & 12,000 & 12,000 & $N / A$ & $N / A$ \\
\hline Ireland & N/A & N/A & 2,000 & 1,800 & 1,800 & 1,300 & $\mathrm{~N} / \mathrm{A}$ & $\mathrm{N} / \mathrm{A}$ \\
\hline Kazakhstan & 14,000 & 14,000 & 17,000 & 12,000 & 12,000 & 10,000 & $\mathrm{~N} / \mathrm{A}$ & $\mathrm{N} / \mathrm{A}$ \\
\hline Mexico & 7,000 & 7,000 & 14,000 & 17,000 & 17,000 & 16,000 & $\mathrm{~N} / \mathrm{A}$ & $\mathrm{N} / \mathrm{A}$ \\
\hline Peru & 18,000 & 18,000 & 19,000 & 19,000 & 19,000 & 18,000 & 360 & 360 \\
\hline Russia & $\mathrm{N} / \mathrm{A}$ & $\mathrm{N} / \mathrm{A}$ & $\mathrm{N} / \mathrm{A}$ & $\mathrm{N} / \mathrm{A}$ & $\mathrm{N} / \mathrm{A}$ & $\mathrm{N} / \mathrm{A}$ & 80 & 80 \\
\hline $\begin{array}{l}\text { United } \\
\text { States }\end{array}$ & 14,000 & 14,000 & 14,000 & 12,000 & 12,000 & 11,000 & 280 & 220 \\
\hline Other & 49,000 & 49,000 & 62,000 & 68,000 & 68,000 & 55,000 & 1,800 & 3,700 \\
\hline Total & 182,000 & 182,000 & 200,000 & 250,000 & 250,000 & 250,000 & 11,000 & 15,000 \\
\hline \multicolumn{9}{|c|}{ Zn reserves growth } \\
\hline \multicolumn{2}{|c|}{ Annualized growth } & $-0.5 \%$ & $7.8 \%$ & $27.4 \%$ & $0.0 \%$ & $0.0 \%$ & & \\
\hline \multicolumn{2}{|c|}{ CAGR (2007 - \#) } & $-0.5 \%$ & $3.5 \%$ & $11.0 \%$ & $8.1 \%$ & $6.4 \%$ & & \\
\hline
\end{tabular}

${ }^{\text {a }}$ Estimates of zinc content of zinc concentrate and direct shipping ore.

${ }^{\mathrm{b}}$ USGS estimates of indium content of zinc ores (from Tolcin 2008a; Roskill 2010).

${ }^{\mathrm{c}}$ Indicative estimate only. Indium reserves in 2012 are based on a pro rata increase in zinc reserves since 2007 where reserves data are available. "Other" countries used as a balancing figure.

${ }^{\mathrm{d}}$ Estimated zinc resources in 2012 are approximately 1.9 billion tonnes.

Sources: Own estimates; Tolcin 2008b, 2009b, 2010b, 2011b, 2012b, and 2013; Trelway and Pearce 2009 
Table 22. Global Estimates of Zinc Mine Production From 2007 to 2011

\begin{tabular}{|c|c|c|c|c|c|}
\hline & \multicolumn{5}{|c|}{$\begin{array}{c}\text { Zinc Mine Production } \\
(' 000 \text { s tonnes)* }\end{array}$} \\
\hline & 2007 & 2008 & 2009 & 2010 & 2011 \\
\hline Australia & 1,520 & 1,510 & 1,290 & 1,480 & 1,400 \\
\hline Bolivia & $\mathrm{N} / \mathrm{A}$ & N/A & 422 & 411 & 430 \\
\hline Canada & 620 & 660 & 699 & 649 & 660 \\
\hline China & 2,900 & 3,200 & 3,100 & 3,700 & 3,900 \\
\hline India & $\mathrm{N} / \mathrm{A}$ & $\mathrm{N} / \mathrm{A}$ & 695 & 700 & 760 \\
\hline Ireland & $\mathrm{N} / \mathrm{A}$ & $\mathrm{N} / \mathrm{A}$ & 386 & 342 & 350 \\
\hline Kazakhstan & 390 & 420 & 480 & 500 & 500 \\
\hline Mexico & 430 & 460 & 390 & 518 & 630 \\
\hline Peru & 1,440 & 1,450 & 1,510 & 1,470 & 1,400 \\
\hline United States & 803 & 770 & 736 & 745 & 760 \\
\hline Other & 2,800 & 2,840 & 1,490 & 1,490 & 1,600 \\
\hline Total & 10,900 & 11,300 & 11,200 & 12,000 & 12,400 \\
\hline \multicolumn{6}{|c|}{ Zinc Production Growth } \\
\hline Annualized growth & & $3.7 \%$ & $-0.9 \%$ & $7.1 \%$ & $3.3 \%$ \\
\hline CAGR (2007 - \#) & & $3.7 \%$ & $1.4 \%$ & $3.3 \%$ & $3.3 \%$ \\
\hline CAGR (2009 - \#) & & & & $7.1 \%$ & $5.2 \%$ \\
\hline
\end{tabular}

* Estimated zinc content of concentrates and shipping ores.

Sources: Own calculations; Tolcin, 2009b, 2012b, and 2011b 
Table 23. Global Estimates of Copper Mine Production and Reserves From 2007 to 2011

\begin{tabular}{|c|c|c|c|c|c|c|c|c|}
\hline & \multicolumn{5}{|c|}{$\begin{array}{l}\text { Mine Production } \\
\text { ('000s tonnes) }^{*}\end{array}$} & \multicolumn{3}{|c|}{$\begin{array}{c}\text { Reserves } \\
\text { ('000s tonnes) }\end{array}$} \\
\hline & 2007 & 2008 & 2009 & 2010 & 2011 & 2007 & 2009 & 2011 \\
\hline Australia & 860 & 886 & 900 & 870 & 940 & 24,000 & 24,000 & 86,000 \\
\hline Canada & 585 & 607 & 520 & 525 & 550 & 9,000 & 8,000 & 7,000 \\
\hline Chile & 5,700 & 5,330 & 5,320 & 5,420 & 5,420 & 150,000 & 160,000 & 190,000 \\
\hline China & 920 & 950 & 960 & 1,190 & 1,190 & 26,000 & 30,000 & 30,000 \\
\hline Congo (Kinshasa) & $\mathrm{N} / \mathrm{A}$ & $\mathrm{N} / \mathrm{A}$ & $\mathrm{N} / \mathrm{A}$ & 343 & 440 & $\mathrm{~N} / \mathrm{A}$ & $\mathrm{N} / \mathrm{A}$ & 20,000 \\
\hline Indonesia & 780 & 651 & 950 & 872 & 625 & 35,000 & 31,000 & 28,000 \\
\hline Kazakhstan & 460 & 420 & 410 & 380 & 360 & 14,000 & 18,000 & 7,000 \\
\hline Mexico & 400 & 247 & 250 & 260 & 365 & 30,000 & 38,000 & 38,000 \\
\hline Peru & 1,200 & 1,270 & 1,260 & 1,250 & 1,220 & 30,000 & 63,000 & 90,000 \\
\hline Poland & 470 & 430 & 440 & 425 & 425 & 30,000 & 26,000 & 26,000 \\
\hline Russia & 730 & 750 & 750 & 703 & 710 & 20,000 & 20,000 & 30,000 \\
\hline United States & 1,190 & 1,310 & 1,190 & 1,110 & 1,120 & 35,000 & 35,000 & 35,000 \\
\hline Zambia & 530 & 546 & 655 & 690 & 715 & 19,000 & 19,000 & 20,000 \\
\hline Other & 1,800 & 2,030 & 2,180 & 1,900 & 2,000 & 65,000 & 70,000 & 80,000 \\
\hline Total & 15,600 & 15,400 & 15,800 & 15,900 & 16,100 & 490,000 & 540,000 & 690,000 \\
\hline \multicolumn{9}{|c|}{ Copper Production Growth } \\
\hline Annualized growth & & $-1.3 \%$ & $2.6 \%$ & $0.6 \%$ & $1.3 \%$ & & $10.2 \%$ & $27.8 \%$ \\
\hline CAGR (2007 - \#) & & $-1.3 \%$ & $0.6 \%$ & $0.6 \%$ & $0.8 \%$ & & $5.0 \%$ & $8.9 \%$ \\
\hline CAGR (2009 - \#) & & & & $0.6 \%$ & $0.9 \%$ & & & $13.0 \%$ \\
\hline
\end{tabular}

* Estimates copper content of concentrates and shipping ores.

Sources: USGS (Edelstein 2008, 2010, and 2012) 
Table 24. Global Estimates of Tin Mine Production and Reserves From 2007 to 2011

\begin{tabular}{|c|c|c|c|c|c|c|c|c|}
\hline & \multicolumn{5}{|c|}{$\begin{array}{l}\text { Tin Mine Production } \\
\text { ('000s tonnes) }\end{array}$} & \multicolumn{3}{|c|}{$\begin{array}{l}\text { Tin Reserves } \\
\text { ('000s tonnes) }\end{array}$} \\
\hline & 2007 & 2008 & 2009 & 2010 & 2011 & 2007 & 2009 & 2011 \\
\hline Australia & 2,200 & 1,800 & 2,000 & 7,000 & 8,000 & 150,000 & 150,000 & 180,000 \\
\hline Bolivia & 18,000 & 17,000 & 16,000 & 20,200 & 20,700 & 450,000 & 450,000 & 400,000 \\
\hline Brazil & 12,000 & 12,000 & 12,000 & 11,000 & 12,000 & 540,000 & 540,000 & 590,000 \\
\hline China & 130,000 & 110,000 & 115,000 & 120,000 & 110,000 & $1,700,000$ & $1,700,000$ & $1,500,000$ \\
\hline Congo (Kinshasa) & 3,000 & 12,000 & 12,000 & 6,700 & 5,700 & $\mathrm{~N} / \mathrm{A}$ & $\mathrm{N} / \mathrm{A}$ & $\mathrm{N} / \mathrm{A}$ \\
\hline Indonesia & 85,000 & 96,000 & 100,000 & 56,000 & 51,000 & 800,000 & 800,000 & 800,000 \\
\hline Malaysia & 3,000 & 2,200 & 2,000 & 1,770 & 2,000 & $1,000,000$ & 500,000 & 250,000 \\
\hline Peru & 38,000 & 39,000 & 38,000 & 33,800 & 34,600 & 710,000 & 710,000 & 310,000 \\
\hline Portugal & 200 & 100 & 100 & 30 & 100 & 70,000 & 70,000 & 70,000 \\
\hline Russia & 4,000 & 1,500 & 2,000 & 1,100 & 1,000 & 300,000 & 300,000 & 350,000 \\
\hline Thaliand & 200 & 100 & 100 & 150 & 100 & 170,000 & 170,000 & 170,000 \\
\hline Vietnam & 3,500 & 3,500 & 3,500 & 5,500 & 6,000 & $\mathrm{~N} / \mathrm{A}$ & $\mathrm{N} / \mathrm{A}$ & $\mathrm{N} / \mathrm{A}$ \\
\hline Other & 4,000 & 4,000 & 4,000 & 2,000 & 2,000 & 180,000 & 180,000 & 180,000 \\
\hline Total & 300,000 & 299,000 & 307,000 & 265,000 & 253,000 & $6,100,000$ & $5,600,000$ & $4,800,000$ \\
\hline \multicolumn{9}{|c|}{ Tin Production Growth } \\
\hline Annualized growth & & $-0.3 \%$ & $2.7 \%$ & $-13.7 \%$ & $-4.5 \%$ & & & \\
\hline CAGR (2007 - \#) & & $-0.3 \%$ & $1.2 \%$ & $-4.1 \%$ & $-4.2 \%$ & & & \\
\hline CAGR (2009 - \#) & & & & $-13.7 \%$ & $-9.2 \%$ & & & \\
\hline
\end{tabular}

Sources: Carlin 2008, 2010, and 2012 


\section{Appendix B: Secondary Production}

Table 25. Overall Recovery Efficiency of Indium Use in a Hypothetical ITO Sputtering Application With Closed Loop Recycling of Manufacturing Waste Where Total Measured Indium Recycled Is $\sim 608.5$ Tonnes

\begin{tabular}{|c|c|c|c|c|c|c|c|c|c|c|c|}
\hline \multicolumn{12}{|c|}{ Indium Secondary Production Loop } \\
\hline Cycle & 1 & 2 & 3 & 4 & 5 & 6 & 7 & 8 & 9 & 10 & Total \\
\hline Units available for ITO & $729^{c}$ & 332 & 151 & 69 & 31 & 14 & 6 & 3 & 1 & 1 & $1,337^{\mathrm{d}}$ \\
\hline $\begin{array}{l}\text { Units successfully } \\
\text { deposited }^{\mathrm{a}}\end{array}$ & $219^{c}$ & 99 & 45 & 21 & 9 & 4 & 2 & 1 & 0 & 0 & $401^{e}$ \\
\hline $\begin{array}{l}\text { Units available for } \\
\text { recycling }^{a}\end{array}$ & 510 & 232 & 106 & 48 & 22 & 10 & 5 & 2 & 1 & 0 & $936^{f}$ \\
\hline $\begin{array}{l}\text { Units successfully } \\
\text { recycled }^{\mathrm{b}}\end{array}$ & 332 & 151 & 69 & 31 & 14 & 6 & 3 & 1 & 1 & 0 & $609^{9}$ \\
\hline Units forever lost & 179 & 81 & 37 & 17 & 8 & 3 & 2 & 1 & 0 & 0 & $328^{h}$ \\
\hline$\%$ of indium deposited & & $55 \%$ & & & & & & & & & \\
\hline$\%$ of indium wasted & & $45 \%$ & & & & & & & & & \\
\hline
\end{tabular}

${ }^{a}$ Deposition success rate assumed to be $30 \%$; therefore, $70 \%$ of indium is available for recycling. We assume that if indium is not successfully deposited upon application of ITO, it is available for recycling. In other words, there are no

"losses" at the manufacturing stage--only at the recycling stage.

${ }^{\mathrm{b}}$ Indium recycling efficiency estimated to be $65 \%$ per recycling cycle.

${ }^{\mathrm{c}}$ Primary indium. All other figures relate to indium that is either entering recycling or has been recycled.

${ }^{\mathrm{d}}$ If 729 tonnes of primary indium become used in ITO applications with recycling, the ITO applications will appear to have consumed 729 tonnes (primary) +609 tonnes (secondary) indium. The figure of 1,337 units of indium is likely the figure of indium demand reported by manufacturers.

${ }^{\mathrm{e}}$ Of the original 729 tonnes of primary indium entering the manufacturing process, 401 tonnes (55\%) is effectively deposited when factoring in that spent ITO targets and other manufacturing wastes are recycled.

${ }^{\mathrm{f}}$ Out of every 729 tonnes of primary indium used in ITO applications, 936 tonnes might appear to be entering the recycling plant, because the same indium may enter the plant more than once per period.

${ }^{\mathrm{g}}$ Out of every 729 tonnes of primary indium used in ITO applications, 510 tonnes actually enters the recycling plant. Because the 510 tonnes enters more than once, the plant appears to produce 609 tonnes of refined indium over 10 cycles. This figure of 609 tonnes is most likely representative of recycling plant throughput as measured by producers.

${ }^{\mathrm{h}}$ Of the 729 tonnes of primary indium entering the manufacturing process, 328 tonnes (45\%) is forever lost. This is due to a combination of (1) deposition efficiency, which drives the number of times the same indium must be recycled; and (2) recycling efficiency.

Sources: Own calculations; Mikolajczak 2009 


\section{Appendix C. Metal Prices}

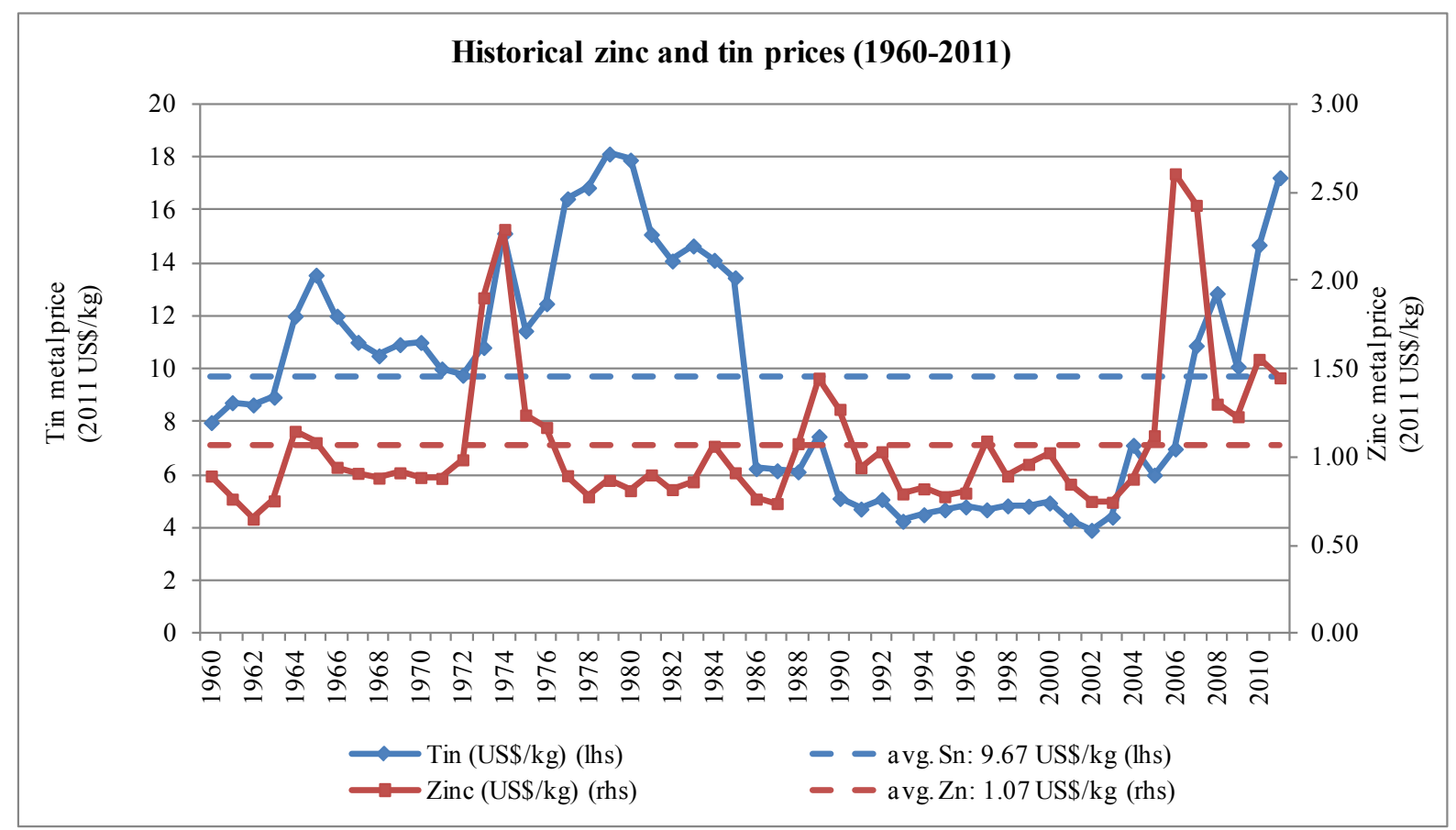

Figure 27. Historical zinc and tin prices in 2011 USD as indicated

${ }^{1}$ In 2011 USD terms, since 1960 zinc averaged $\$ 1.07 / \mathrm{kg}$ with a high of and minimum price of $\$ 0.65 / \mathrm{kg}$ in 1962 and a maximum of $\$ 2.61 / \mathrm{kg}$ in 2006 . Over the same period, the tin price has averaged $\$ 9.67 / \mathrm{kg}$, reaching a minimum of $\$ 3.92 / \mathrm{kg}$ in 2002 and a maximum of $\$ 18.13$ in 1979.

${ }^{2}$ Tin price surged in the early 1980 s and its subsequent collapse may have been due to market manipulation (Anderson and Gilbert 1988).

${ }^{3}$ Metal prices from the World Bank were adjusted to 2011 USD using the Manufactures Unit Value Index, a proxy for the price of developing country imports of manufactures in USD. The index is a weighted average of export prices of manufactured goods for the G-5 economies, with local currency-based prices converted into current USD using market exchange rates.

${ }^{4}$ Derived from World Bank (2012). 


\section{Appendix D: Methodology Used To Derive the Short- and Medium-Term Supply Curves}

Primary indium production is largely the result of byproduct production from sphalerite (zinc) ores. As such, it is not significant to most indium-producing mining companies, and the value chain from mining to refined metal often involves several companies with few companies spanning the entire value chain. Furthermore, with total global primary production valued at approximately $\$ 493$ million, ${ }^{41}$ indium recovery is likely not of key economic importance for many smelters or special metal refineries. As a result, data surrounding the explicit incremental costs to recover indium are not publically available and, because costs are intermingled between main product, coproduct, and byproduct metals, miners and smelters probably do not explicitly track the costs of indium internally.

As is often the case with mineral properties, technical reports filed by midsized and junior mining companies with the securities exchanges as part of their disclosure requirements contain the best and most detailed information available. ${ }^{42}$ This information can then be used together with various resource characteristics, recovery efficiencies, costs of capital, etc. to generate a representative view of costs and production levels for various deposits. We adopt this approach when examining what a supply curve for indium might currently look like and how this might change going forward. We use a Monte Carlo simulation to generate short- and medium-term supplies. As will subsequently be discussed in greater detail, we use data from the following sources to build the supply curves:

- A recent preliminary economic assessment of the Mount Pleasant indium-zinc-tin deposit in Canada (Thibault et al. 2010)

- A catalogue of known indium-bearing deposits (Schwarz-Schampera and Herzig 2002)

- Historical (long run) commodity prices for tin and zinc

- Growth of main product zinc production and therefore extrapolated byproduct indium production

- Estimates of medium-term potential recovery efficiencies at new facilities (Thibault et al. 2010).

The steps taken to generate the results differ slightly between generating the short- and mediumterm supply curves. In the short term, the indium need only cover its share of direct operating costs; in the medium to long term, the indium needs to cover operating and capital costs and generate a fair return to capital. We now look at each of these approaches in detail.

\section{The Short Term}

Focusing first on the short run, the operating cost estimate for the Mount Pleasant deposit is examined in detail (Thibault et al. 2010). The preliminary assessment for Mount Pleasant

\footnotetext{
${ }^{41}$ Assuming 822 tpa of indium metal $\times 1000 \mathrm{~kg} /$ tonne $\times \$ 600 / \mathrm{kg}$ indium metal.

${ }^{42}$ Large mining companies are often not required to disclose detailed technical information about development projects or ongoing operations, because the performance of a single operation is not essential to the overall value of the company.
} 
contains three production cases labeled "A," "B," and "C," all of which assume that same mine and plant head feed capacity but vary the degree to which the zinc, tin, and indium are refined.

In case " $A$ " the design accommodates the recovery of a tin concentrate as well as a combined indium and zinc concentrate. These concentrates are then shipped to third-party smelters for further processing. Case " $B$ " includes the concentrator plant from case " $A$ " to recover a tin concentrate that is shipped to third-party smelters; however, the treatment plant is expanded and includes a hydrometallurgical plant for production of indium sponge of $95 \%$ purity and zinc metal. Indium sponge is then pressed into briquettes and shipped to a third-party refinery for upgrading to 4N8 purity. The zinc metal is sold directly to the market. Case " $\mathrm{C}$ " includes the concentrator/hydrometallurgical plant of Case " $\mathrm{B}$ " indium sponge and zinc metal in addition to a pyrometallurgical plant for production of tin chloride instead of tin concentrate. Various design parameters for the three cases and their respective final products are summarized in Table 26.

Table 26. Mount Pleasant Production and Product Revenue Summary for Production Cases "A" Through "C"

\begin{tabular}{|c|c|c|c|c|c|c|}
\hline Parameter & Units & Tin Conc. $^{a}$ & $\begin{array}{c}\text { Tin } \\
\text { Chloride }\end{array}$ & $\begin{array}{l}\text { Zinc and } \\
\text { Indium } \\
\text { Conc. } \\
\end{array}$ & $\begin{array}{l}\text { Zinc } \\
\text { Metal }\end{array}$ & $\begin{array}{l}\text { Indium } \\
\text { Sponge }\end{array}$ \\
\hline Annual production rate & $\mathrm{DMT}^{\mathrm{a}} / \mathrm{yr}$ & 3231 & 2142 & 8,658 & 4056 & 40.5 \\
\hline Product grade & wt $\%$ & $\begin{array}{l}46.0 \mathrm{wt} \% \\
\text { Tin }\end{array}$ & $\begin{array}{l}99 \% \text {, Tin } \\
\text { Chloride }\end{array}$ & $\begin{array}{l}50 \% \text { Zinc, } \\
0.49 \% \text { Indium }\end{array}$ & $99.50 \%$ & $95 \%$ Indium \\
\hline Market price & $C \$^{\mathrm{b}} / \mathrm{kg}$ & $\begin{array}{l}\$ 16.25 / \mathrm{kg} \\
\text { Tin }\end{array}$ & $\begin{array}{l}\$ 15.23 / \mathrm{k} \\
\text { g } 99 \% \\
\text { Tin } \\
\text { Chloride }\end{array}$ & $\begin{array}{l}\$ 2.70 / \mathrm{kg} \text { Zinc, } \\
\$ 639.67 / \mathrm{kg} \\
\text { Indium }\end{array}$ & $\begin{array}{l}\$ 2.70 / \mathrm{kg} \\
\text { Zinc }\end{array}$ & $\begin{array}{l}\$ 639.67 / \mathrm{kg} \\
\text { Indium (4N) }\end{array}$ \\
\hline $\begin{array}{l}\text { Market price } \\
\text { adjustment }\end{array}$ & $\mathrm{C} \$ / \mathrm{kg}$ & $\mathrm{n} / \mathrm{a}$ & $\mathrm{n} / \mathrm{a}$ & $\mathrm{n} / \mathrm{a}$ & $\mathrm{n} / \mathrm{a}$ & $81.38 \%^{\mathrm{c}}$ \\
\hline $\begin{array}{l}\text { Total treatment } \\
\text { charges }\end{array}$ & $\mathrm{C} \$ / \mathrm{DMT}$ & $\$ 783.37$ & $\$ 0$ & $\$ 390.60$ & $\$ 0$ & $\$ 66,000^{d}$ \\
\hline Total unit deductions & wt $\%$ & $3.70 \%$ Tin & $0 \%$ & $8.00 \%$ (Zinc) & $0 \%$ & $0 \%$ \\
\hline Annual revenue & $\mathrm{C} \$ \mathrm{mn} / \mathrm{yr}$ & $\$ 20$ & $\$ 33$ & $\$ 11$ & $\$ 11$ & $\$ 17$ \\
\hline $\begin{array}{l}\text { Revenue relative to } \\
100 \% \text { market }\end{array}$ & $\%$ & $81.50 \%$ & $100 \%$ & $\begin{array}{l}54.3 \% \text { (Zinc) } \\
15 \% \text { (Indium) }\end{array}$ & $100 \%$ & $71.10 \%$ \\
\hline \multicolumn{2}{|l|}{ Mill characteristics } & \multicolumn{5}{|c|}{850 tpd design capacity, $90 \%$ availability, 279,226 tpa } \\
\hline \multicolumn{2}{|l|}{ Applicable to case A } & $\mathrm{Y}$ & $\mathrm{N}$ & $\mathrm{Y}$ & $\mathrm{N}$ & $\mathrm{N}$ \\
\hline \multicolumn{2}{|l|}{ Applicable to case B } & Y & $\mathrm{N}$ & $\mathrm{N}$ & Y & Y \\
\hline \multicolumn{2}{|c|}{ Applicable to case C } & $\mathrm{N}$ & $\mathrm{Y}$ & $\mathrm{N}$ & $\mathrm{Y}$ & Y \\
\hline \multicolumn{7}{|c|}{${ }^{\mathrm{a}}$ DMT = dry metric tonnes; "conc." = concentrate. } \\
\hline \multicolumn{7}{|c|}{${ }^{\mathrm{b}} \mathrm{C} \$$ refers to Canadian dollars. The conversion used by Thibault et al. (2010) at the time of drafting their report was C\$1.10/US\$. } \\
\hline \multicolumn{7}{|c|}{$\begin{array}{l}{ }^{\mathrm{C}} \text { Market price adjustment factor accounts for loss of indium in refining process to } 4 \mathrm{~N} 8 \text { grade and a price discount for indium sponge relative to the } \\
\text { price for } 4 \mathrm{~N} \text { indium. } \\
\text { d Indium sponge treatment charges are per tonne of } 4 \mathrm{~N}^{*} \text { indium metal recovered after refining losses. } \\
\text { Source: based on Thibault et al. } 2010\end{array}$} \\
\hline
\end{tabular}

To assess the cost of producing indium, we concern ourselves with cases " $\mathrm{A}$ " and "B" only, because the upgrading of tin concentrate to tin chloride is not of interest. In the case of the Mount Pleasant property, 40.5 tpa of indium may be produced as a coproduct along with zinc 
and tin. Indium's contribution is important in determining the feasibility of the project; thus, we allocate certain costs equally across all three coproducts. Therefore, as we progress through allocating costs from the Mount Pleasant deposit, costs that are generally considered to be necessary for the production of all coproducts or are fixed overheads are distributed equally among all metals, while other costs that are directly related to the production of one of the metals (such as marketing, packaging, or special refining) are allocated directly to that metal.

The overall summary effect of this cost allocation is shown in Table 27, where total costs are shown in terms of a Canadian dollar (C\$) per tonne processed and C\$ per tonne of metal or concentrate produced. Mining costs totaling C\$30.03/tonne are shared equally among the metals. Under case "B," processing costs are borne disproportionately by zinc and indium metals. This is because in case "B," these metals are processed to a higher purity than the tin that is produced in concentrate form. Site administration costs are borne principally by the indium metal, and to a lesser degree, by zinc and tin, mainly because incremental differences are associated with going from case "A" to case "B." Similarly, capital costs ${ }^{43}$ are borne disproportionately by zinc and indium because the treatment plant requires increased capital to improve the refined purity of these metals.

Table 27. Summary of Cost Allocation Between Metals at Adex Mining's Mount Pleasant Project

\begin{tabular}{|c|c|c|c|c|c|c|c|}
\hline \multicolumn{8}{|c|}{ Summary } \\
\hline \multicolumn{8}{|c|}{ Mount Pleasant - Adex Mining: Total Operating Cost Allocation Between Metals } \\
\hline & & \multicolumn{3}{|c|}{ Total Cost (A) } & \multicolumn{3}{|c|}{ Total Cost (B) } \\
\hline $\begin{array}{l}\text { Cost per tonne by } \\
\text { activity }\end{array}$ & units & Tin & Zinc & Indium & Tin & Zinc & Indium \\
\hline \multicolumn{8}{|c|}{ Mining and Concentration Cost } \\
\hline Mine operating cost & $\begin{array}{l}\mathrm{C} \$ / \mathrm{t} \\
\text { processed }\end{array}$ & 10.01 & 10.01 & 10.01 & 10.01 & 10.01 & 10.01 \\
\hline $\begin{array}{l}\text { Process operating } \\
\text { cost }\end{array}$ & $\begin{array}{l}\mathrm{C} \$ / \mathrm{t} \\
\text { processed }\end{array}$ & 10.18 & 10.70 & 10.86 & 9.18 & 16.93 & 22.78 \\
\hline $\begin{array}{l}\text { Site administration } \\
\text { operating cost }\end{array}$ & $\begin{array}{l}\mathrm{C} \$ / \mathrm{t} \\
\text { processed }\end{array}$ & 0.58 & 0.61 & 0.62 & 0.58 & 0.85 & 1.84 \\
\hline $\begin{array}{l}\text { Capital cost } \\
\text { allocation }\end{array}$ & $\begin{array}{l}\mathrm{C} \$ / \mathrm{t} \\
\text { processed }\end{array}$ & 6.52 & 6.52 & 6.52 & 6.52 & 13.63 & 13.63 \\
\hline $\begin{array}{l}\text { Subtotal (mining } \\
\text { and concentration) }\end{array}$ & $\begin{array}{l}\mathrm{C} \$ / \mathrm{t} \\
\text { processed }\end{array}$ & 27.29 & 27.83 & 28.00 & 26.28 & 41.42 & 48.26 \\
\hline$\%$ allocation & & $33 \%$ & $33 \%$ & $34 \%$ & $23 \%$ & $36 \%$ & $42 \%$ \\
\hline \multicolumn{8}{|c|}{ Mining and Concentration Cost } \\
\hline Mine operating cost & $\mathrm{C} \$ / \mathrm{kg}^{\mathrm{a}}$ & $\mathrm{n} / \mathrm{a}$ & $\mathrm{n} / \mathrm{a}$ & $\mathrm{n} / \mathrm{a}$ & 0.86 & 0.69 & 72.57 \\
\hline $\begin{array}{l}\text { Process operating } \\
\text { cost }\end{array}$ & $\mathrm{C} \$ / \mathrm{kg}^{\mathrm{a}}$ & $\mathrm{n} / \mathrm{a}$ & $\mathrm{n} / \mathrm{a}$ & $\mathrm{n} / \mathrm{a}$ & 0.79 & 1.17 & 165.19 \\
\hline $\begin{array}{l}\text { Site administration } \\
\text { operating cost }\end{array}$ & $\mathrm{C} \$ / \mathrm{kg}^{\mathrm{a}}$ & $\mathrm{n} / \mathrm{a}$ & $\mathrm{n} / \mathrm{a}$ & $\mathrm{n} / \mathrm{a}$ & 0.05 & 0.06 & 13.35 \\
\hline $\begin{array}{l}\text { Capital cost } \\
\text { allocation }\end{array}$ & $\mathrm{C} \$ / \mathrm{kg}^{\mathrm{a}}$ & $\mathrm{n} / \mathrm{a}$ & $\mathrm{n} / \mathrm{a}$ & $\mathrm{n} / \mathrm{a}$ & 0.56 & 0.94 & 98.88 \\
\hline Subtotal (mining & $\mathrm{C} \$ / \mathrm{kg}^{\mathrm{a}}$ & - & 0.00 & 0.00 & 2.27 & 2.85 & 350.00 \\
\hline
\end{tabular}

\footnotetext{
${ }^{43}$ To convert capital costs to an annualized operating cost, the lump sum capital is treated as an annuity over the life of the Mount Pleasant property--12 years. We adopt the real interest rate of $12 \%$ used by Thibault et al. 2010 in their preliminary economic assessment of the Mount Pleasant property.
} 


\begin{tabular}{llllllll}
\hline and concentration) & \multicolumn{7}{c}{ Refining Cost } \\
\hline $\begin{array}{l}\text { Additional } \\
\text { smelting/refining } \\
\text { charges }\end{array}$ & $\mathrm{C} \$ / \mathrm{kg}^{\mathrm{a}}$ & 0.78 & 0.39 & 0.39 & 0.78 & 0.00 & 66.00 \\
\hline $\begin{array}{l}\text { Subtotal processing } \\
\text { stage }\end{array}$ & $\mathrm{C} \$ / \mathrm{kg}^{\mathrm{a}}$ & 0.78 & 0.39 & 0.39 & 0.78 & 0.00 & 66.00 \\
\hline $\begin{array}{l}\text { Total production } \\
\text { cost }\end{array}$ & $\mathrm{C} \$ / \mathrm{kg}^{\mathrm{a}}$ & $\mathrm{n} / \mathrm{a}$ & $\mathrm{n} / \mathrm{a}$ & $\mathrm{n} / \mathrm{a}$ & 3.06 & 2.85 & 416.00 \\
\hline $\begin{array}{l}\text { Total production } \\
\text { cost }\end{array}$ & $\mathrm{US} \$ / \mathrm{kg}^{\mathrm{a}}$ & $\mathrm{n} / \mathrm{a}$ & $\mathrm{n} / \mathrm{a}$ & $\mathrm{n} / \mathrm{a}$ & 2.78 & 2.59 & 378.18 \\
\hline
\end{tabular}

${ }^{a}$ Case A: Tin Concentrate, Zinc/Indium Concentrate. Case B: Tin Concentrate, Zinc Metal, Indium Sponge Costs in $\$ / \mathrm{kg}$ of refined metal or concentrate corresponding to the particular scenario.

${ }^{\mathrm{b}}$ Exchange rate of C\$1.10/U.S.\$ used in accordance with Thibault et al. (2010).

Source: Thibault et al. (2010)

On the basis of this cost allocation we see that approximately $42 \%$ of the total costs are borne by indium, while the remaining 58\% are shared by zinc and tin. Converting the costs from a $\$ /$ tonne figure to $\$ / \mathrm{kg}$ of metal produced, we see that total on-mine costs for indium amount to $\mathrm{C} \$ 350 / \mathrm{kg}$. Because the mine plans to produce an indium sponge of only $95 \%$ purity, additional refining charges of $\$ 66 / \mathrm{kg}$ are require to upgrade the indium to commercial qualities of $99.998 \%$ (4N8), bringing the total cost to $\mathrm{C} \$ 416.00 / \mathrm{kg}$ of $4 \mathrm{~N} 8$ indium. Converting this cost to U.S. dollars at a rate of C\$1.10/U.S.\$ in accordance with the exchange rate used to compile the cost estimates (Thibault et al. 2010), Mount Pleasant is likely to produce 40.5 tpa of indium at a total unit cost of $\$ 378 / \mathrm{kg}$ of $4 \mathrm{~N} 8$ metal. Once capital is sunk, the deposit would likely continue to produce indium provided that price did not dip below U.S. $\$ 288 / \mathrm{kg}$.

The estimates for Mount Pleasant are preliminary and according to the authors of that study, have an accuracy level of $-10 \%,+35 \%$. (i.e., the costs could be underestimated by $35 \%$ or overestimated by $10 \%$ ). Furthermore, costs in the model are driven by key assumptions about:

- Grades and recoveries of indium. Aside from determining the amount of indium metal recovered, these determine the ultimate contribution of indium and whether it should be treated as a byproduct, coproduct, or main product mineral.

- The percentage of costs that indium should bear depending on whether it's treated as a byproduct, coproduct, or main product. There is an element of subjectivity to this assessment.

- Life of mine and discount rate. Together these determine the capital cost allocated to each year's production.

By varying these input deposits, the Mount Pleasant cost model can be used to simulate global indium production. To ensure the validity of the simulation, we use the following inputs: (1) a representative distribution of indium concentrations at known deposits compiled by SchwarzSchampera and Herzig (2002); (2) ranges of indium recovery at typical at each stage in the recovery process; (3) known ranges for the cost of capital for companies in the extractive industries; (4) typical ranges for the life of many mining operations; and (5) the cost estimate 
accuracy range of $-10 \%,+35 \%$ described by Thibault et al. (2010). These inputs, their ranges, and types of distribution are listed in Table 28.

Table 28. Monte Carlo Simulation Input Distributions for Grade, Recovery, and Costs

\begin{tabular}{|c|c|c|c|c|c|c|c|c|c|}
\hline Name & Graph & Min & Mean & Max & Std Dev & $5 \%$ & $50 \%$ & $95 \%$ & p95-p5 \\
\hline Grade (ppm) & & 0.00 & 33.38 & $+\infty$ & 146.750 & 0.37 & 7.37 & 128.77 & 128.39 \\
\hline \multicolumn{10}{|c|}{ Recovery - Short-Term Base Case } \\
\hline $\begin{array}{l}\text { Recovery (ore } \\
\text { to concentrate, } \\
\% \text { ) }\end{array}$ & & 0.40 & 0.50 & 0.60 & 0.041 & 0.43 & 0.50 & 0.57 & 0.14 \\
\hline $\begin{array}{l}\text { Recovery } \\
\text { (concentrate to } \\
\text { sponge, \%) }\end{array}$ & & 0.50 & 0.60 & 0.70 & 0.041 & 0.53 & 0.60 & 0.67 & 0.14 \\
\hline $\begin{array}{l}\text { Recovery } \\
\text { (sponge to } \\
4 \mathrm{~N} 8, \% \text { ) }\end{array}$ & & 0.70 & 0.80 & 0.90 & 0.041 & 0.73 & 0.80 & 0.87 & 0.14 \\
\hline \multicolumn{10}{|c|}{ Recovery - Short-Term "Scenario 2" and Medium-Term "Base Case" } \\
\hline $\begin{array}{l}\text { Recovery (ore } \\
\text { to concentrate, } \\
\% \text { ) }\end{array}$ & & 0.75 & 0.80 & 0.85 & 0.020 & 0.77 & 0.80 & 0.83 & 0.07 \\
\hline $\begin{array}{l}\text { Recovery } \\
\text { (concentrate to } \\
\text { sponge, \%) }\end{array}$ & & 0.80 & 0.90 & 1.00 & 0.041 & 0.83 & 0.90 & 0.97 & 0.14 \\
\hline $\begin{array}{l}\text { Recovery } \\
\text { (sponge to } \\
4 \mathrm{~N} 8, \% \text { ) }\end{array}$ & & 0.90 & 0.95 & 1.00 & 0.020 & 0.92 & 0.95 & 0.98 & 0.07 \\
\hline \multicolumn{10}{|c|}{ Costs, Amortization, and Discount Rate } \\
\hline $\begin{array}{l}\text { Operating cost } \\
\text { ( } \% \text { from base) }\end{array}$ & & -0.10 & 0.08 & 0.35 & 0.096 & -0.05 & 0.07 & 0.26 & 0.31 \\
\hline $\begin{array}{l}\text { Capital cost }(\% \\
\text { from base) }\end{array}$ & & -0.10 & 0.08 & 0.35 & 0.096 & -0.05 & 0.07 & 0.26 & 0.31 \\
\hline $\begin{array}{l}\text { Amortization } \\
\text { (years) }\end{array}$ & & 10.00 & 15.00 & 20.00 & 2.041 & 11.58 & 15.00 & 18.42 & 6.84 \\
\hline $\begin{array}{l}\text { Discount rate } \\
(\%, \text { real })\end{array}$ & & 0.05 & 0.10 & 0.15 & 0.020 & 0.07 & 0.10 & 0.13 & 0.07 \\
\hline $\begin{array}{l}\text { Indium - } \\
\text { byproduct cost } \\
\text { allocation (\%) }\end{array}$ & & 0.00 & 0.03 & 0.10 & 0.024 & 0.00 & 0.03 & 0.08 & 0.08 \\
\hline $\begin{array}{l}\text { Indium - main } \\
\text { product cost } \\
\text { allocation }(\%)\end{array}$ & & 0.80 & 0.93 & 1.00 & 0.047 & 0.84 & 0.94 & 0.99 & 0.15 \\
\hline
\end{tabular}


We then run the simulation. Because we are concerned with the short term, we want to include all simulation realizations that cover direct operating costs only. We assume that capital costs are sunk and therefore these are not a consideration for the mine or refiner when determining whether to produce indium. No provision is made for potential taxes or royalties, which would vary depending on jurisdiction and profitability of the operation. Once these realizations are eliminated, the total is normalized to the midpoint annual estimate for 2011 - that is, 711 tonnes of refined indium metal. The simulated cases are ranked in order of increasing cost to generate the supply curve for 2011 in Figure 29.

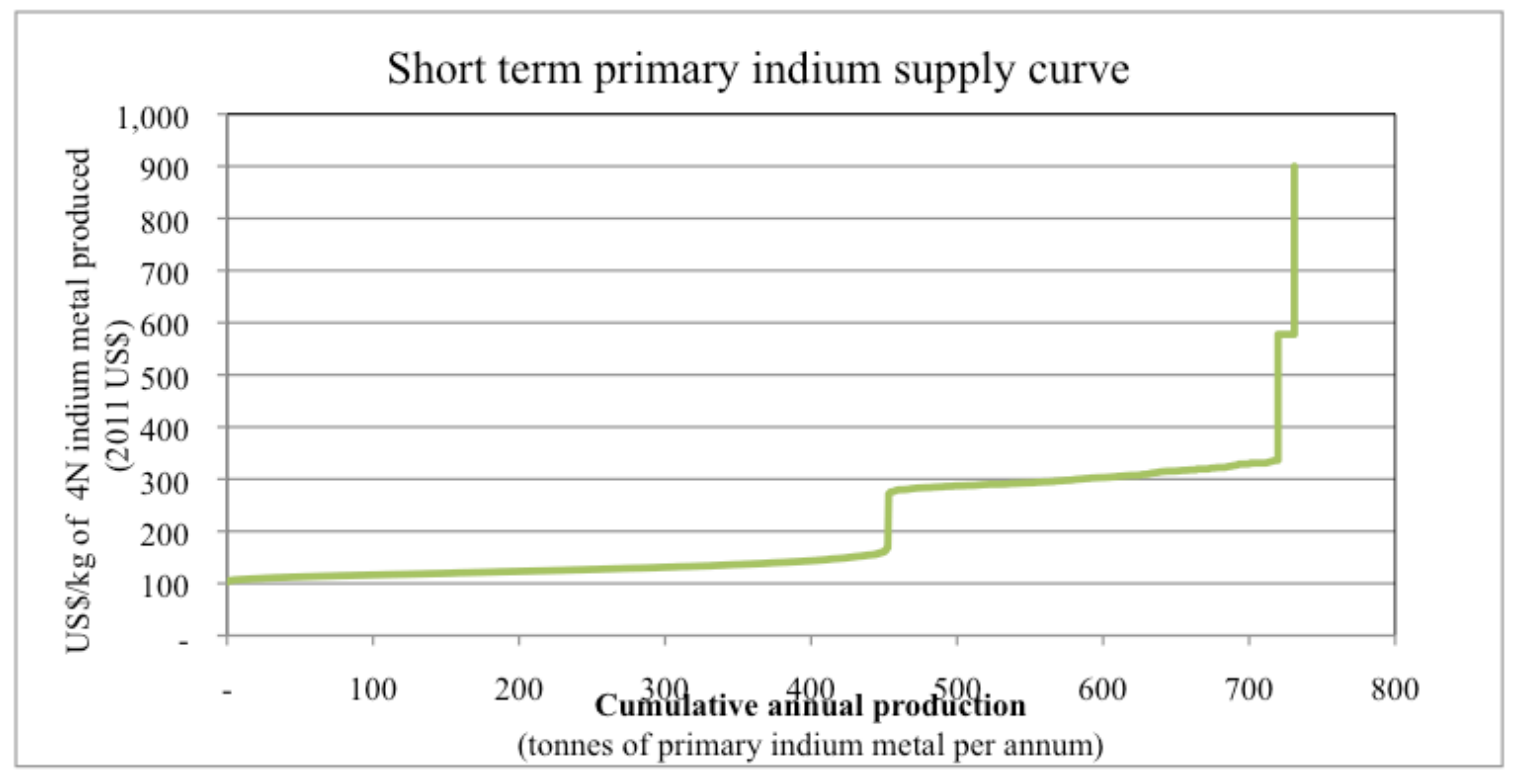

Figure 28. Short-term primary indium supply curve

When considering overall recovery rates in the short run and the amount of indium that could potentially be recovered from current mining operations, it useful to consider three scenarios:

- Refined primary indium production from mines' structure of the value chain and recovery efficiencies (i.e., the midpoint figure of 731 tonnes refined metal from 2011)

- Refined indium production if the pipeline were structured such that all indium-bearing concentrates were sent to indium-capable smelters, but assuming current recovery rates

- Refined indium production given in the first bullet, but also assuming that recovery efficiencies are possible to the extent highlighted by existing feasibility studies (Section 4.2), and ignoring any necessary investment.

Table 29 shows that, when considering overall yields of $14 \%-20 \%, 3,730-5,221$ tonnes of indium must be mined to yield 731 tpa of refined metalis. Using these values as inputs to the value chain and varying efficiencies across the pipeline such that all indium-bearing concentrates are shipped to indium-capable smelters, overall recovery of the refined metal increases from 731 tpa in the base case to 1,044 tpa, corresponding with overall recovery rates of $20 \%-28 \%$. Once we vary recovery efficiencies to correspond with current technologies, recovery of indium 
increases to 3,348 tpa to 2,710 tpa with a midpoint of 2,976 tpa. This corresponds with an overall recovery rate of $64 \%-73 \%$.

Table 29. Short-Term Indium Supply Scenarios

\begin{tabular}{|c|c|c|c|c|c|c|}
\hline \multicolumn{7}{|c|}{ Short-Term Indium Recovery Scenarios } \\
\hline & \multicolumn{3}{|c|}{$\begin{array}{c}\text { Recovery at Each Stage } \\
\text { (tonnes) }\end{array}$} & \multicolumn{3}{|c|}{$\begin{array}{c}\text { Corresponding Recovery } \\
\text { Efficiency (\%) }\end{array}$} \\
\hline & Low & Mid & High & Low & Mid & High \\
\hline Indium contained in mined zinc ores & 100 & 100.0 & 100 & & & \\
\hline Indium reporting to concentrate & 50.0 & 60.0 & 70.0 & $50 \%$ & $60 \%$ & $70 \%$ \\
\hline Indium sent to indium-capable smelter & 35.0 & 42.0 & 49.0 & $70 \%$ & $70 \%$ & $70 \%$ \\
\hline Indium recovered by smelter & 17.5 & 21.0 & 24.5 & $50 \%$ & $50 \%$ & $50 \%$ \\
\hline $\begin{array}{l}\text { Indium recovered by special metal } \\
\text { refinery }\end{array}$ & 14.0 & 16.8 & 19.6 & $80 \%$ & $80 \%$ & $80 \%$ \\
\hline Estimates of indium metal recovered & 731 & 731 & 731 & & & \\
\hline Overall indium recovery rate & $14 \%$ & $17 \%$ & $20 \%$ & & & \\
\hline Equivalent amount of indium 'mined' & 5,221 & 4,351 & 3,730 & & & \\
\hline \multicolumn{7}{|c|}{ Scenario 1: If All Indium Concentrates Make Their Way to Indium-Capable Smelters } \\
\hline Indium contained in mined zinc ores & 5,221 & 4,351 & 3,730 & & & \\
\hline Indium reporting to concentrate & 2,611 & 2,611 & 2,611 & $50 \%$ & $60 \%$ & $70 \%$ \\
\hline Indium sent to indium-capable smelter & 2,611 & 2,611 & 2,611 & $100 \%$ & $100 \%$ & $100 \%$ \\
\hline Indium recovered by smelter & 1,305 & 1,305 & 1,305 & $50 \%$ & $50 \%$ & $50 \%$ \\
\hline $\begin{array}{l}\text { Indium recovered by special metal } \\
\text { refinery }\end{array}$ & 1,044 & 1,044 & 1,044 & $80 \%$ & $80 \%$ & $80 \%$ \\
\hline Estimates of indium metal recovered & 1,044 & 1,044 & 1,044 & & & \\
\hline Overall indium recovery rate & $20 \%$ & $24 \%$ & $28 \%$ & & & \\
\hline \multicolumn{7}{|c|}{ Scenario 2: Scenario $1+$ Improved Recovery Efficiencies $^{\mathrm{b}}$} \\
\hline Indium contained in mined zinc ores & 5,221 & 4,351 & 3,730 & & & \\
\hline Indium reporting to concentrate & 3,916 & 3,481 & 3,170 & $75 \%$ & $80 \%$ & $85 \%$ \\
\hline Indium sent to indium-capable smelter & 3,916 & 3,481 & 3,170 & $100 \%$ & $100 \%$ & $100 \%$ \\
\hline Indium recovered by smelter & 3,524 & 3,133 & 2,853 & $90 \%$ & $90 \%$ & $90 \%$ \\
\hline $\begin{array}{l}\text { Indium recovered by special metal } \\
\text { refinery }\end{array}$ & 3,348 & 2,976 & 2,710 & $95 \%$ & $95 \%$ & $95 \%$ \\
\hline Estimates of indium metal recovered & 3,348 & 2,976 & 2,710 & & & \\
\hline Overall indium recovery rate & $64 \%$ & $68 \%$ & $73 \%$ & & & \\
\hline
\end{tabular}

${ }^{a}$ The quantity of mined indium is the value with the highest uncertainty in our analysis. As a result, we back calculate mined indium from refined indium and a range of overall recovery efficiencies. From these starting points for mined indium, we then proceed to vary recovery rates to calculate the potential amount of metal recovered.

${ }^{\mathrm{b}}$ Highlighted cells in light green show values that have changed from the base case.

${ }^{\mathrm{c}}$ Target recovery efficiencies are based on current technologies and have been taken from feasibility studies.

Using the midpoint data from Scenarios 1 and 2 in Table 29, we can now see how short-term initiatives might affect the availability of primary indium and the cost at which that supply might be available. The supply curves depicted in Figure 30 include the status quo scenario from Figure 29 as well as Scenarios 1 and 2. The cost allocations in the simulation remain unaltered per 
individual simulation realizations; ${ }^{44}$ only the quantity produced is scaled to match the increased average recovery coinciding with Scenarios 1 and 2, respectively.

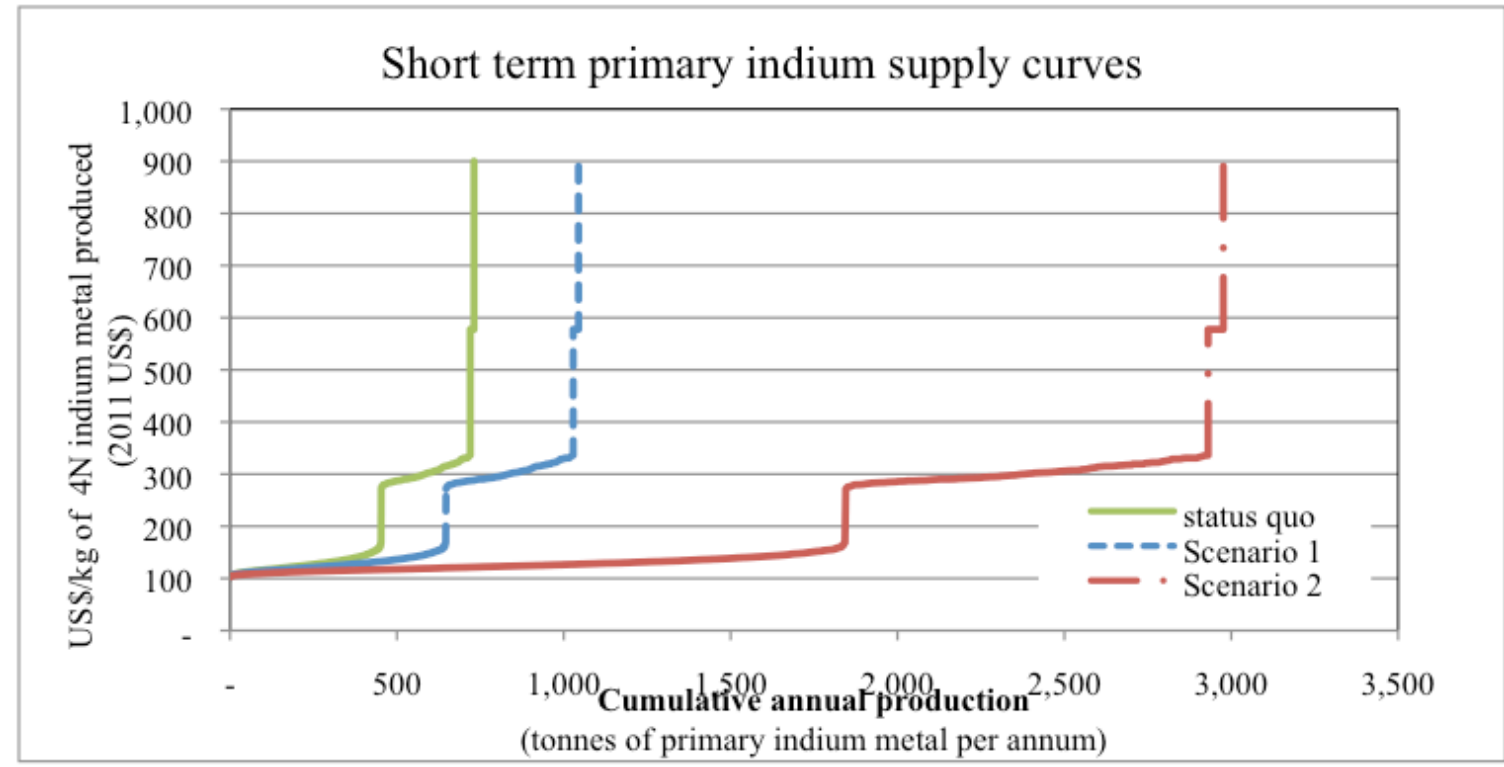

Figure 29. Short-term primary indium supply, including pipeline efficiency improvements

\section{The Medium Term}

We use a similar approach to generate the medium-term supply curves but have made certain adjustments:

- Capital costs are included. Because operators have the option to invest in new capacity or shut down in the medium term, we adjust costs to reflect returns to capital and eliminate all realizations in the simulation that would not generate positive returns for investors.

- Variations in the long-term main-product average prices are used to assess feasibility. Readers should examine the long-term historical prices of tin and zinc in Appendix C.

Primary indium is, to our knowledge, currently produced only as a byproduct from zinc, and to a lesser degree tin and copper ores; thus, we may reasonably assume that the growth of indium production will follow anticipated changes to main product supply. For this analysis, we concern ourselves only with the growth of zinc production and assume that the ratio of total indium production to total zinc production is constant over time. Taking two medium-term snapshots, one in 2016 and the other at 2031, and assuming a possible range of main product growth of 2\%$3 \%$, total indium production in 2016 and 2031 is forecasted to be 827 tonnes and 1,365 tonnes, respectively (see Table 31 ).

\footnotetext{
${ }^{44}$ By increasing the recovery efficiency one would anticipate that indium increases in significance to a particular simulation realization. If the model were rerun, assuming that recoveries of other main product metals remained unchanged, indium could move from byproduct to coproduct and then costs would be reallocated on the appropriate basis. This level of detail has not been considered for the short run and the curves above should be considered a first pass at how quantities of indium and costs might react to changing recovery efficiencies.
} 
Table 30. Monte Carlo Simulation Input Distributions for Metal Prices

\begin{tabular}{|c|c|c|c|c|c|c|c|c|c|c|}
\hline Name & Graph & & Min & Mean & Max & $\begin{array}{l}\text { Std } \\
\text { Dev }\end{array}$ & $5 \%$ & $50 \%$ & $95 \%$ & $\begin{array}{c}\text { p95- } \\
\text { p5 }\end{array}$ \\
\hline $\begin{array}{l}\text { Tin price } \\
\text { (US\$/kg) }\end{array}$ & & $\stackrel{22}{*}$ & 3.56 & 8.55 & 18.52 & 3.527 & 3.94 & 7.95 & 15.18 & 11.24 \\
\hline $\begin{array}{l}\text { Zinc price } \\
\text { (US\$/kg) }\end{array}$ & & 2.2 & 0.57 & 0.97 & $+\infty$ & 0.610 & 0.65 & 0.86 & 1.59 & 0.94 \\
\hline
\end{tabular}

Data for the distributions consist of 52 observations of average annual metal prices between 1960 and 2011 (World Bank 2012).

The data were fitted in @Risk computer software and selection of the distribution type was based on examining the Chi-Sq distribution ranking for the corresponding data.

Recoveries reflect latest commercially available technologies when making assumptions regarding recovery efficiency.

Table 31. Main Product Growth and Associated Forecasted Byproduct Indium Production

\begin{tabular}{|c|c|c|c|}
\hline \multicolumn{4}{|c|}{ Medium-Term Primary Indium Refinery Production } \\
\hline $\begin{array}{c}\text { Main Product Growth* } \\
\text { CAGR, \% }\end{array}$ & 2011 & 2016 & 2031 \\
\hline $2.0 \%$ & 731 & 807 & 1,199 \\
\hline $3.0 \%$ & 731 & 847 & 1,531 \\
\hline Average & 731 & 827 & 1,365 \\
\hline
\end{tabular}

* Main product CAGR range based on historical zinc production growth between 2007 and 2011 as calculated from USGS data and estimates for 2012 growth from Willis et al. (2012).

These projected byproduct indium levels, as well as the assumptions listed above, form the basis for a series of medium-term supply scenarios. Briefly, these are:

- Base case 2016. This scenario uses the current levels of indium recovery efficiency and its associated current production ( 731 tonnes) and forecasts main product expansion and associated indium expansion until 2016.

- Base case 2031. This scenario uses current levels of indium recovery efficiency and its associated current production (731 tonnes) and forecasts main product expansion until 2031.

- Scenario 1: Base case + improved recovery and pipeline efficiency (2016). This scenario uses the base case 2016 levels but builds in improved overall pipeline efficiency described in short-term Scenarios 1 and 2. However, because we are now considering the medium term, capital costs associated with these efficiency improvements are reflected in the cost of indium.

- Scenario 1: Base case + improved recovery and pipeline efficiency (2031). Same as the scenario in the third bullet, except byproduct indium production has been forecast to 2031.

Figure 31 contains the supply curves for the first two scenarios. Compared with Figure 30, the cost curves have shifted upward because capital costs are now included. In the medium term the 
elasticity of primary indium supply appears high $(\$ 350-\$ 450 / \mathrm{kg})$ and inelastic at prices higher than $\$ 800$ and lower than $\sim \$ 275$.

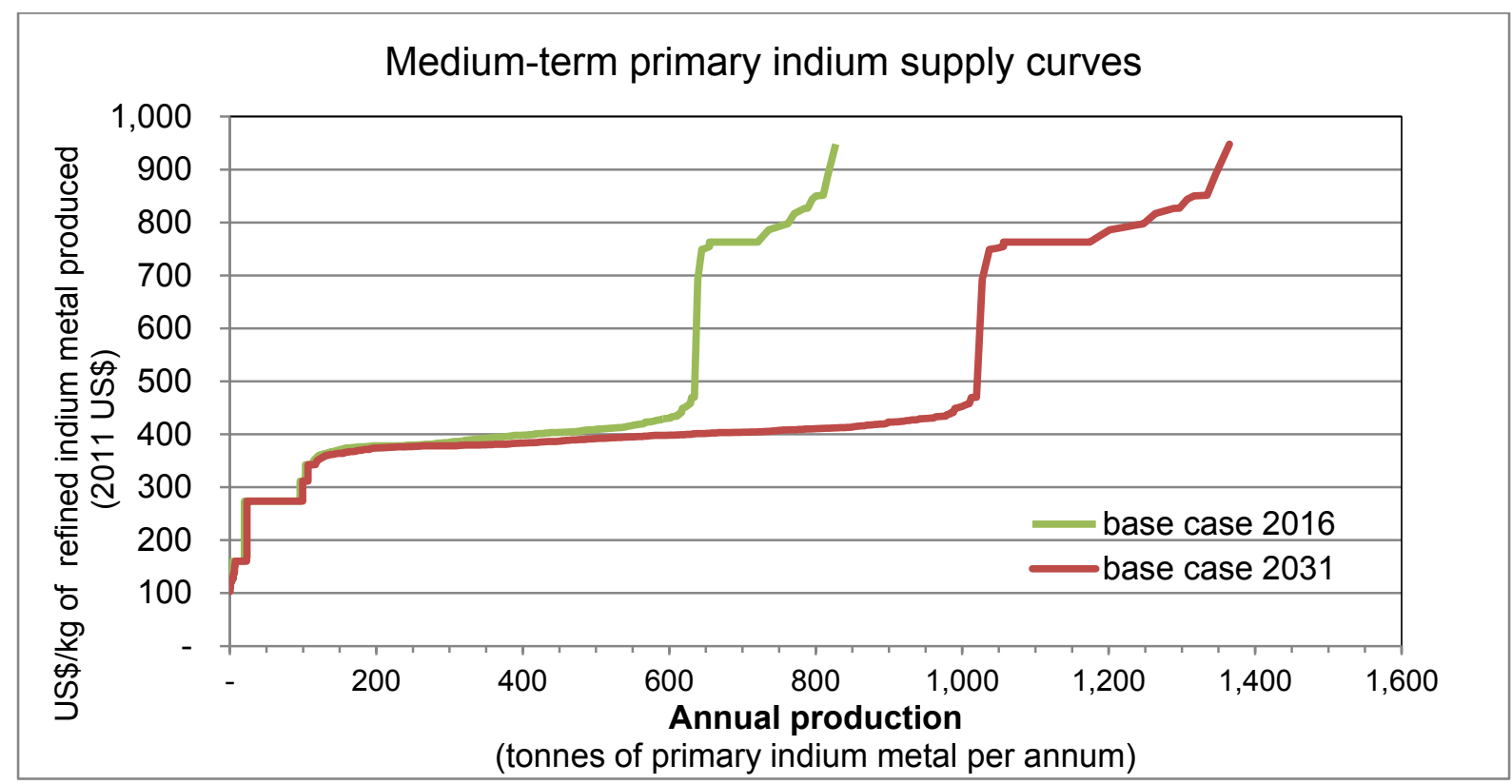

Figure 30. Medium-term base case primary indium supply projected to 2016 and 2031

The base case scenarios are self-explanatory, but the derivation of figures for the other two scenarios that examine improved recovery efficiency require more explanation. As discussed in the short-term supply curves, recovery inefficiency has two principal causes: (1) indium-bearing concentrates not being sent to indium-capable smelters; and (2) metallurgical losses through the recovery process, due possibly to less efficient technologies being used at existing plants, smelters, and refineries. In deriving the medium-term supply curves, we assume that $100 \%$ of indium-bearing concentrates are sent to indium-capable smelters, which increases 2016 indium primary production from 827 tonnes to 1,182 tonnes and 2031 primary production from 1,365 tonnes to 1,950 tonnes. These calculations are detailed in Table 32.

Table 32. Medium-Term Indium Supply Scenarios

\begin{tabular}{lcccccc}
\hline & \multicolumn{2}{c}{$\begin{array}{c}\text { Recovery Efficiency } \\
\text { (tonnes) }\end{array}$} & \multicolumn{2}{c}{ Recovery Efficiency } \\
\hline & Low & Mid & High & Low & Mid & High \\
\hline Indium contained in mined zinc ores & 100 & 100.0 & 100 & & & \\
\hline Indium reporting to concentrate & 75.0 & 80.0 & 85.0 & $75 \%$ & $80 \%$ & $85 \%$ \\
\hline Indium sent to indium-capable smelter & 52.5 & 56.0 & 59.5 & $70 \%$ & $70 \%$ & $70 \%$ \\
\hline Indium recovered by smelter & 47.3 & 50.4 & 53.6 & $90 \%$ & $90 \%$ & $90 \%$ \\
\hline Indium recovered by special metal refinery & 44.9 & 47.9 & 50.9 & $95 \%$ & $95 \%$ & $95 \%$ \\
\hline Overall indium recovery rate & $45 \%$ & $48 \%$ & $51 \%$ & & & \\
\hline & $\mathbf{2 0 1 6}$ & & & & \\
\hline Estimates of indium metal recovered & 827 & 827 & 827 & & \\
\hline Equivalent amount of indium "mined" & 5,909 & 4,924 & 4,221 & & \\
\hline & $\mathbf{2 0 3 1}$ & & & & \\
\hline Estimates of indium metal recovered (2031) & 1,365 & 1,365 & 1,365 & & \\
\hline Equivalent amount of indium "mined" & 9,749 & 8,125 & 6,964 \\
\hline
\end{tabular}




\begin{tabular}{|c|c|c|c|c|c|c|}
\hline \multicolumn{7}{|c|}{$\begin{array}{c}\text { Scenario 1: Improved Recoveries + All in Concentrates } \\
\text { Make Their Way to Indium-Capable Smelters (2016) }\end{array}$} \\
\hline Indium contained in mined zinc ores & 5,909 & 4,924 & 4,221 & & & \\
\hline Indium reporting to concentrate & 4,432 & 3,939 & 3,588 & $75 \%$ & $80 \%$ & $85 \%$ \\
\hline Indium sent to indium-capable smelter & 4,432 & 3,939 & 3,588 & $100 \%$ & $100 \%$ & $100 \%$ \\
\hline Indium recovered by smelter & 3,989 & 3,545 & 3,229 & $90 \%$ & $90 \%$ & $90 \%$ \\
\hline Indium recovered by special metal refinery & 3,789 & 3,368 & 3,067 & $95 \%$ & $95 \%$ & $95 \%$ \\
\hline Estimates of indium metal recovered & 3,789 & 3,368 & 3,067 & & & \\
\hline Overall indium recovery rate & $64 \%$ & $68 \%$ & $73 \%$ & & & \\
\hline \multicolumn{7}{|c|}{$\begin{array}{c}\text { Scenario 1: Improved Recoveries + All in Concentrates } \\
\text { Make Their Way to Indium-Capable Smelters (2031) }\end{array}$} \\
\hline Indium contained in mined zinc ores & 9,749 & 8,125 & 6,964 & & & \\
\hline Indium reporting to concentrate & 7,312 & 6,500 & 5,919 & $75 \%$ & $80 \%$ & $85 \%$ \\
\hline Indium sent to indium-capable smelter & 7,312 & 6,500 & 5,919 & $100 \%$ & $100 \%$ & $100 \%$ \\
\hline Indium recovered by smelter & 6,581 & 5,850 & 5,327 & $90 \%$ & $90 \%$ & $90 \%$ \\
\hline Indium recovered by special metal refinery & 6,252 & 5,557 & 5,061 & $95 \%$ & $95 \%$ & $95 \%$ \\
\hline Estimates of indium metal recovered & 6,252 & 5,557 & 5,061 & & & \\
\hline Overall indium recovery rate & $64 \%$ & $68 \%$ & $73 \%$ & & & \\
\hline
\end{tabular}

We back-calculate mined indium from refined indium and a range of overall recovery efficiencies. From these starting points for mined indium, we then vary the percentage of indium concentrates sent to indium-capable smelters to calculate the potential quantity of indium metal recovered.

Highlighted cells in light green show values that have changed from the base cases.

Target recovery efficiencies are based on current technologies and have been taken from feasibility studies.

Examining potential indium supply where pipeline efficiencies are gained yields the primary indium supply curves depicted in Figure 32 and Figure 33 for 2016 and 2031, respectively. Costs are kept in 2011 U.S. dollar terms to facilitate comparison across time, though one would expect costs to rise in nominal terms between 2016 and 2031.

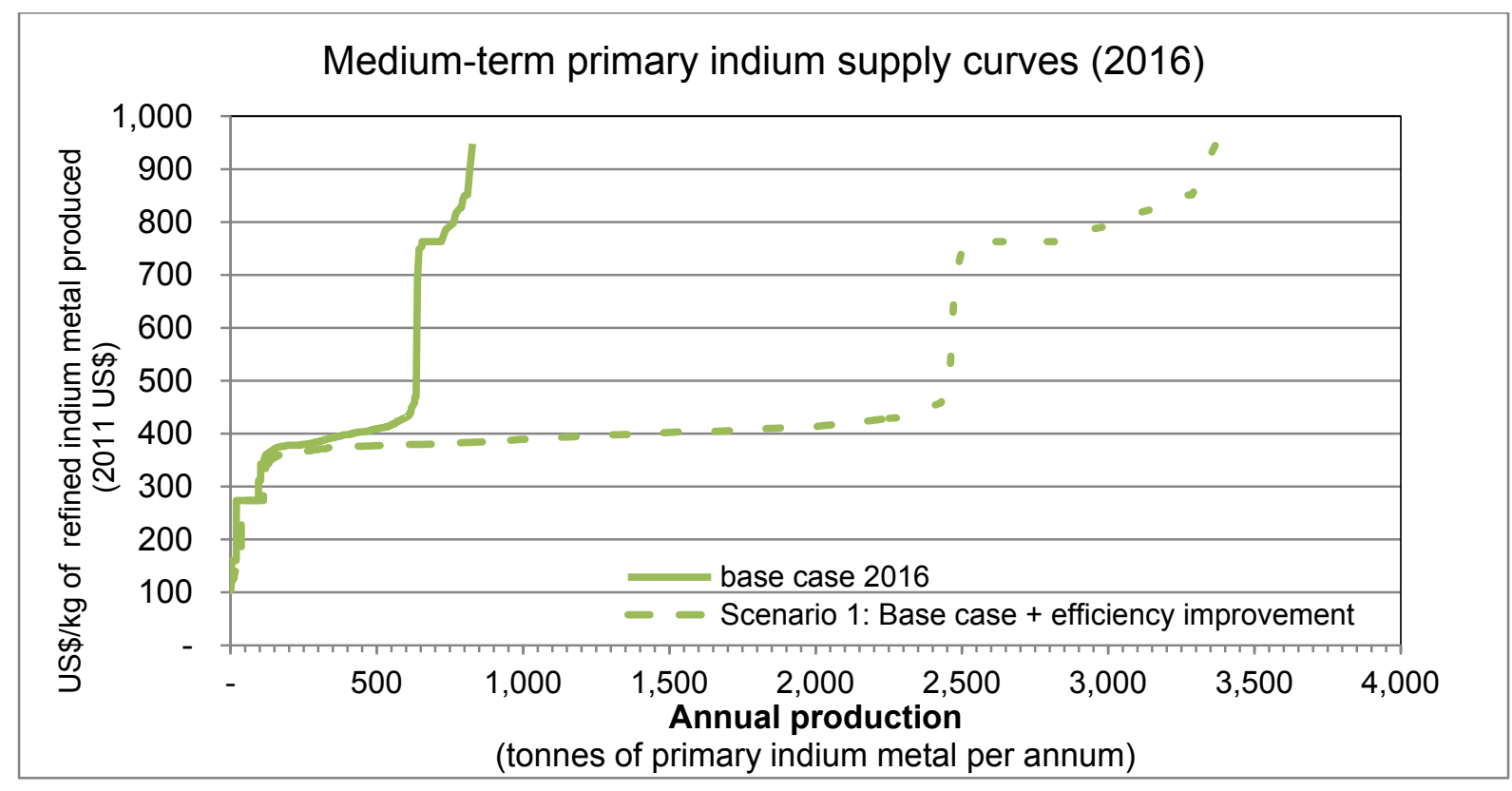

Figure 31. Medium-term primary indium supply (2016) 


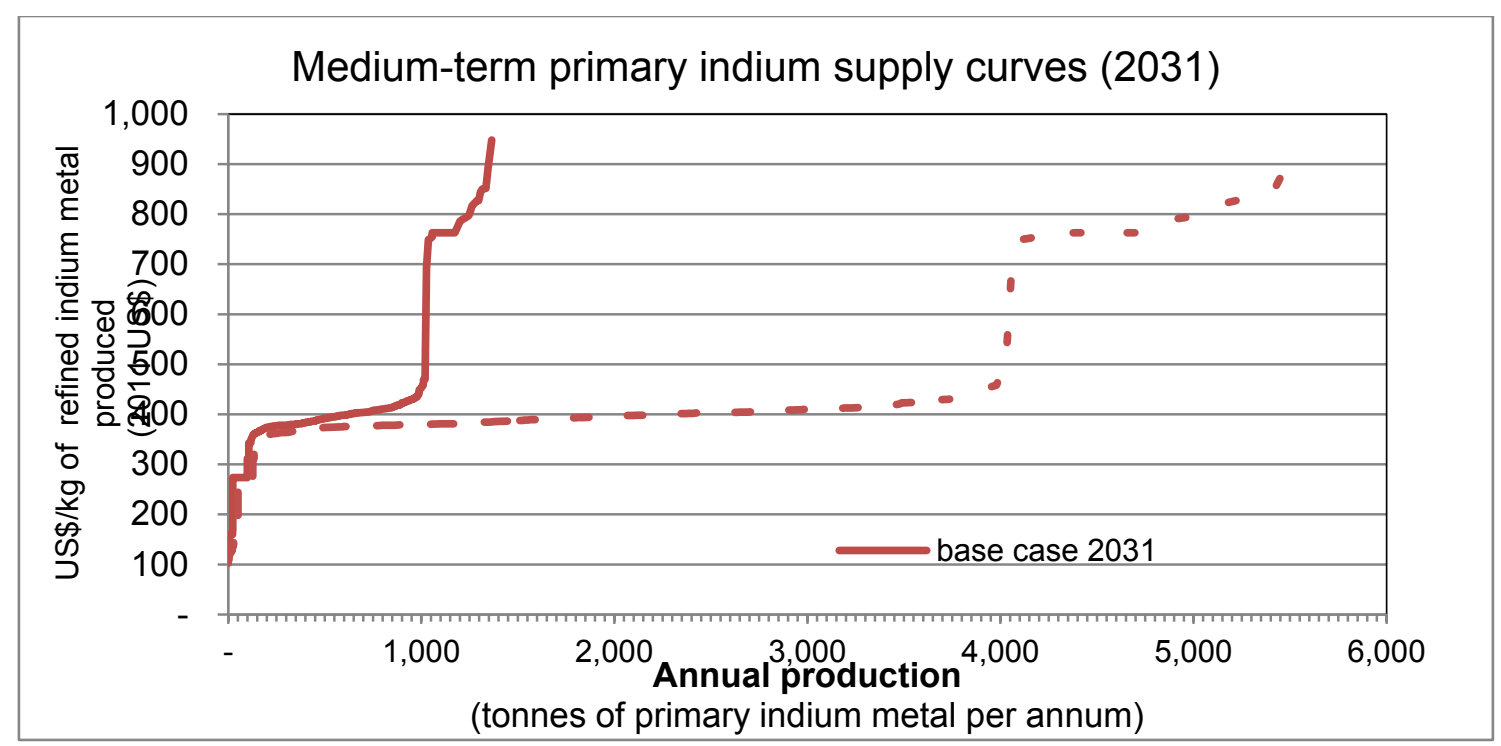

Figure 32. Medium-term primary indium supply (2031)

In all these scenarios, we have included supply anticipated to come from known indium projects identified in Section 4.1, namely: Mount Pleasant, Malku Khota, Pirquitas, Pinquito, and South Crofty. The La Oroya complex is not included because, as a metallurgical and refinery complex, we are hesitant to treat La Oroya as "new production" and believe that it may simply reflect a shift of production.. These are explicitly depicted in Figure 34 to give the reader an idea of where these deposits might feature competitively and what fraction of primary indium they might contribute in 2016.

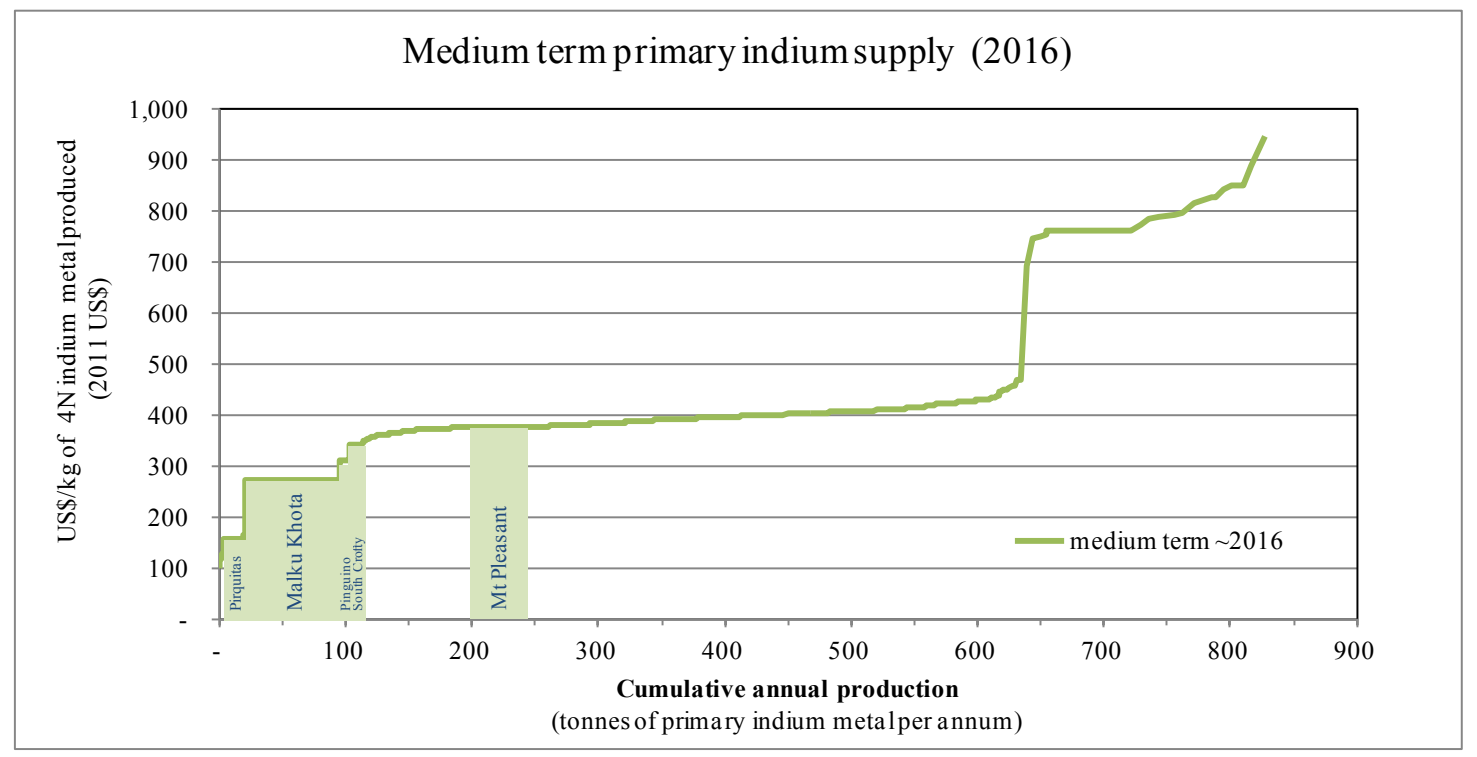

Figure 33. Medium-term primary indium supply (2016), including positioning of known potential future sources of supply

The costs and quantities for these deposits were determined with a bottom-up approach using publically available information. A similar approach was to determine the allocation of costs between indium and other metals at Adex's Mount Pleasant deposit. 


\section{Appendix E: Earth Abundance of Various Elements}

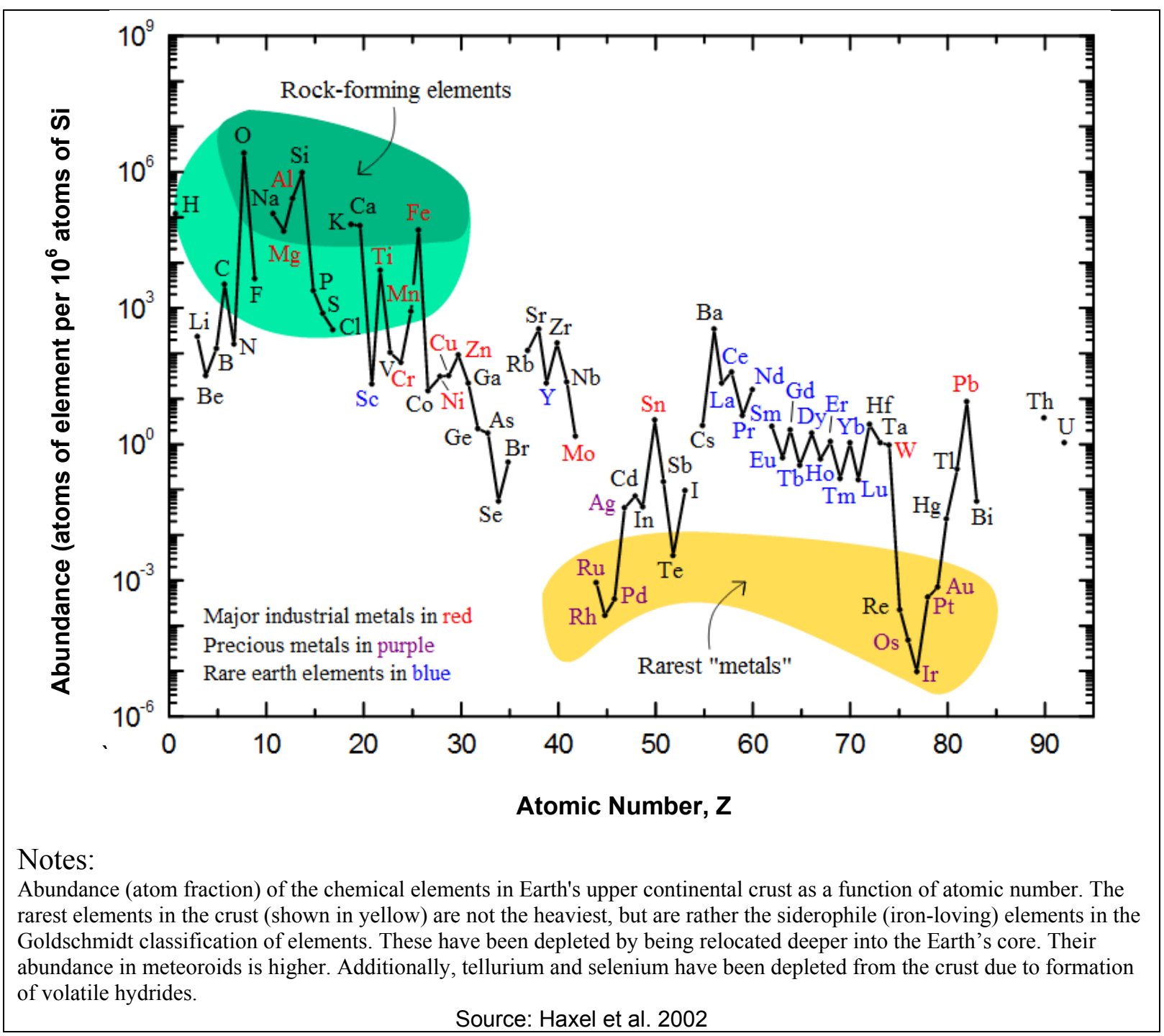

Figure 34. Abundance of elements in the Earth's upper continental crust as a function of atomic number 